\title{
A Field Investigation of Diffusion Within a Submerged Plant Canopy
}

by

\author{
Alvin E. Tarrell \\ B.S. Chemical Engineering \\ University of Nebraska - Lincoln, 1984
}

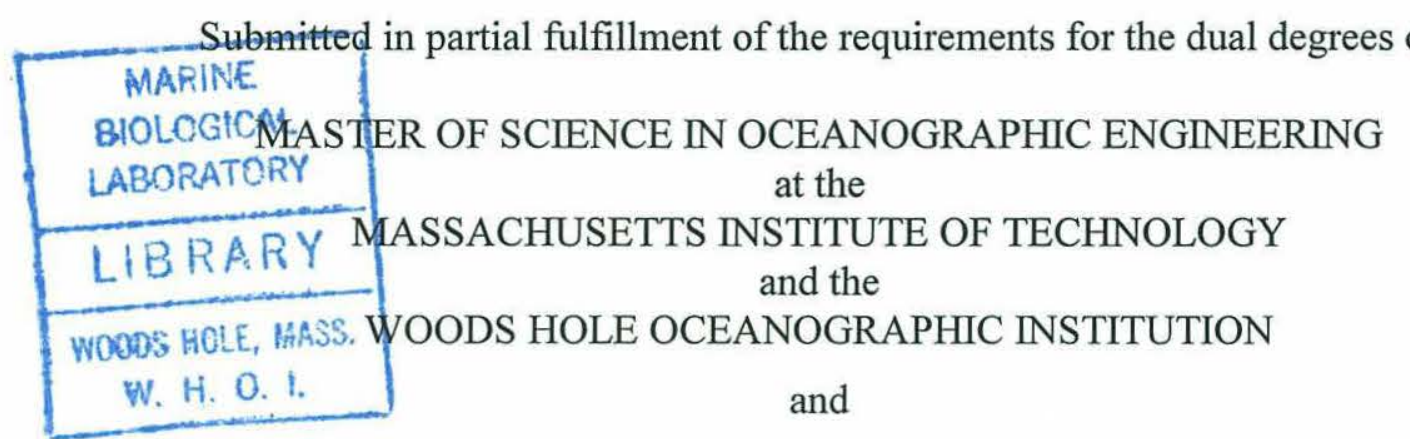
MASTER OF ENGINEERING IN CIVIL AND ENVIRONMENTAL ENGINEERING at the MASSACHUSETTS INSTITUTE OF TECHNOLOGY

September 1997

(C) 1997 Massachusetts Institute of Technology and Woods Hole Oceanographic Institute All rights reserved

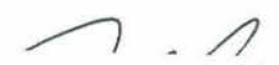

Author:

Y.4.

Department of Ocean Engineering, MIT and the MIT-WHOI

Joint Program in Oceanographic Engineering, July 25, 1997

1

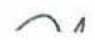

Certified by: $\ldots \ldots, \ldots \ldots \ldots \ldots, \ldots, \cdots$

Department of Civil and Environmental Engineering, MIT

$$
11
$$

Thesis Supervisor

Certified by: .......

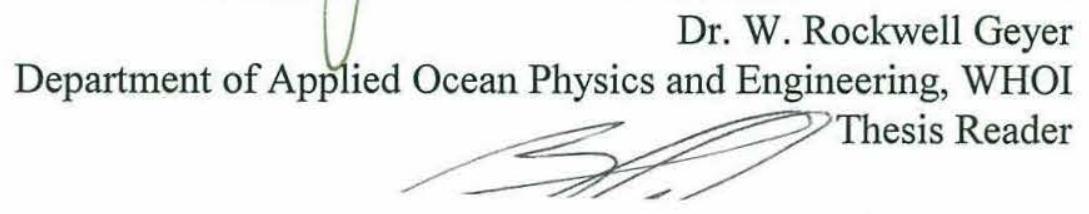

Accepted by:

Professor Henrik Schmidt, Chair, Joint Committee for Applied Ocean Science ane Engineering, MIT-WHOI 


\title{
A Field Investigation of Diffusion Within a Submerged Plant Canopy
}

by

\author{
Alvin E. Tarrell
}

\begin{abstract}
Submitted to the Departments of Ocean Engineering and Civil and Environmental Engineering

on July 25,1997 in partial fulfillment of the requirements for the degrees of Master of Science in Oceanographic Engineering and Master of Engineering in Civil and Environmental Engineering
\end{abstract}

\begin{abstract}
Saltwater marshes and wetlands are important buffers at the land-sea interface. Among the most biologically active ecosystems on Earth, natural and man-made wetlands are important interceptors of pollutants and nutrients bound for the coastal ocean. The transport, dilution, and deposition processes occurring within the marsh are key factors in determining this interception, and these are in turn determined largely by tidally driven flows as influenced by marsh vegetation and other physical characteristics. Vegetation type and density are of primary importance in these processes, both for pollutant/nutrient uptake concerns and in determining hydrodynamic characteristics of the marsh.

This study examines the effect of vegetation density and ambient flow on diffusivity within a tidal marsh canopy, specifically Spartina alterniflora. Vegetation densities from $0-1.4 \%$ stem coverage and flows from $2-12 \mathrm{~cm} / \mathrm{sec}$ were investigated using Rhodamine WT tracer, with resultant measured diffusivities ranging from approximately 0.5-3.0 $\mathrm{cm}^{2} / \mathrm{sec}$. Diffusivity was found to be a strong function of ambient current, but a much weaker function of vegetation density. Presence of vegetation caused transverse and vertical diffusivities to be essentially isotropic over all vegetation densities, as opposed to the order of magnitude difference found in earlier non-vegetated studies. Only slight vegetation coverage was found to be necessary to produce this isotropy, with little additional change as stem density increased.
\end{abstract}

Thesis Supervisor: Heidi Nepf

Title: Assistant Professor of Civil and Environmental Engineering 


\section{Acknowledgments}

There are many who had a part in this project, and I owe thanks to each of them. This thesis would not have been possible without the support and guidance of Heidi Nepf, my Thesis Supervisor. She accepted me for this project without knowing anything about me, and provided just enough direction to make it all work out. She never complained about the inevitable schedule slips and really let this be 'my' project, and for that I am truly thankful. Thanks go also to Rocky Geyer at WHOI who volunteered his time and efforts as a reader. His initial insights into the project proved invaluable in the early going, and his thoughtful comments on the manuscript definitely led to a much improved product. Thanks also to Terry Donoghue for his help getting me up to speed on fluorometry and Rhodamine, I might still be calibrating if not for him. I also want to thank the U.S. Navy for allowing me the opportunity to attend these fine institutions, and I know the education I received here will be put to good use someday.

The most special thanks go to my family, they are the ones who truly made this possible and rewarding. Thanks to my wife, Kena, who acted as both Mom and Dad for awhile so that I could get through all this. Thanks to my four children; Alejandra, Andrea, Ariel, and Amanda; who only complained slightly when I told them time and again that "Daddy needs the computer now" and who described my work as "Cool!" just often enough to keep me going.

Thanks also to all the other people involved on the sidelines. The Education Office staff who try to make students' lives as painless as possible, the OE and CEE Office staff who do much the same thing, and the M. Eng. Group who go so far out of their way for the students all receive my heartfelt thanks. Thanks also to my fellow students, and good luck to each and all of you. Last but not least, thanks to the WHOI shuttle and Bonanza Bus drivers with whom I have spent untold hours with over the last two years and who I hope to never see again (nothing personal!). 


\section{Table of Contents}

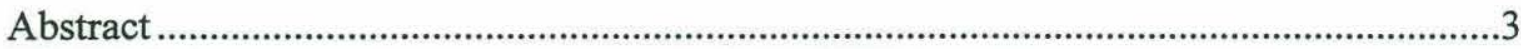

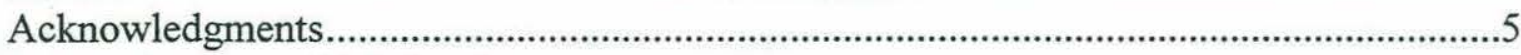

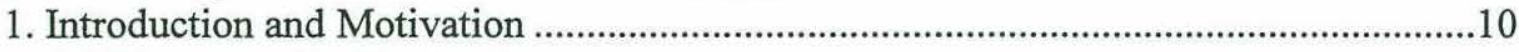

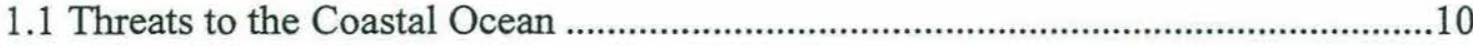

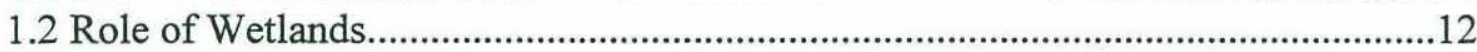

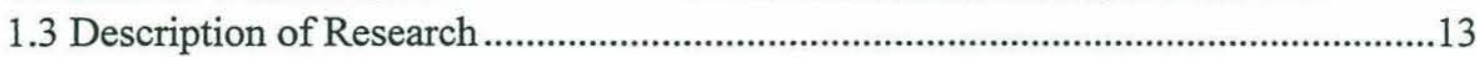

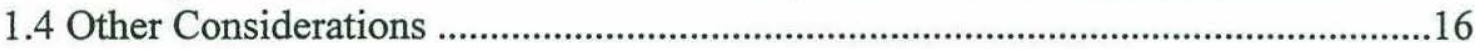

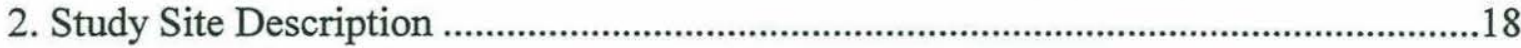

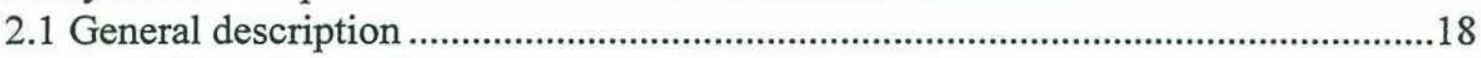

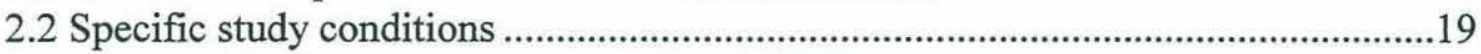

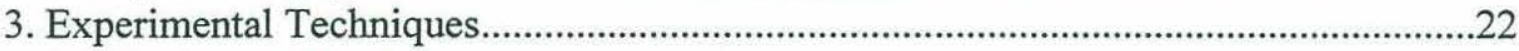

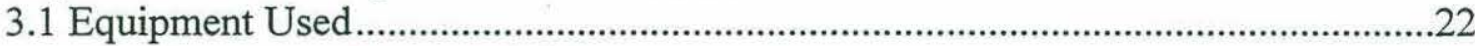

3.1.1 Fluorescent Tracer Addition ............................................................................22

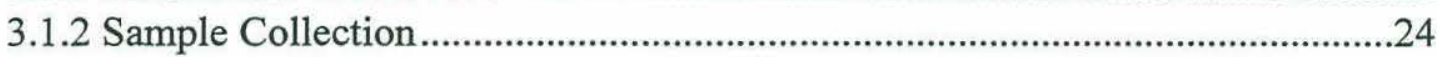

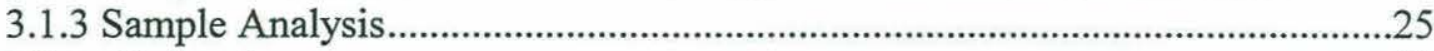

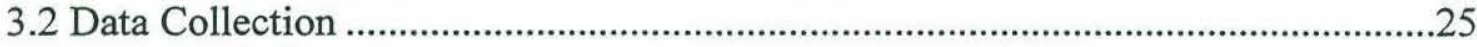

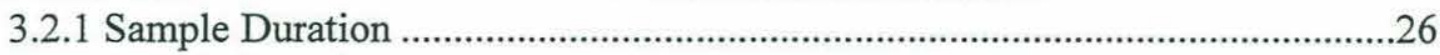

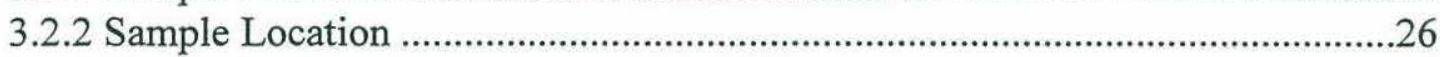

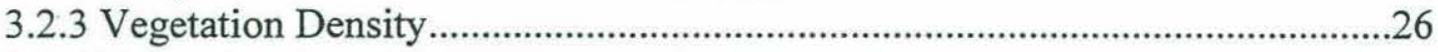

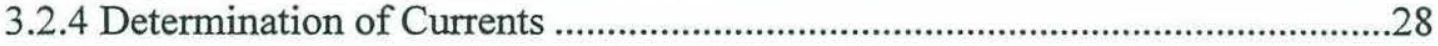

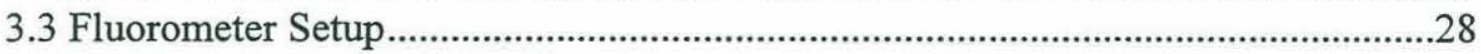

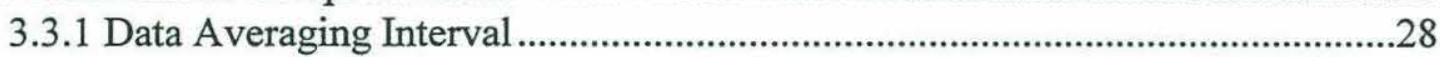

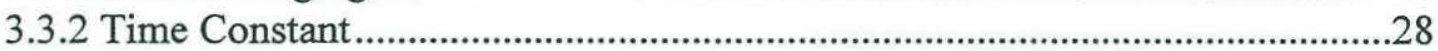

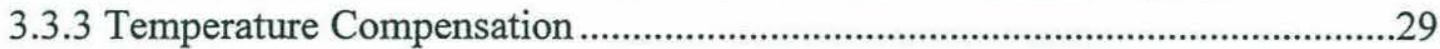

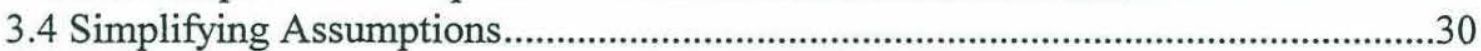

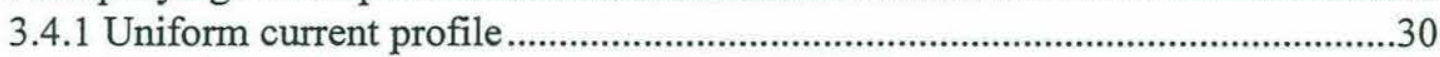

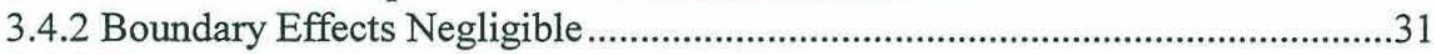

3.4.3 Fluorescence Changes Negligible .......................................................................32

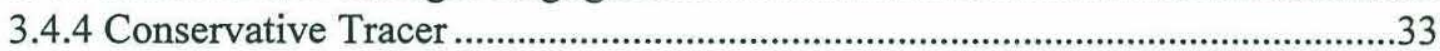

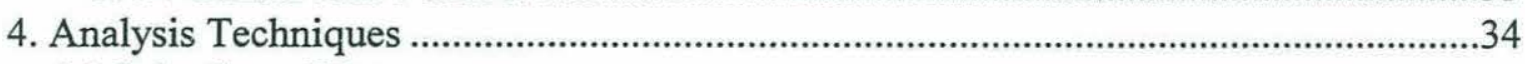

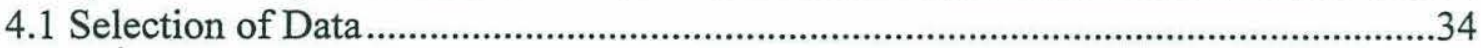

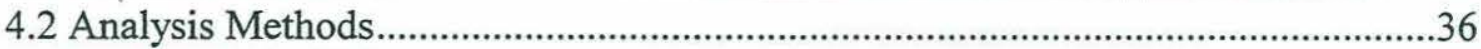

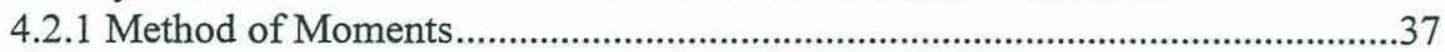

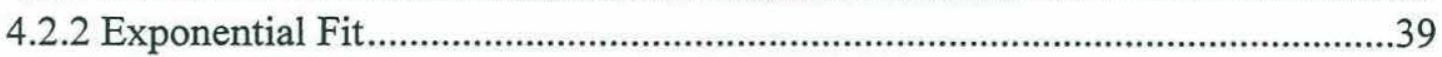

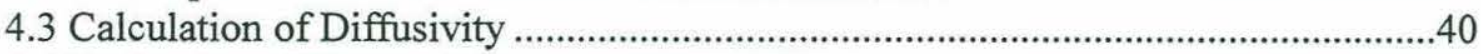

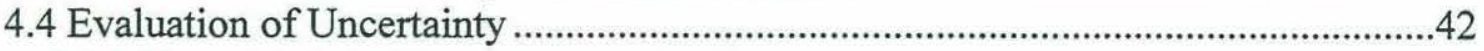

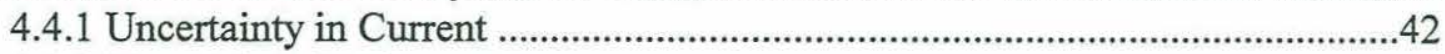

4.4.2 Uncertainty in Plume Variance .........................................................................43

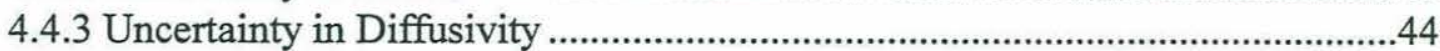

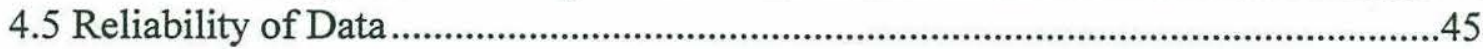




\section{Table of Contents (cont.)}

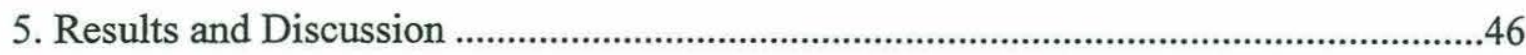

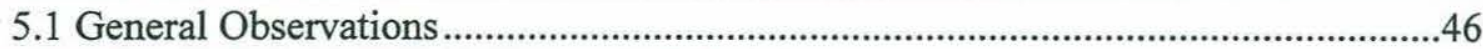

5.2 Vegetated versus Non-Vegetated Diffusivity ........................................................48

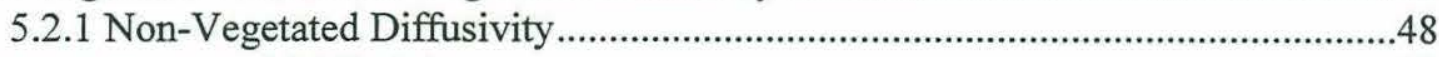

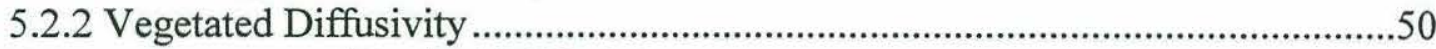

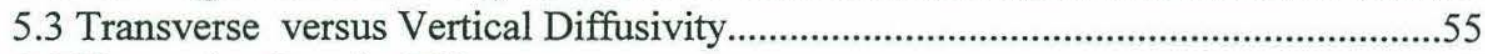

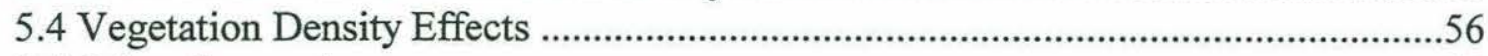

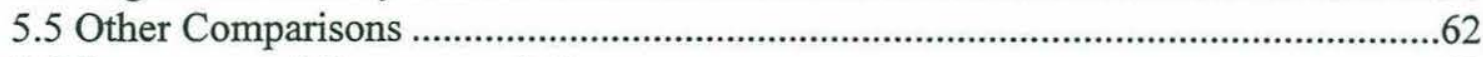

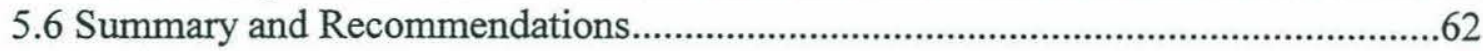

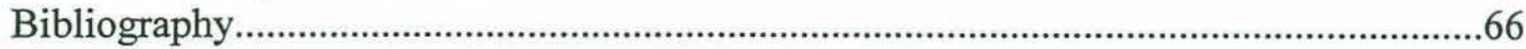

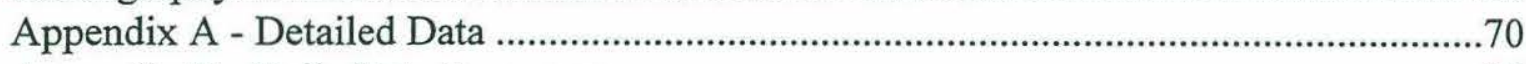

Appendix B - Daily Data Summary ..............................................................................96 


\section{List of Figures}

Figure 2-1: Overhead View of Great Sippewissett Marsh ...............................................20

Figure 2-2: Study Site and Immediate Surroundings .....................................................21

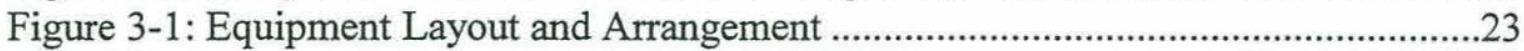

Figure 3-2: Schematic Representation of Physical Layout ................................................23

Figure 4-1: Representative Full Horizontal Profile............................................................35

Figure 4-2: Data Used for Individual Profile Points ........................................................35

Figure 4-3: Method of Moments Analysis - Representative Profile ...................................38

Figure 4-4: Best Fit Exponential Curve - Representative Profile .....................................40

Figure 4-5: Representative Current Profile .........................................................................41

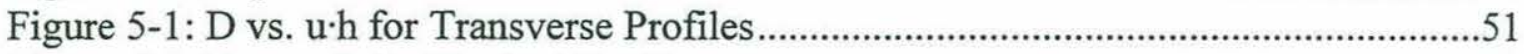

Figure 5-2: D vs. u·h for Vertical Profiles ......................................................................51

Figure 5-3: Transverse and Vertical Diffusivities vs. Reynolds Number ..........................53

Figure 5-4: Diffusivities vs. Reynolds Number by Vegetation Density .............................53

Figure 5-5: Diffusivity vs. $\mathrm{u} / \mathrm{P}$ for Vegetated Profiles .....................................................54

Figure 5-6: Transverse Diffusivity versus Reynolds Number - Laboratory Study ............57

Figure 5-7: D/ud vs. Percent Stem Coverage - Transverse Diffusivity ..............................59

Figure 5-8: D/ud vs. Percent Stem Coverage - Vertical Diffusivity ...................................59

Figure 5-9: D vs. P·Re for Transverse Profiles ..............................................................61

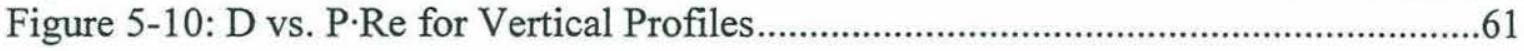

\section{List of Tables}

Table 3-1: Vegetation Densities and Percent Coverages .................................................27

Table 4-1: Mean Fluorescence Values for Profile Points ...................................................36

Table 5-1: Transverse Diffusivity Results for Field Study ...............................................47

Table 5-2: Vertical Diffusivity Results for Field Study ..................................................47

Table 5-3: Best Fit Slopes for D vs. u·h Plots................................................................52

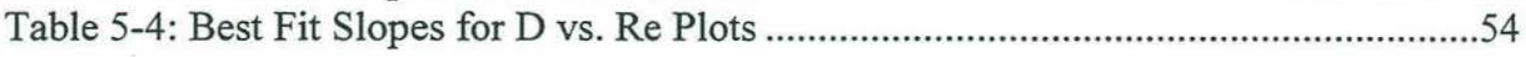




\section{Introduction and Motivation}

Pollution of the coastal ocean is a problem attracting increasing attention as coastal zones continue their rapid development. This development directly impacts coastal water quality, and hence coastal ecosystems. Few would disagree that maintaining coastal water quality is critical to wise management of any coastal region, although there is disagreement on the magnitude of the threat and the degree of action required to protect coastal ecosystems from pollutant damage. Reducing pollutant inputs to coastal waters is one way to minimize this damage, and both natural and constructed wetlands have been shown to be very effective in making this reduction. This chapter provides a brief synopsis of the pollution threats to coastal waters and the role that fringing wetlands may play in mitigating the effects of these pollutants on coastal ecosystems. A clearer understanding of this role, along with the potential improvement in wetland functioning that may come with this improved understanding, is the ultimate goal of this research.

\subsection{Threats to the Coastal Ocean}

The overconcentration of population and commerce in the relatively small land area bordering the ocean presents the largest threat to coastal waters. The specific components of this threat may vary widely from locale to locale, although deteriorating coastal water quality is a concern common to all areas. This deterioration may have severe impact, with effects ranging from closure of shellfish beds for harvesting to closure of beaches due to medical waste disposal or toxic algal blooms. Loss of habitat in ecologically productive areas is also a concern, as is increased erosion and escalating storm damage costs that this increased coastal development brings. The Committee on Environment and Natural Resources (CENR), one of nine committees of the National Science and Technology Council (NTSC), summarizes all these effects in their list of 'major coastal environmental issues' (National Research Council (NRC), 1994): 
- Eutrophication

- Habitat modification

- Hydrologic and hydrodynamic disruption

- Exploitation of resources

- Toxic effects

- Introduction of nonindigenous species

- Global climate change and variability

- Shoreline erosion and hazardous storms

- Pathogens and toxins affecting human health

Although the NTSC-CENR did not prioritize among the major coastal environmental issues it identified, other groups have attempted to rank these issues in terms of the threats they pose. For example, the Committee on Wastewater Management for Coastal Urban Areas, a committee of the Water Science and Technology Board (WSTB) of the $\mathrm{NRC}$, identified nutrients, toxic organics, and pathogens as "high priority" on a national level for managing coastal water quality (NRC, 1993). While they go on to say that different constituents may pose more severe threats on a local level, these three are most important on the larger scale.

Although toxic organics and pathogens may be significant human health concerns, excessive nutrient addition arguably poses the greatest threat to coastal oceans.

Eutrophication is one of the primary dangers facing estuarine ecosystems (Land Margins Ecosystems Research (LMER) Coordinating Committee, 1992, NRC, 1993, NRC, 1994). Although coastal and estuarine waters are already among the most heavily fertilized environments in the world (LMER Coordinating Committee, 1992), primary production in these areas is still limited by available nitrogen supply in many cases. Primary production is closely tied to all other ecological processes at work in the estuaries, so maintaining it within natural bounds is key to preserving the ecosystem as a whole. A large body of scientific evidence demonstrates the direct relationship between nutrient 
inputs and primary productivity, with nitrogen being the nutrient of most concern (Valiela, et al., 1990).

\subsection{Role of Wetlands}

Although wetlands may play a significant role in reduction of all pollutant fluxes, most data available concerns their nutrient removal capabilities. For simplicity, this topic will be emphasized in what follows, although many of the conclusions reached may be valid for other types of pollutant inputs as well.

Fresh and salt water wetlands present in many estuarine regions can have a significant impact on the flux of nutrients entering coastal waters, and hence on the estuary's susceptibility to eutrophication. Constructed and managed wetlands have been used extensively for natural treatment of sewage and other effluents, and the natural wetlands and marshes surrounding an estuary serve much the same function. Salt marshes are highly complex and diverse ecosystems, with biological production rates higher than those found even in intensively used agricultural lands (Teal and Teal, 1969). Additionally, fringing tidal marshes have been shown to more than double soil contact times of discharged groundwater relative to unvegetated subtidal sediments. This increased contact time, coupled with the high organic carbon content of wetland soils (critical for denitrification), translates into greater opportunity for immobilization of nutrients prior to export to coastal waters (Harvey and Odum, 1990). The high productivity and soil contact times of these marshes make them very effective interceptors of nutrients bound for the coastal oceans.

This interception occurs through a number of mechanisms which vary in importance from marsh to marsh. These processes generally impact only the dissolved inorganic nitrogen (DIN), the dissolved organic nitrogen (DON) passes through the marsh essentially unaffected (Valiela and Teal, 1979). The DON is less energetically useful than the DIN 
to organisms within both the marsh and the coastal ocean, however, so effects from its input are less severe. Nitrogen uptake by wetland vegetation is generally an important sink for nitrogen, and nitrogen fixation by bacteria and algae also make significant contributions. Data from constructed wetlands indicate a range of $11-94 \%$ nitrogen removal capability depending on the degree and type of vegetation present (Reed, et al., 1988). Natural marshes exhibit up to $64 \%$ nitrogen removal capability (Valiela and Teal, 1979), indicating that some enhancement of their performance may be possible.

Much of the nitrogen not intercepted and retained within the marsh ecosystem is converted in form before export to the coastal ocean, often to forms which reduce eutrophication potential. $80-95 \%$ of the DIN entering the marsh is in the highly energetically useful nitrate form, but the majority of this is converted to particulate nitrogen before export from the marsh (Valiela and Teal, 1979). This particulate nitrogen is much less biologically available for stimulating primary production than is the dissolved form (Valiela and Teal, 1979), so eutrophic effects are further minimized.

\subsection{Description of Research}

The preceding discussion delineates the critical role that wetlands may play in reducing nutrient (and potentially other pollutant) fluxes to the coastal oceans, but does little to quantify specific effects of various wetland characteristics. This is very difficult to quantify given the incredible complexity of salt marsh ecosystems, and may well depend on nutrient/pollutant type and other marsh-specific attributes. In general, this exchange/conversion process is governed by diffusion from marsh sediments, uptake by plants, tidal flushing characteristics, and other factors (Valiela, et al, 1990). Vegetation has a major impact on these processes, since uptake and tidal flushing characteristics are greatly influenced by vegetation type and density. This research focuses specifically on the effects of vegetation density on diffusivity within the marsh. While this is just one 
parameter in a combination of vegetation-related parameters influencing the marsh's nutrient removal effectiveness, improved understanding of this effect may lead to better understanding of other processes occurring within the marsh, and may ultimately lead to ways to improve wetland performance.

Equation 1-1 gives a simplified expression for the transport and conversion processes occurring for a given substance within the salt marsh. All uptake and conversion processes have been combined into a single rate constant $(K)$, and otherwise the substance is assumed to behave conservatively. Advection is governed by the 3-D currents throughout the marsh $(u, v$, and $w)$, while diffusion is controlled by the 3-D diffusivities $\left(D_{x}, D_{y}\right.$, and $\left.D_{z}\right)$.

$$
\begin{aligned}
& \frac{\partial C}{\partial t}+ u \frac{\partial C}{\partial x}+v \frac{\partial C}{\partial y}+w \frac{\partial C}{\partial z}= \\
& K C+\frac{\partial}{\partial x}\left(D_{x} \frac{\partial C}{\partial x}\right)+\frac{\partial}{\partial y}\left(D_{y} \frac{\partial C}{\partial y}\right)+\frac{\partial}{\partial z}\left(D_{z} \frac{\partial C}{\partial z}\right)
\end{aligned}
$$

The relative importance of advective versus diffusive transport depends on the scale one is interested in. At larger scales (such as the marsh as a whole) advection dominates diffusion, and the exchange process could reasonably be thought of as wholly a tidal advection problem. For example, to determine the amount of nitrogen entering Buzzards Bay from Great Sippewissett Marsh, one need only monitor tidal exchange volumes and nitrogen content of exchanged water at the mouth of Sippewissett Creek. (This marsh is the study site for this research, a more detailed description is found in Chapter 2.) As the scale of interest is reduced diffusion plays a larger and larger role, with the nitrogen balance for Great Sippewissett Marsh as a whole providing an excellent example. Groundwater flow provides roughly $90 \%$ of the total nitrogen supply to the marsh, with most of this flow diffusing up through the bed in sandy creek channels or from a number 
of springs located around the periphery of the marsh (Valiela, et al, 1990). Groundwater is unlikely to enter the marsh in significant quantities in any highly vegetated areas, since these areas generally have a much lower hydraulic conductivity (due to the higher organic content) than other areas of the marsh (Valiela, et al, 1990). Vegetated areas are critical for nitrogen removal, however, with over $95 \%$ of bacterial nitrogen fixation and roughly $50 \%$ of the denitrification for the marsh as a whole occurring there (Valiela, et al, 1990). These processes together account for over $85 \%$ of the marsh's nitrogen removal capability (Valiela and Teal, 1979). It is therefore necessary to account for the transport of nitrogen from the non-vegetated regions where it is introduced to the vegetated regions where it is utilized. This transport is both advective and diffusive. The sandy creek channels where the majority of the groundwater (and hence nitrogen) enters the marsh make up roughly $13 \%$ of the total marsh area, while the vegetated areas where it is utilized cover over $60 \%$ of the total marsh area. The disparity in these two percentages illustrates the importance that diffusion must have in determining the overall nitrogen-utilization capacity of the marsh as a whole. Consideration of only advective transport may be sufficient for determining nitrogen flux to the coastal ocean, but diffusive transport must definitely be considered when characterizing processes occurring within the marsh itself. Providing reliable estimates for diffusivities based on vegetation densities and ambient flows may then enable us to fine tune the marsh to improve performance, perhaps by altering vegetation density or distribution to maximize nutrient removal capability.

These diffusivities depend on the turbulence levels throughout the marsh, with higher turbulence leading to greater diffusivity. The stem size and population density of marsh vegetation can be a key determiner of turbulence levels in the marsh. Although vegetation coverage is generally less than $10 \%$ in natural marshes (Kadlec, 1990), even this minor coverage can have significant impact on turbulence (and hence diffusivity) levels. In the presence of adequate flow, addition of a small number of stems increases turbulence due to vortex shedding. This effect is enough to counterbalance the decrease in bed production associated with the decrease in mean flow due to increased drag from 
the stems. Increasing the stem density does lead to a reduction in turbulence levels, however, as sufficient flow restriction eventually exists to limit flow enough to prohibit vortex shedding (Nepf, et al, 1997, Burke and Stolzenbach, 1983). Based on a numerical model this critical stem density is expected to be around $1 \%$ coverage, with turbulence levels falling off at both higher and lower stem densities (Burke and Stolzenbach, 1983). This field study is designed to explore these findings.

It should be noted that the hydrodynamically-optimized stem density discussed above may or may not be the overall ideal stem spacing for the marsh in general. For example, it has been noted that a prolonged increase in nutrient loading causes Spartina alterniflora plants to shift from a short to a tall form (Valiela and Teal, 1979). This change in plant height leads to a concurrent increase in average plant spacing, potentially altering the size and types of species able to use the marsh for protection, foraging, and other purposes. No attempt will be made to quantify these effects, but their consideration may be critical when determining what the truly optimum vegetation density is for a given marsh.

\subsection{Other Considerations}

As discussed above, diffusivity levels observed within marsh vegetation are dependent on the turbulence structure present. While the goal of this research is to examine diffusivity directly, the extension to turbulence levels may also be useful in a number of other areas. For example, reduced turbulence and flow within stands of vegetation may increase deposition or decrease erosion within these same areas - a fact which may be important in the study of sediment transport or particulate pollutant deposition. Reduced turbulence may also be an important determinant of food supply to certain marine organisms, since turbulent mixing may be critical to replenishing the food supply in heavy consumption areas (Fréchette, et al, 1989, Butman, et al, 1994). Additionally, Anderson and Charters (1982) observed that the coastal aquatic plant Gelidium nudifrons generates turbulence at 
flows exceeding $6 \mathrm{~cm} / \mathrm{s}$ and suggested that stem size is adaptively selected to optimize the scale of turbulence for maximum nutrient uptake. Other researchers have related sediment-water column and plant-water column exchange of oxygen, phosphorus, nitrate, and ammonium to the level of water column turbulence (Koch, 1993, Ziegler, 1993, Heuttel and Gost, 1992). Since turbulence is the common factor in all these concerns, relative quantification of turbulence levels within vegetation stands may provide useful insight in a number of areas. 


\section{Study Site Description}

This study was carried out in Great Sippewissett Marsh, a tidal salt marsh located on Buzzards Bay on the western shore of Cape Cod, Massachusetts. Great Sippewissett Marsh is generally characteristic of tidal marshes found in this region, specific characteristics are as described below.

\subsection{General description}

Great Sippewissett Marsh itself occupies $483,800 \mathrm{~m}^{2}$, with approximately $44 \%$ of this area being classified as 'low marsh' and 20\% as 'high marsh' (Valiela and Teal, 1979). Short and tall forms of Spartina alterniflora (cordgrass) are the dominant vegetation in the low marsh region, while Spartina patens and Distichlis spicata dominate the high marsh. The remainder of the marsh is broken down into muddy creek bottoms, sandy creek bottoms, and algal mats - with each being present in roughly equal quantities.

Seawater from Buzzards Bay enters and leaves the marsh through a single entrance known as Sippewissett Creek. The marsh is flooded twice daily by this seawater, with the average tidal excursion being 1.6 meters (Valiela and Teal, 1979). Freshwater enters the marsh through a combination of stream and groundwater inputs, but totals only about three percent of the saltwater tidal exchange (Valiela and Teal, 1979). Circulation within the marsh is therefore almost totally controlled by tidally driven currents.

Tidally averaged depths in Great Sippewissett Marsh are on the order of a meter, although large areas of the marsh are very shallow. Figure 2-1 shows an overhead view of Great Sippewissett Marsh with the study area and other prominent features called out. 


\subsection{Specific study conditions}

This dye release experiment was carried out in an isolated patch of Spartina alterniflora located in the 'low marsh' region of the greater marsh. Figure 2-2 shows this patch and the area immediately surrounding it. The patch itself was roughly 3 meters by 3 meters in size with a fairly even distribution of vegetation over this area. The larger area around the patch had a relatively smooth and flat bed (bed being the lower water column boundary) and was exposed during low tide conditions, allowing both for ease of equipment setup and relatively undisturbed flow conditions during measurements. The study area was located immediately to the south of a major west-to-east creek channel in the marsh as well, so the currents found there during tidal changes are believed to be among the highest of those found throughout the marsh (excluding those found in the creek mouth and inlet channel). This combination of strong currents, smooth bed and small flow resistance seemed to make this an ideal site for the dye release study. Also, the limited extent of the patch encourages more uniform flow, i.e. no dead end effects caused by lack of an outlet for the water flowing into the vegetation. Tidal excursions during the course of the study ranged from roughly 1.3 meters early on to 0.9 meters at the conclusion. 


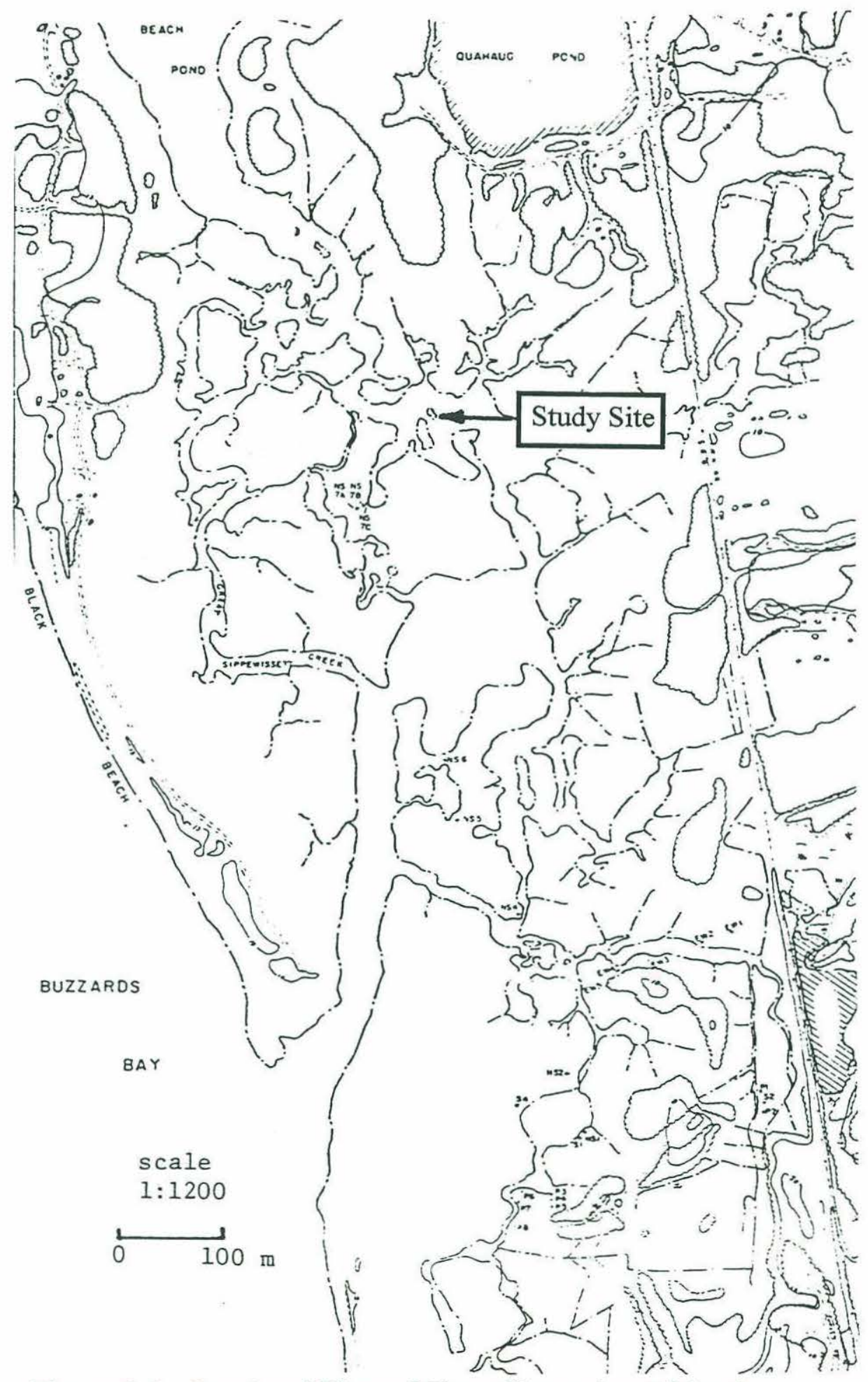

Figure 2-1: Overhead View of Great Sippewissett Marsh 


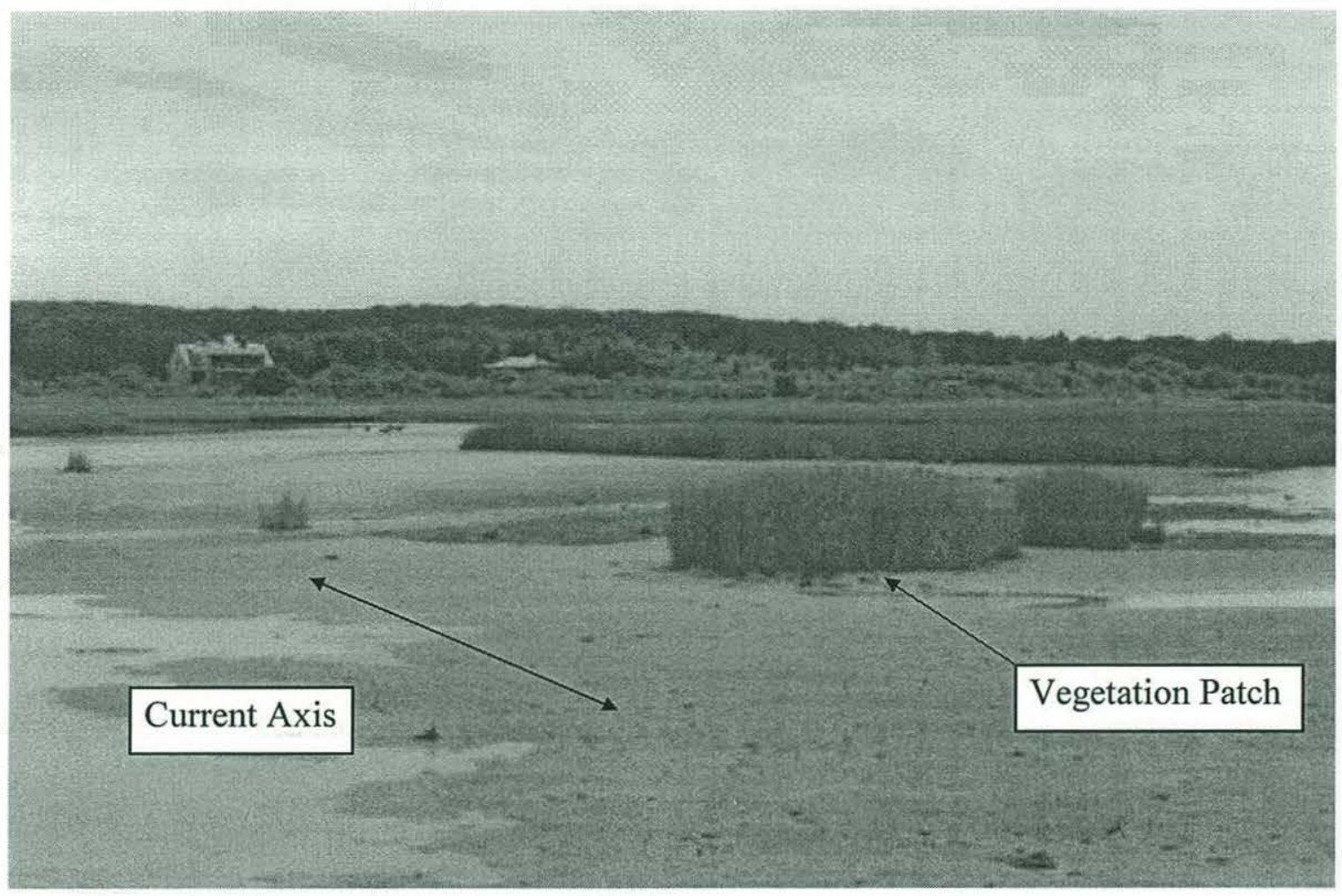

Figure 2-2: Study Site and Immediate Surroundings 


\section{Experimental Techniques}

To determine diffusivities, Rhodamine WT fluorescent dye was continuously injected at the midpoint of the vegetation patch, and the resulting fluorescence profiles were measured using a flow-through fluorometer as the dye plume emerged from the patch. These profiles were then used to estimate diffusivities for the vegetation and flow conditions present. This chapter discusses the equipment used to accomplish this injection and sampling, operational parameters used with the equipment, specific sampling techniques used, and the assumptions used in gathering and analyzing this data.

\subsection{Equipment Used}

Equipment used included that required to inject the Rhodamine, to collect water samples, and then to analyze these samples. Figure 3-1 shows a photograph of the equipment in the field, while Figure 3-2 shows a schematic drawing of the general layout. More details are provided in the paragraphs which follow.

\subsubsection{Fluorescent Tracer Addition}

The tracer solution was prepared each day by mixing $2-4 \mathrm{ml}$ of a $20 \%$ solution of the dye in 10 liters of marsh water. The resulting mixture was then injected into the ambient flow using a variable-stroke positive displacement pump, with the flow rate being adjusted as necessary to provide adequate tracer concentrations at the downstream sampling point. The injection rate varied from day to day depending on tidal height and currents, but generally was on the order of $60 \mathrm{ml} /$ minute. This allowed a sampling window of up to about 3 hours without depleting the dye source.

The dye injection tube itself was a $1 / 4$ " $\mathrm{D}$ tygon tube secured to a $3 / 8$ " diameter threaded rod, with the combination (along with the dye bottle and the injection pump) being mounted on a 0.5 meter by 1 meter table constructed from $3 / 4$ " PVC piping. The threaded 


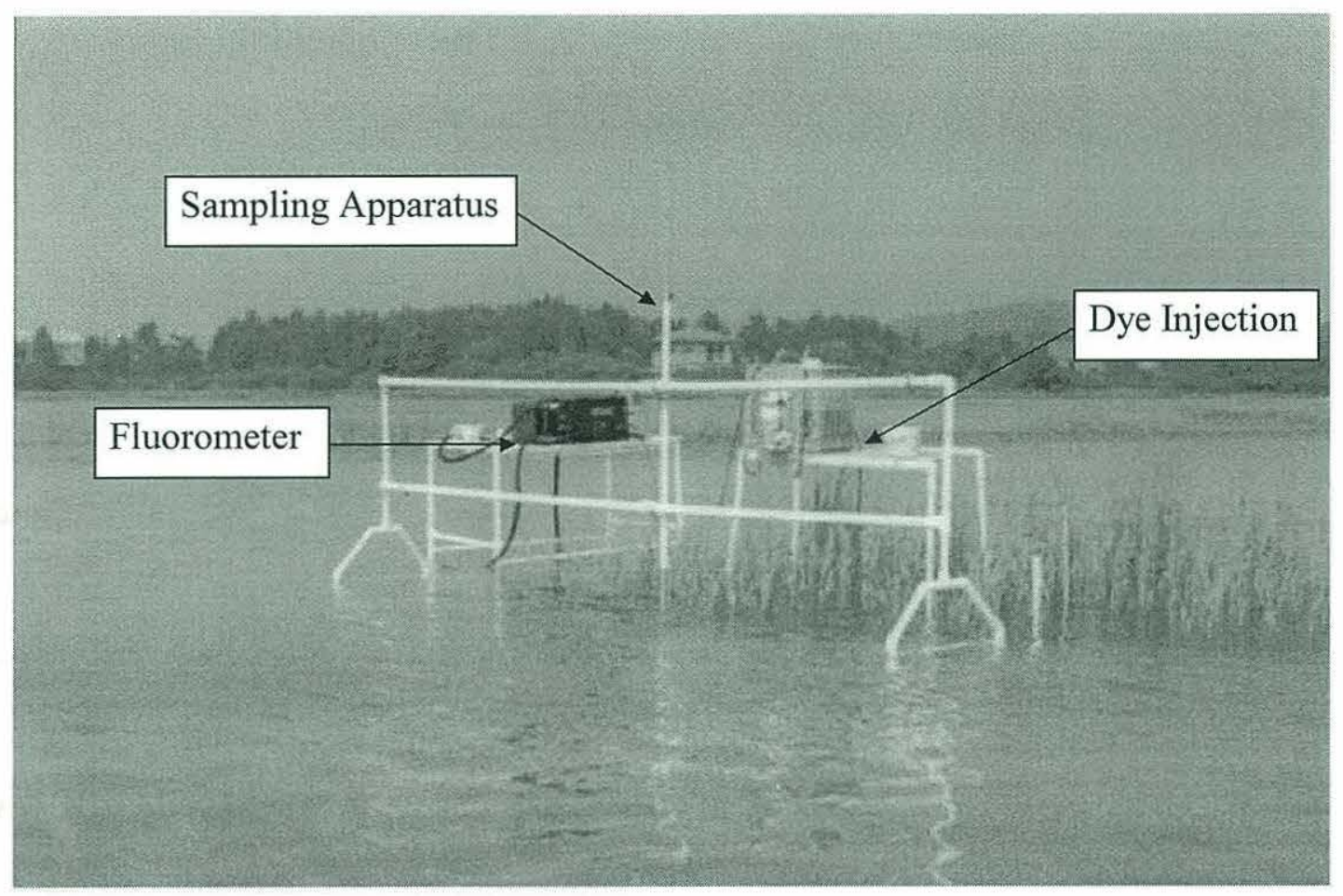

Figure 3-1: Equipment Layout and Arrangement

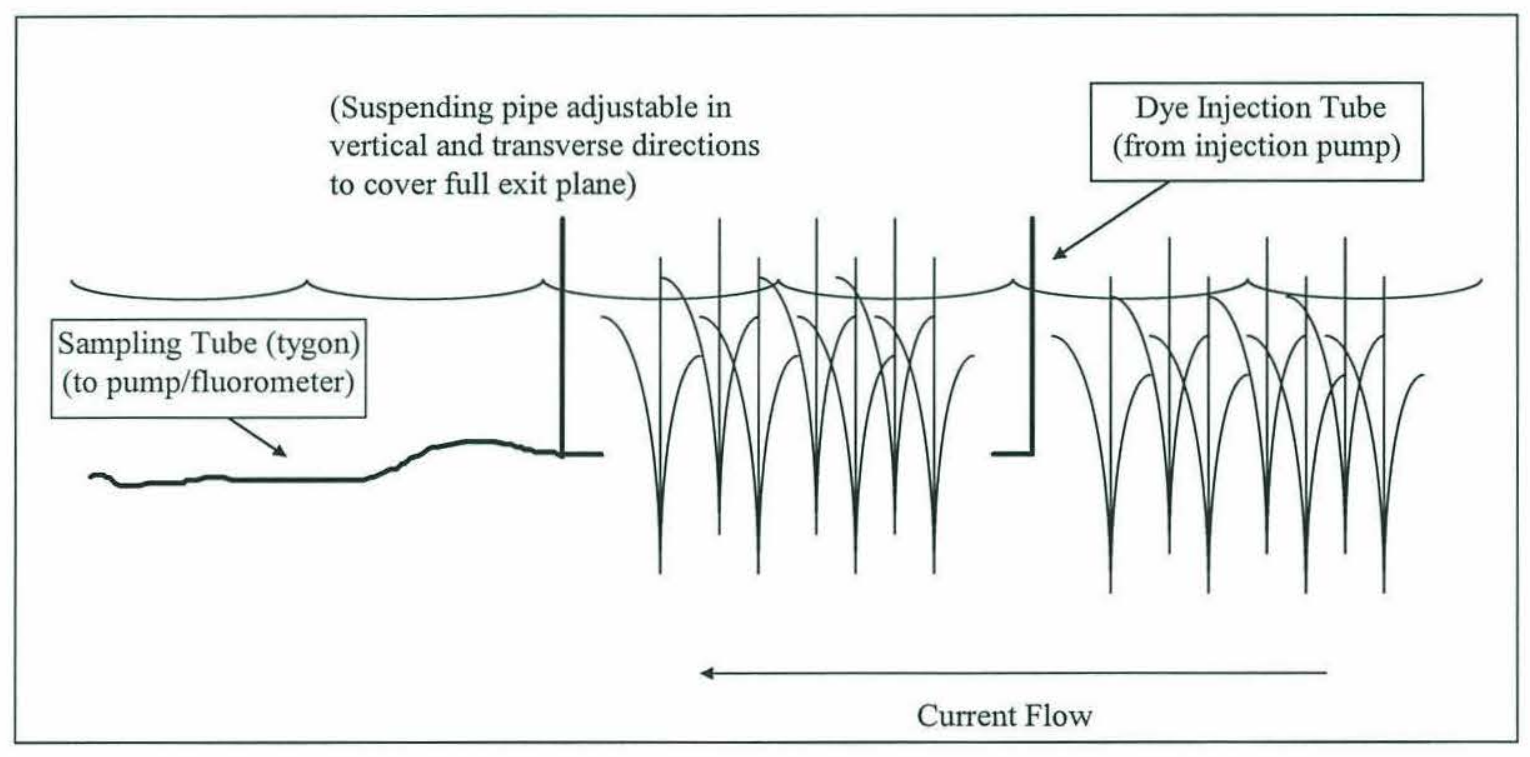

Figure 3-2: Schematic Representation of Physical Layout 
rod allowed the injection height to be easily and quickly adjusted vertically, and the dimensions of the tube/rod combination were selected to minimize flow disruption. The mean stem diameter of vegetation in the patch was found to be 0.27 " $(0.69 \mathrm{~cm})$, so the tube/rod combination would be seen much like another stem by the flow. An "L" fitting on the free end of the tygon tubing directed the dye discharge parallel to the ambient flow, minimizing any mixing due to shear effects. The table itself was oriented with its long axis perpendicular to the ambient current, again to minimize effects from the table legs on the turbulence structure near the dye injection point.

\subsubsection{Sample Collection}

Water was collected from a plane located roughly 1.5 meters downstream from the injection point by means of a sampling pump and a second tygon tube. This sampling tube was suspended from PVC pipes located above the water's surface, so the only intrusion into the sampling region was from the $1 / 2$ " diameter pipe connected to the sampling tube and used to adjust it vertically. The position of this suspending pipe was adjustable both horizontally and vertically, allowing samples to be gathered throughout a vertical plane immediately downstream from the vegetation patch. The suspending pipe itself was only slightly larger diameter than a standard plant stem (again minimizing flow disruption), and the sample tube itself was made to extend roughly $5 \mathrm{~cm}$ upstream of this suspending pipe to further minimize any disruptive effects near the sampling point.

The sample tube was $1 / 2$ " $\mathrm{D}$ tygon tubing, and the sample pump drew samples at a nominal $1.5 \mathrm{gpm}$. This provided for a velocity at the sample tube inlet of roughly 75 $\mathrm{cm} /$ second, approximately an order of magnitude higher than ambient flows. This condition was thought to be unacceptable, so the end of the sample tube was fitted with a "T" fitting, with the arms of the "T" trimmed off slightly, to minimize this problem. This had the effect of roughly halving the inlet velocity and also of directing the suction from 
the sample pump perpendicular to ambient current flow. This condition was thought to yield more acceptable conditions for several reasons:

1. Distances of only several centimeters from either end of the " $\mathrm{T}$ " are required to get suction flow velocities essentially equal to ambient values.

2. Dye concentration profiles over distances such as these (between the two inlets plus far enough into the fluid for suction velocity to be roughly ambient velocity) should be well approximated linearly, so drawing samples from both sides may tend to average the dye concentration very close to the true value.

While this condition was still not ideal, it was deemed acceptable due to the need to sample large volumes of water very quickly and because of the reasons above.

\subsubsection{Sample Analysis}

Samples collected with the above apparatus were analyzed in situ using a Turner Designs Model AU-10 fluorometer in continuous flow mode. Water was drawn through the fluorometer by connecting the sample tube to the inlet of the fluorometer's sample chamber and pump suction to the outlet of the sample chamber. A background fluorescence reading was obtained at the beginning of each day's sampling; and time, water temperature and fluorescence above background were recorded throughout the sampling period using the internal data logger installed on the AU-10. Further details on instrument setup and data collection are presented in the following sections.

\subsection{Data Collection}

Data collected included fluorescence at a number of locations in the vertical plane at the downstream boundary of the vegetation patch, as well as vegetation density and ambient current values. Fluorescence was in general measured in one vertical profile (same 
transverse coordinate) and one transverse profile (same vertical coordinate), with additional readings obtained as possible. More detailed information on this data collection is presented below.

\subsubsection{Sample Duration}

Length of sampling at any particular coordinate was a compromise between obtaining adequate data to provide a representative fluorescence reading at that point and obtaining readings at a sufficient number of these coordinates prior to significant changes in the tidal flow. The method settled upon as being the most productive involved sampling for one minute per coordinate for one full vertical and one full transverse profile, and then returning to take longer readings at each coordinate if conditions allowed. In general, the one minute per coordinate snapshot profiles resulted in fluorescence measurements which were more precise and more normally distributed than the longer reading profiles due to the rapid changes in tidal flow.

\subsubsection{Sample Location}

In general, a vertical profile was taken at what appeared to be the horizontal center of the plume, followed by a transverse profile at the vertical coordinate which seemed to have the maximum averaged fluorescence reading. These averages were done based on the visual display of the $\mathrm{AU}-10$, and so were not always precise as shown by later, more detailed, data analysis. Readings for any given profile were normally taken at $10 \mathrm{~cm}$ increments, although finer and more coarse profiles were also taken as time and conditions allowed.

\subsubsection{Vegetation Density}

Vegetation density was determined by randomly casting a $0.1 \mathrm{~m}^{2}$ frame onto the vegetation island and counting the number of stems within the frame. This measurement was repeated five times for each vegetation density to be measured, with the density used 
for further calculations being the mean of the five individual measurements. These measurements were first taken at the natural density, then stems were selectively (and randomly) removed in a series of steps to gradually reduce vegetation density to zero. In each step, roughly one-half of the remaining stems were removed. This removal was done by trimming off the stems 3-4 centimeters above the bottom, allowing the stem to be removed without killing the plant. (Full vegetation density has already been restored due to stem regrowth.) A representative sample of roughly 100 stems from the first cutting was measured for diameter at the base of the stem; mean stem diameter was found to be $0.69 \pm 0.03 \mathrm{~cm}$. This value was then used to compute percent vegetation coverage, defined as the percentage of the bed area actually occupied by plant stems and designated as $P$. For example, a stem density of $200 \mathrm{stems} / \mathrm{m}^{2}$ gives a total stem area of $74.8 \mathrm{~cm}^{2}$ $\left(200 * \pi^{*}(0.69 / 2)^{2}\right)$, resulting in a percent vegetation coverage of $0.75 \%$. This technique does not consider the effects of any leaves attached to the stem or any variation in stem size with depth, but since these effects should (at least to the first order) be proportional to stem density, it provides a reasonable measure of vegetation coverage. Table 3-1 shows the vegetation densities and percent stem coverages found in this study.

Table 3-1: Vegetation Densities and Percent Coverages

\begin{tabular}{|c|c|c|c|}
\hline Vegetation & Stems/0.1 m2 & Stems/m2 & Percent \\
Density & (each of 5 trials) & (mean) & Stem \\
Coverage \\
\hline \hline High & $40,36,37,37,35$ & 370 & 1.38 \\
\hline Medium & $19,17,21,21,20$ & 196 & 0.73 \\
\hline Low & $9,8,11,10,10$ & 96 & 0.36 \\
\hline Zero & stubble only & 0 & 0 \\
\hline
\end{tabular}




\subsubsection{Determination of Currents}

Currents were measured by injecting a parcel of dye at roughly mid-depth and timing its transit across a known distance. This measurement was repeated for a number of trials at several different times (roughly 15 minute intervals) over the course of a given sample profile, with the individual readings at a given time being averaged to give the mean current for that time. The mean sample time for all coordinates used in a given profile was also obtained, and a current for this time was found via linear interpolation between the measured current values on either side of the time in question. This current was then used in all further calculations for that particular profile.

\subsection{Fluorometer Setup}

The Turner Designs Model AU-10 fluorometer used in this study has several userdefinable parameters for customizing the data gathered. Settings used, and the rationale behind these choices, are discussed in the sections below.

\subsubsection{Data Averaging Interval}

The visual display on the AU-10 is updated with a new fluorescence reading every one second; the value is recorded in the internal data logger is either these instantaneous values or some time-average of these readings. Readings were logged every one second throughout this study to maximize data availability, so the data averaging interval was selected as one second. This in effect records the instantaneous values, however, since only one reading is averaged to obtain the recorded fluorescence.

\subsubsection{Time Constant}

The fluorometer also has an internal time constant setting which works to reduce variability in fluorescence readings. As discussed above, the fluorometer's display is updated every second, but the AU-10 is actually sampling internally at 10 Hertz. These 
internal readings are then averaged (using the time constant setting) to give the value displayed on the visual display and sent to the internal data logger. A time constant of 1 second was used throughout this study. This setting causes the AU-10 to use the previous 1.6 seconds worth of internal readings to determine the value to be displayed/sent to the data logger, and is the shortest time constant available without modifying the instrument. Alternate time constants available are 2, 4, or 8 seconds; these use the previous 3.2, 6.4, and 12.8 seconds worth of internal readings, respectively, when determining the fluorescence value displayed and sent to the logger. Using the 1 second time constant then allowed for maximum instrument response and minimized any internal smoothing of the data.

\subsubsection{Temperature Compensation}

Fluorescence decreases with increasing temperature in accordance with Equation 3-1.

$$
\begin{array}{rll}
F=F_{0} * e^{n\left(t-t_{0}\right)} & \text { Equation 3-1 } \\
\text { where } \mathrm{F} & =\text { fluorescence reading at a given temperature } \\
\mathrm{F}_{0} & =\quad \text { fluorescence reading at the chosen reference temperature } \\
\mathrm{n} & =\text { the temperature exponent for the dye in use } \\
\mathrm{t}_{0} & =\quad \text { the chosen reference temperature }
\end{array}
$$

The reference temperature was chosen as $25^{\circ} \mathrm{C}$ for this study, and the temperature exponent was set at -0.027 for Rhodamine WT as suggested in the literature (Smart and Laidlaw, 1977). Experiments conducted using a closed-loop recirculation system showed that this compensation scheme removed roughly $75 \%$ of the effect of temperature on fluorescence readings, but left a variation of $2 \%$ of the fluorescence reading per degree $\mathrm{C}$. This is not as exact a compensation as might be hoped for, but since temperature variations over a sampling period were at most $2^{\circ}-3^{\circ} \mathrm{C}$, the maximum effect on relative 
fluorescence readings should be roughly $5 \%$. Temperature changes over any individual profile were never more than $0.5^{\circ} \mathrm{C}$, however, so errors due to temperature compensation effects should be $1 \%$ over any profile. This error is well within the uncertainty associated with any mean fluorescence value, and so may considered negligible. One must be conscious of this potential disparity, however, when comparing absolute fluorescence readings at differing temperatures rather than relative readings across a single profile.

\subsection{Simplifying Assumptions}

A number of simplifying assumptions were made in this study due to equipment and personnel availability. Specific assumptions are discussed below.

\subsubsection{Uniform current profile}

Currents within the patch of vegetation were measured by injecting a parcel of dye approximately midway between the water surface and the bed and timing its transit across a measured distance. This injection was done only at one height within the canopy, so the current was actually measured only at this one height. Vertical variations in plant morphology (and thus drag) might be expected to create some vertical variation in the current profile, although studies have shown (Leonard and Luther, 1995, Gambi, et al, 1990, Shi, et al, 1996, El-Hakim and Salama, 1992) this variation within vegetation canopies to be relatively small - generally on the order of $10 \%$ of the mean velocity. Therefore, the simple single-point measurement obtained should give a reasonable approximation for the depth averaged velocity.

The current was also assumed to be uniform throughout the spatial extent of the vegetation patch. This is likely to be true except very near the edges of the patch (due to boundary effects), and since no injections or measurements were made near the edges of the patch, seemed to be a good assumption. This uniform three-dimensional current 
assumption then removes the effect of shear dispersion, leaving turbulent diffusion effects as the major parameter being measured.

\subsubsection{Boundary Effects Negligible}

Since the goal was to isolate the contributions of the plant stems to turbulence, all other effects had to be minimized. These included the influence of nonuniform conditions present near the edges of the vegetation patch, turbulence introduced by the bed, turbulence structure carried into the patch with the current, and wind and wave effects. The first factor was discussed above and was assumed negligible since no injections or measurements were made near the patch boundaries. All measurements were in fact taken at least 0.5 meters from the edge of the patch, the best that could be done with a patch of this size.

To minimize contribution from the bed, dye injections were made approximately midway between the surface and the bed, and measurements were taken longitudinally close enough to the injection point so that the plume had not yet grown sufficiently in the vertical to feel the presence of the bed. It is probable that bed-generated turbulence was present at the height of the plume, but stem-generated turbulence generally dominates the contribution from the bed (Nepf, et al, 1997), at least at higher stem densities. At lower stem densities this assumption may not be as valid, since reduced stem-generated turbulence may cause bed-generated turbulence to become more significant. These findings, coupled with the mid-water column injection and close-in sampling, make it reasonable to neglect bed-generated turbulence within the vegetation patch, at least as a first approximation.

Turbulence structure carried into the vegetation patch was also a concern. The site was

selected to minimize this contribution, with approximately 25 meters of relatively straight flow channel with a smooth and flat bed existing both up- and downstream of the vegetation patch. This minimized any flow disruptions and allowed for data gathering on 
both incoming and outgoing tides. Additionally, since the dye injection point was essentially in the center of the vegetation patch, approximately 1.5 meters of vegetation provided a zone of adjustment before the flow reached the injection point. These characteristics combined to minimize the effects of externally induced turbulence within the vegetation patch.

Wind and wave effects were not specifically accounted for, although there also were no specific days which seemed significantly more (or less) windy or wavy than any other days. These effects are then assumed to be relatively insignificant, although no hard evidence was analyzed to support this conclusion.

\subsubsection{Fluorescence Changes Negligible}

Changes in the fluorescence conditions could occur during the course of the concentration measurements. These changes could be due either to changes in the water temperature affecting fluorescence readings or to changes in the composition of the marsh water. Fluorescence readings change as temperature changes. Temperature variations over the full tidal cycle were routinely seen to be roughly $3^{\circ} \mathrm{C}$, but the range over any related series of measurements (taken over a period of at most 30 minutes) would then be less than half a degree. This, coupled with the temperature compensation feature of the fluorometer used, made this effect negligible. Fluorescence readings could also change with water composition, due to either background fluorescence changes or changes in salinity. Measurements of background fluorescence over a full tidal cycle showed negligible change. These results were then extrapolated to later days and this effect was assumed not to be important throughout the study. Changes in fluorescence readings due to salinity are more complex. There is a marked decrease in measured fluorescence from Rhodamine WT as salinity increases, with the most significant breaking point being around $0.03 \mathrm{M} \mathrm{NaCl}$ (2 ppt salinity)(Smart and Laidlaw, 1977). The decrease is also quite time dependent, however, with other studies suggesting minimal initial effect 
followed by major changes as the sample solution stands for several days. For example, $0.6 \mathrm{M} \mathrm{NaCl}$ (35 ppt salinity) causes a 50\% reduction in fluorescence over a 27 hour period (Smart and Laidlaw, 1977). A series of comparative measurements between standards prepared using distilled water and several marsh water samples showed a decrease in fluorescence of 4-8\% for the marsh water samples over the distilled water samples. This demonstrated minor effect over a range of possible salinities, coupled with the relatively short elapsed time during any series of related measurements, led to this effect being assumed as negligible in this study.

\subsubsection{Conservative Tracer}

The Rhodamine WT dye used as the tracer in this experiment was considered to behave conservatively. This assumption took into account the dependence on salinity as discussed above as well as adsorptive and photochemical losses. Rhodamine WT is one of the most conservative tracers available, with minimal adsorptive or decay losses, particularly at low concentrations. Several studies have measured overall losses at less than 5\% for this tracer (Smart and Laidlaw, 1977), so these losses were not considered in this study. During the course of the study, no evidence of adsorption to the vegetation was found, although there did appear to be some adsorption to sediments well outside the study area. This was based on a distinct pink color present in the sediment for several days after the dye release. 


\section{Analysis Techniques}

This chapter presents the techniques used in analyzing the data gathered as described in the previous chapter. Example analyses and calculations are provided using a representative profile.

\subsection{Selection of Data}

The sampling port was moved between locations at set times, but since this movement was not instantaneous and since the sample pump was continuously drawing samples, some of the data points gathered were not truly representative of the conditions at the intended sample point. Points collected during these transitions between sampling points were cut from the data record based on the following discussion.

The sample line consisted of roughly 20 feet of $1 / 2$ inch $\mathrm{D}$ tygon tubing with a small filter located about halfway between the sample inlet and the fluorometer. This volume, along with the small volume inside the fluorometer's sample chamber, totaled approximately one liter and represented the volume to be purged between samples. Since the sample pump had a nominal capacity of $1.5 \mathrm{gpm}$ (5.7 liter/minute), this represented roughly 10 seconds of pumping. The first thirty seconds of data from each sample point were actually discarded, however, to allow for the time delay in shifting the sample line and to allow for adequate purging and instrument stabilization. This allowed for purging roughly three line volumes before gathering data which were actually used in the analysis; these discarded points were recorded and are available for use if needed, however.

Figure 4-1 shows the full horizontal data series for the representative profile, while Figure 4-2 shows the sections of this profile used to calculate fluorescence at each coordinate. The coordinates listed in Figure 4-2 are transverse and vertical displacement from an arbitrary reference point. As discussed earlier, the first 30 data points at each coordinate 


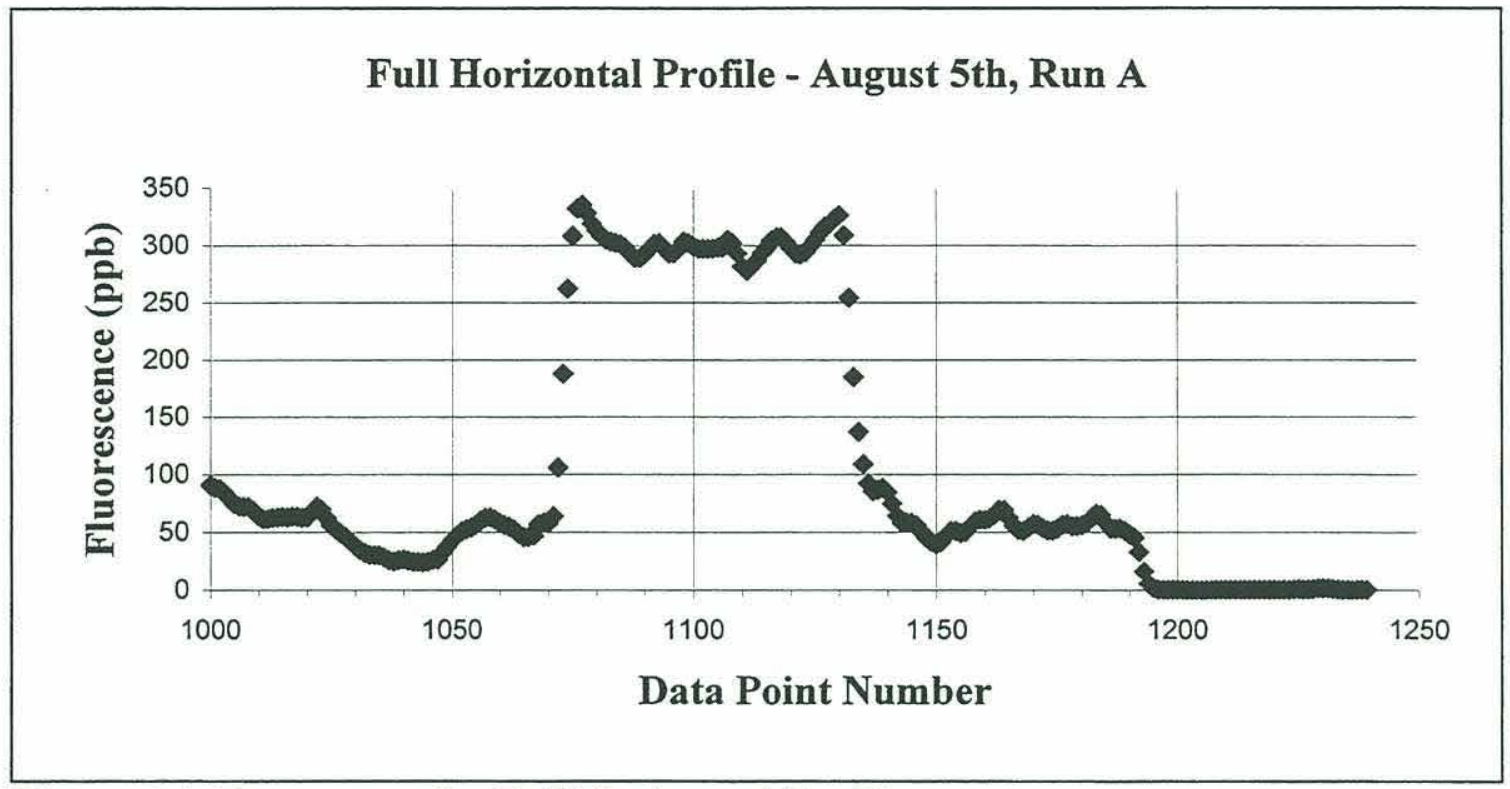

Figure 4-1: Representative Full Horizontal Profile

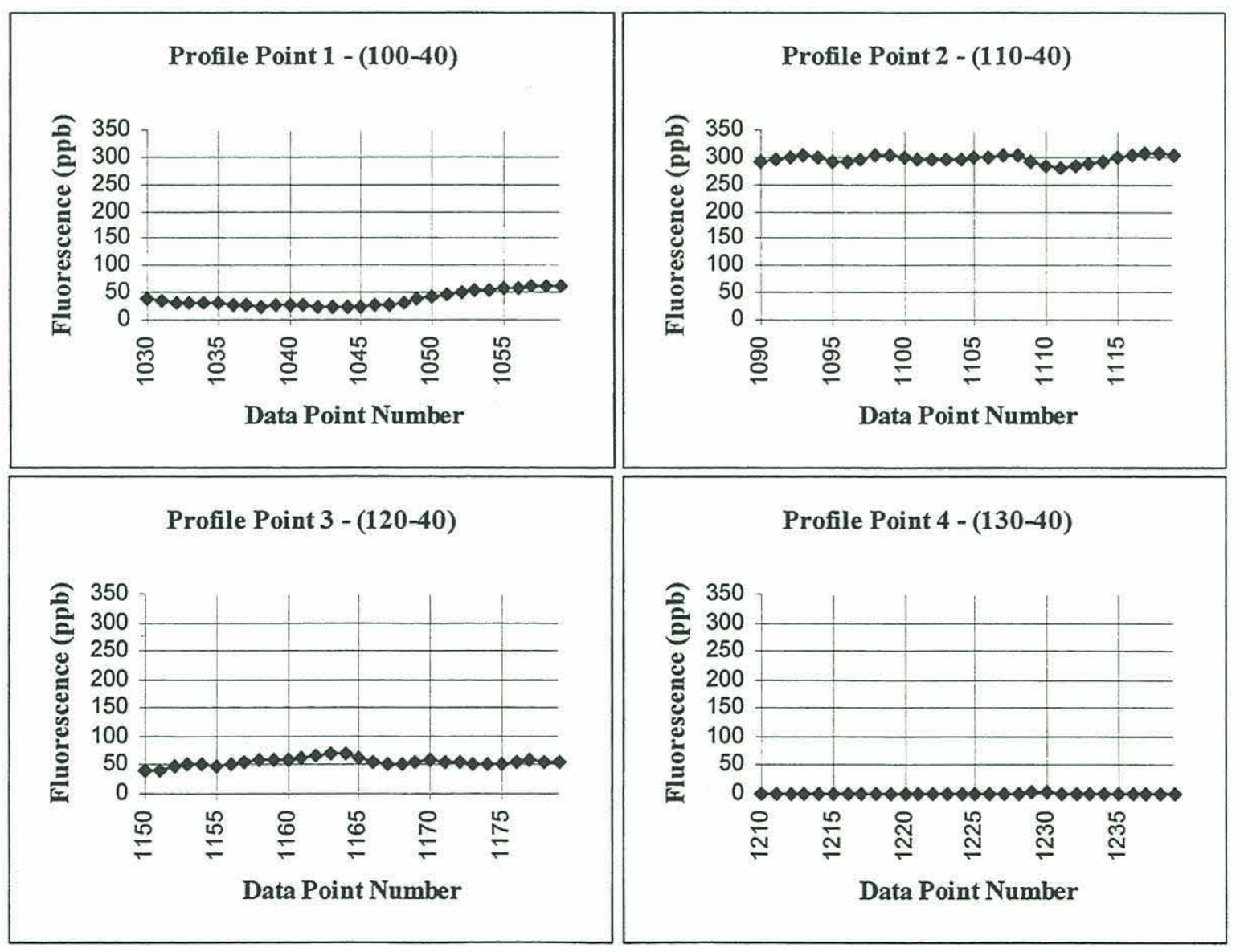

Figure 4-2: Data Used for Individual Profile Points 
were not analyzed, and all remaining data points were used. Each coordinate in this particular profile then had 30 data points which were used in analysis.

\subsection{Analysis Methods}

Remaining data points for each sample location were then averaged to get the mean fluorescence reading at that location. The standard deviation about this mean was also calculated, and the error in the calculated mean value was estimated using Equation 4-1.

$$
\delta_{F}=\frac{1.96 \sigma_{F}}{\sqrt{n}}
$$

where $\delta_{F}$ is the error in the mean fluorescence and $n$ is the number of data points used in finding the mean. This technique assumes that the individual data points used are independent, random samples - this is not absolutely true here, but this method still gives reasonable estimates on the uncertainty associated with the mean as $n$ becomes large. Table 4-1 shows the mean fluorescence and associated uncertainty for each of the points in the representative profile; the standard deviation is also tabulated for use later.

Table 4-1: Mean Fluorescence Values for Profile Points

\begin{tabular}{|c|c|c|c|c|}
\hline Data Point & Coordinates & $\begin{array}{c}\text { Mean } \\
\text { Fluorescence } \\
(\mathbf{p p b})\end{array}$ & $\begin{array}{c}\text { Uncertainty } \\
\text { in Mean } \\
\text { Fluorescence } \\
(\mathbf{p p b})\end{array}$ & $\begin{array}{c}\text { Standard } \\
\text { Deviation } \\
\text { for } \\
\text { Fluorescence }\end{array}$ \\
\hline \hline 1 & $100-40$ & 37.55 & 4.90 & 13.7 \\
\hline 2 & $110-40$ & 296.83 & 2.56 & 7.15 \\
\hline 3 & $120-40$ & 55.20 & 2.44 & 6.81 \\
\hline 4 & $130-40$ & 0.60 & 0.19 & 0.52 \\
\hline
\end{tabular}

Once the average fluorescence values were determined, the distribution of mean concentrations in space was evaluated using two different methods as discussed below. 


\subsubsection{Method of Moments}

The first method followed the Method of Moments analysis presented in Fischer, et al., (1979, p. 39-40), and used Equations 4-2 through 4-6. A linear interpolation was used to approximate the fluorescence profile between adjacent data points, and a linear extrapolation to zero fluorescence was done using the first two and the last two data points in the profile.

$$
\begin{array}{ll}
M 0=\int_{-\infty}^{\infty} C(x, t) d x & \text { Equation 4-2 } \\
M 1=\int_{-\infty}^{\infty} x C(x, t) d x & \text { Equation 4-3 } \\
M 2=\int_{-\infty}^{\infty} x^{2} C(x, t) d x & \text { Equation 4-4 } \\
\bar{x}=M 1 / M 0 & \text { Equation 4-5 } \\
\sigma^{2}=\int_{-\infty}^{\infty}\left(x^{\prime}\right)^{2} C\left(x^{\prime}, t\right) d x^{\prime} / M 0=(M 2 / M 0) & \text { Equation 4-6 }
\end{array}
$$

The value of $x$ in Equations 4-3 and 4-4 above is really distance from the plume center of mass, and since coordinates were measured relative to a fixed point some conversion had to occur. Equations 4-2, 4-3, and 4-5 were first used to determine the coordinate of the center of mass of the profile, then this value was subtracted from all $x$ coordinates to give new coordinates $\left(x^{\prime}\right)$ relative to the center of mass. This technique set $\bar{x}$ (and so $M I$ ) to 0 , and $x^{\prime}$ values ranged over both positive and negative values. Equations 4-2 and 4-4 were then properly evaluated using these new $x^{\prime}$ coordinates, and finally Equation 4-6 was used to find the variance of the profile using the values found for $M 2$ and $M 0$. 
Figure 4-3 shows the four profile points used in the representative analysis as well as the two extra points found by extrapolating fluorescence to zero (the extra point at the right end lies at 130.1, and is basically the same as the last real point); the dashed line connecting the points shows the linear approximation to the normal profile. Analysis as described above gave a plume center of mass at $111.1 \mathrm{~cm}$, a standard deviation of 5.73 $\mathrm{cm}$, and a variance of $32.80 \mathrm{~cm}^{2}$.

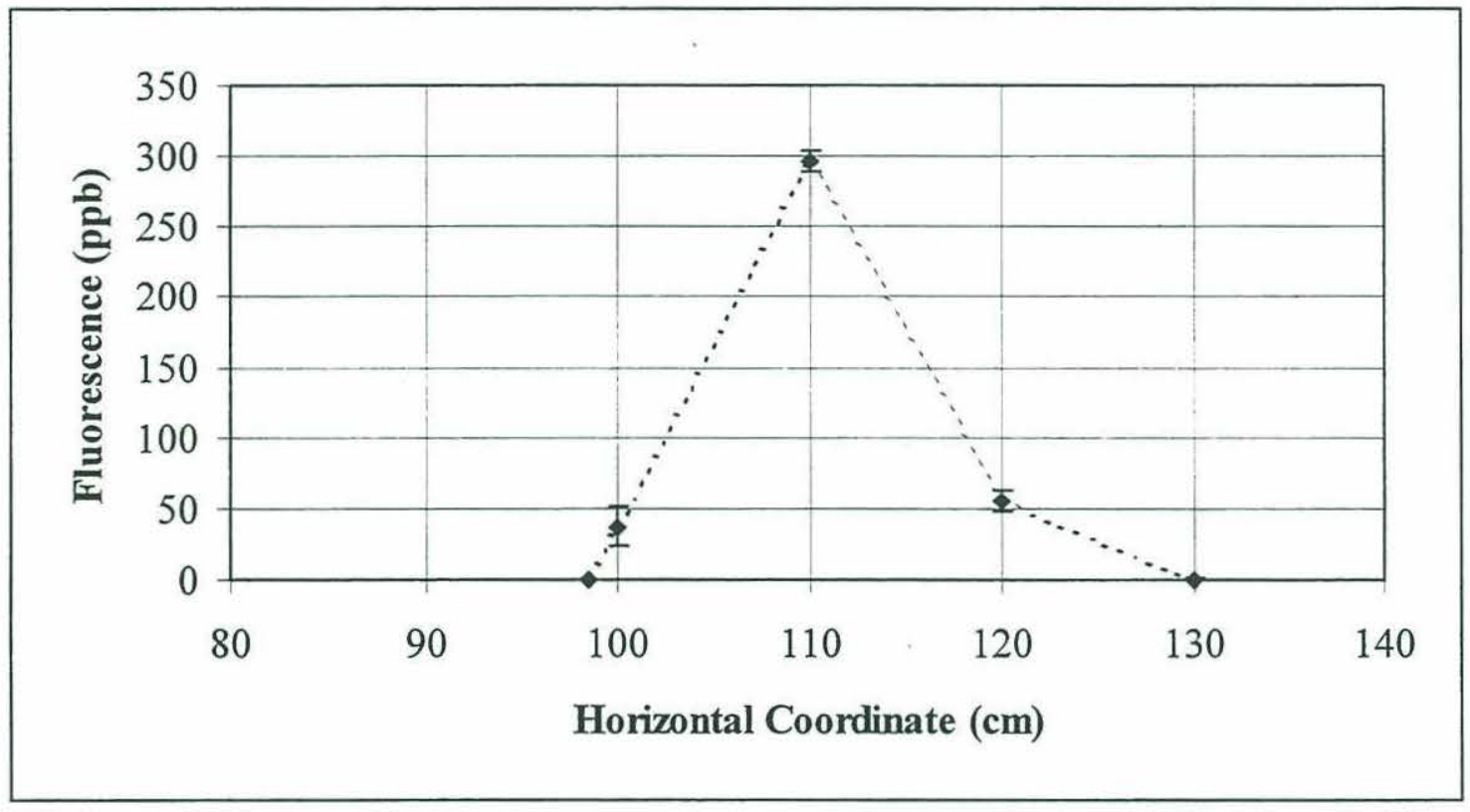

Figure 4-3: Method of Moments Analysis - Representative Profile 


\subsubsection{Exponential Fit}

The fluorescence profiles were expected to be normally distributed, so the second form of analysis involved fitting a standard normal equation to the measured data points. This standard normal equation is given by Equation 4-7, the solution was obtained by linearizing it as in Equation 4-8 and then applying a weighted linear least squares technique. Uncertainties in fluorescence readings were converted to uncertainties on a logarithmic basis using Equation 4-9, then weights for the individual points were computed using Equation 4-10. (Taylor (1982, p. 150) describes the weighting of individual points by the inverse of the square of their standard deviation.) This technique resulted in those points with greater relative uncertainty in fluorescence receiving less weight than more certain points when doing the least squares analysis. The $\bar{x}$ value found using the Method of Moments was used as a starting point for this exponential fit analysis, with values $\pm 5 \mathrm{~cm}$ from this starting point being checked in $0.1 \mathrm{~cm}$ increments to examine quality of fit. The $\bar{x}$ value over this range giving the best linear correlation coefficient for the least squares line was chosen as the best center of mass, and the constants $A$ and $B$ determined for this point were used in further analyses.

$$
\begin{aligned}
& F=A e^{-B(x-\bar{x})^{2}} \\
& \ln (F)=-B(x-\bar{x})^{2}+\ln (A) \\
& \sigma_{\ln F}=\sigma_{F} / F \\
& w_{i}=\left(\sigma_{\ln F_{i}}{ }^{2}\right)^{-1}
\end{aligned}
$$

Equation 4-7

Equation 4-8

Equation 4-9

Equation 4-10

Analysis of the representative profile using this second technique resulted in a center of mass at $110.1 \mathrm{~cm}$, with this value giving an $R^{2}$ value of 0.991 for the least squares fit. Weightings used for points 1 through 4 were $7.5,1724.3,65.6$, and 1.3 , and best values 
for $A$ and $B$ were 5.69 and 0.017 , respectively. Figure $4-4$ shows the individual profile points and the best fit exponential curve found using this method.

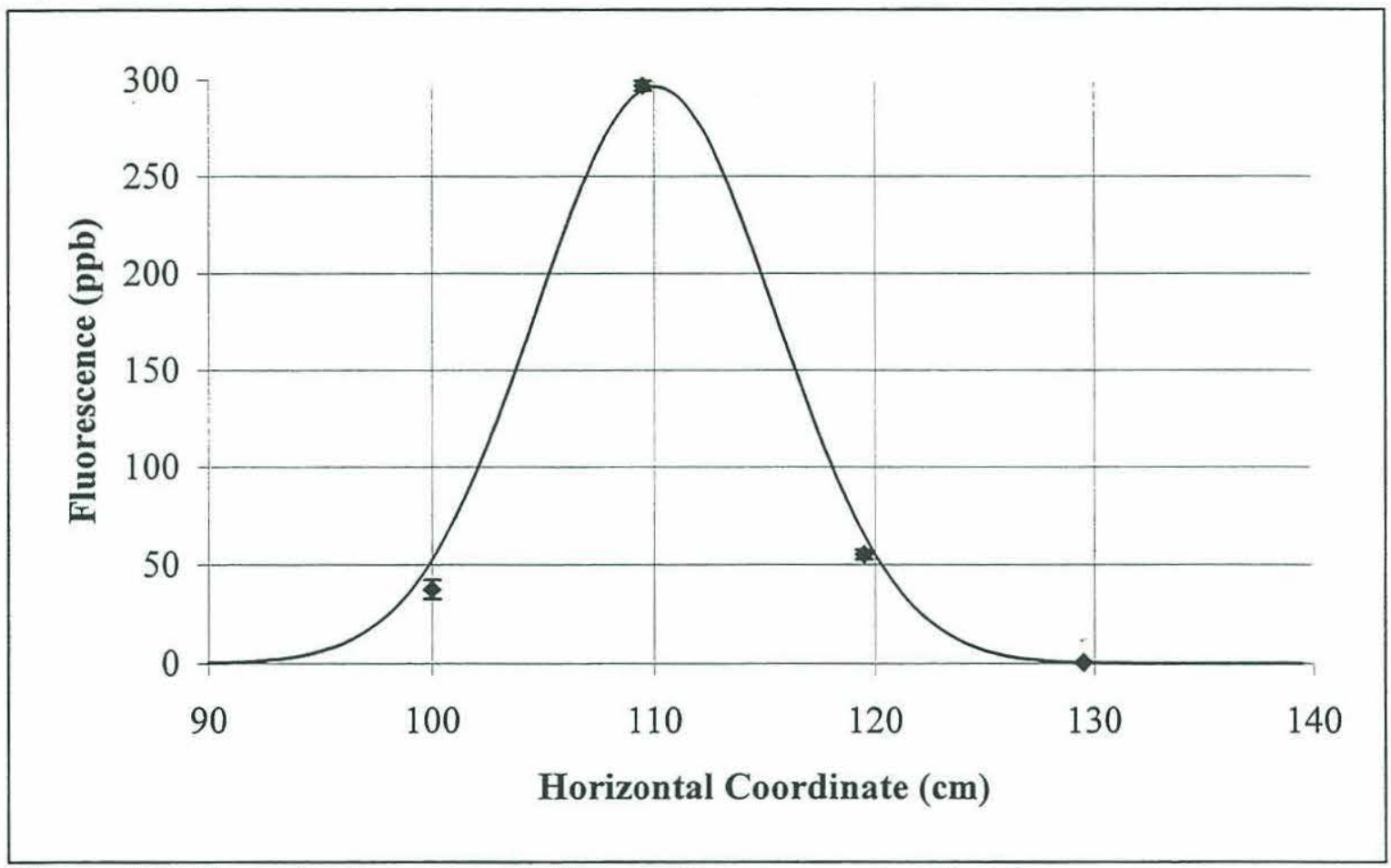

Figure 4-4: Best Fit Exponential Curve - Representative Profile

\subsection{Calculation of Diffusivity}

Diffusivity for a plume at steady state can be found using Equation 4-11, with $u$ being the mean current velocity and $l$ being the longitudinal distance from the source. The variance $\left(\sigma^{2}\right)$ is the direct output of the Method of Moments analysis, so calculation of diffusivity is straightforward in this case. The value of $B$ found in the exponential fit method is equivalent to $1 / 2 \sigma^{2}$, so this calculation is also straightforward after making the conversion from $B$ to variance.

$$
D=\frac{\sigma^{2}}{2 t}=\frac{\sigma^{2} u}{2 l}
$$


The longitudinal displacement (l) for the representative profile was $127 \mathrm{~cm}$. As discussed in section 3.2, currents for profile mean times were determined by linearly interpolating between currents measured at roughly 15 minute intervals throughout each day's study. Equation 4-12 describes the interpolation between points $t_{1}$ and $t_{2}$, while Figure 4-5 shows the measured currents for the day of the representative profile. Data for profile points 1-4 were taken between 2:25 and 2:29, giving a mean time of 2:27 for this profile; interpolation between the first two points in the current profile gives a current of 2.07 $\mathrm{cm} / \mathrm{s}$ for that time. This current was then used in evaluating diffusivities.

$$
u(t)=u\left(t_{1}\right)+\left(\frac{u\left(t_{2}\right)-u\left(t_{1}\right)}{t_{2}-t_{1}}\right)\left(t-t_{1}\right)=u\left(t_{1}\right)+(\text { slope })\left(t-t_{1}\right) \quad \text { Equation 4-12 }
$$

Values obtained for diffusivity were either transverse (horizontal) or vertical depending on the profile being analyzed. Transverse values were designated as $D_{x}$, while vertical values were designated as $D_{y}$. For this profile, $D_{x}$ was found to be $0.27 \mathrm{~cm}^{2} / \mathrm{s}$ using the Method of Moments and $0.24 \mathrm{~cm}^{2} / \mathrm{s}$ using the exponential fit technique.

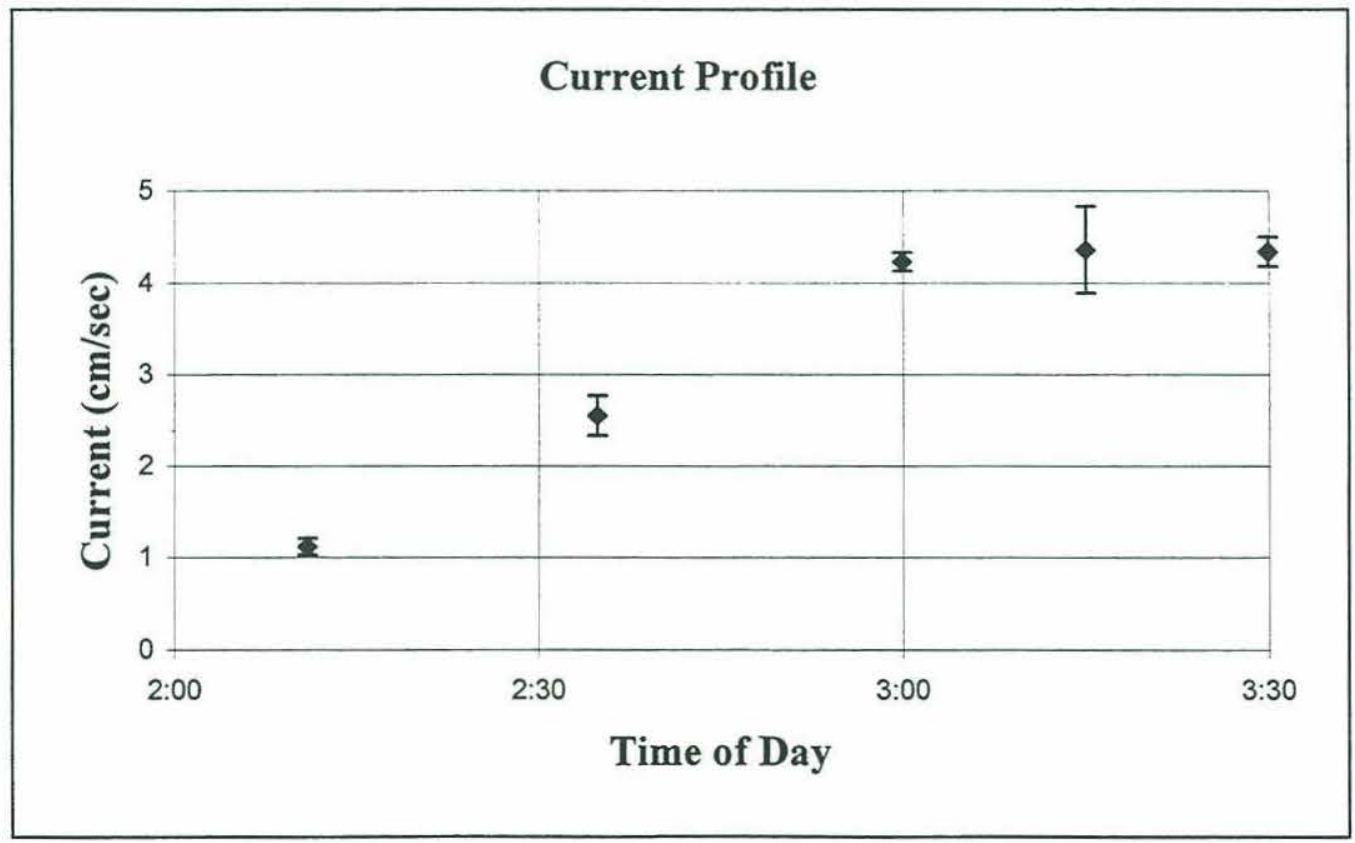

Figure 4-5: Representative Current Profile 


\subsection{Evaluation of Uncertainty}

Uncertainties associated with final and intermediate values were determined using the technique described by Taylor (1982). Equation 4-13 gives this relation for the propagation of uncertainty in a function of several variables, this method was used in evaluating uncertainties in currents, plume variance, and diffusivity as discussed below.

$$
\delta q=\sqrt{\left(\frac{\partial q}{\partial x} \delta x\right)^{2}+\cdots+\left(\frac{\partial q}{\partial z} \delta z\right)^{2}}
$$

Equation 4-13

\subsubsection{Uncertainty in Current}

As discussed earlier, currents at any given time were obtained by linearly interpolating between two measured values as shown by Equation 4-12. The uncertainty in this interpolated current is then related to the uncertainties in the two measured currents according to Equations 4-14 and 4-15. Since times were recorded to the nearest minute, the uncertainty in the time was set at 1 minute for this analysis.

$$
\begin{aligned}
& \delta_{\text {slope }}=\left(\frac{1}{t_{2}-t_{1}}\right) \sqrt{\delta_{u(t 2)}{ }^{2}+\delta_{u(t 1)}^{2}+\left(\frac{u\left(t_{2}\right)-u\left(t_{1}\right)}{t_{2}-t_{1}}\right)^{2}} \\
& \delta_{u(t)}=\sqrt{\delta_{u\left(t_{1}\right)}^{2}+\left(\left(t-t_{1}\right) \delta_{\text {slope }}\right)^{2}+\text { slope }^{2}}
\end{aligned}
$$

For the representative profile, uncertainty in the interpolated current $(2.07 \mathrm{~cm} / \mathrm{s}$ at $2: 27)$ was found to be $\pm 0.19 \mathrm{~cm} / \mathrm{s}$, based on interpolation between the $1.12 \pm 0.09 \mathrm{~cm} / \mathrm{s}$ value at $2: 11$ and the $2.55 \pm 0.22 \mathrm{~cm} / \mathrm{s}$ value at $2: 35$. 


\subsubsection{Uncertainty in Plume Variance}

\subsubsection{Method of Moments}

Since in this case variance is estimated by trapezoidal integration, the resulting uncertainty is due both to uncertainty in the individual data points as well as the errors introduced by approximating the smooth fluorescence profile as a series of trapezoids. This second effect is difficult to quantify reliably, since its effects are likely to vary from profile to profile. Additionally, the magnitude of this contribution is also likely much less than that from uncertainty in the data itself, so efforts focused on estimating the uncertainty due to the data.

To do this analysis, each data point was assigned three values - the mean fluorescence and the mean plus and minus the uncertainty in fluorescence. The trapezoidal integration was then done using every possible permutation of these values for all data points in the profile. The mean of the resulting variance values was then found, and the uncertainty in this mean was set at plus and minus twice the standard deviation of these variances. This technique results in a sort of worst case error estimate, but seems like a reasonable approach given the sparsity of the data and their varying uncertainties. This conservative approach should also help to account for any errors introduced by the trapezoidal integration scheme and not accounted for in the formal error analysis. For the representative profile, plume variance ranged from 31.80 to 33.82 with a mean of 32.80 and a standard deviation of 0.51 , so plume variance was set at $32.80 \pm 1.02 \mathrm{~cm}^{2} / \mathrm{s}$.

\subsubsection{Exponential Fit}

In this case, uncertainties in the data were accounted for in calculating the exponential constant $B$. The variance in $B$ is given by Equation 4-16 (Taylor, 1982), and the uncertainty in $B$ was set at two times the standard deviation (giving the $95 \%$ confidence level) found from this equation. This uncertainty in $B$ was converted to uncertainty in 
profile variance by applying Equation 4-13 to the relation between $B$ and $\sigma^{2}$ to obtain Equation 4-17. For the representative profile, $B$ was found to be $0.0170 \pm 0.0031 \mathrm{~cm}^{-2}$, resulting in a profile variance of $29.36 \pm 5.29 \mathrm{~cm}^{2}$ using this method.

$$
\begin{aligned}
& \sigma_{B}^{2}=\left(\frac{n \Sigma\left(\ln \left(F_{i}\right)-A-B x_{i}\right)^{2}}{(n-2)\left(n\left(\Sigma x_{i}^{2}\right)-\left(\Sigma x_{i}\right)^{2}\right)}\right) \\
& \delta_{\sigma^{2}}=\left(\frac{\delta_{B}}{2 B^{2}}\right)
\end{aligned}
$$

Equation 4-17

\subsubsection{Uncertainty in Diffusivity}

Equation 4-18 provides the uncertainty in the diffusivity based on the uncertainties calculated above, and was obtained by applying Equation 4-13 to Equation 4-11. Uncertainty in $l$ was set at $2 \mathrm{~cm}$ for all analyses, uncertainty in all other parameters was calculated for each profile individually. Horizontal diffusivity was found to be $0.27 \pm$ $0.03 \mathrm{~cm}^{2} / \mathrm{s}$ using the Method of Moments approach, and $0.24 \pm 0.05 \mathrm{~cm}^{2} / \mathrm{s}$ using the exponential fit technique for the representative profile.

$$
\delta D=\sqrt{\left(\frac{u \delta_{\sigma^{2}}}{2 l}\right)^{2}+\left(\frac{\sigma^{2} u \delta_{l}}{2 l^{2}}\right)^{2}+\left(\frac{\sigma^{2} \delta_{u}}{2 l}\right)^{2}}
$$

Analysis for all other profiles is similar to that presented for the representative profile. Results from these analyses are summarized in the next chapter. More detailed information; such as profile point coordinates, fluorescence, and currents; is found in Appendix A at the end of this thesis. 


\subsection{Reliability of Data}

The only remaining factor influencing the viability of the results obtained is the reliability of the data used to generate them. As mentioned earlier, the sampling routine for this experiment became a balance between gathering sufficient data at each individual point and gathering a sufficient number of these points during a given tidal excursion to give a representative profile. The tide comes in and out of Great Sippewissett Marsh very quickly, generally allowing only roughly 30 minutes of data collection on each tide. The technique that seemed to produce the best profiles given the time available entailed taking one minute of data at each point, creating a snapshot of the profile over a 3 - 6 minute period. This routine did by no means encompass the variability of the fluorescence readings at these individual points, however, and even these snapshots are subject to the variabilities in conditions over the time needed to produce them. By visual observation, it would be hard to say if the plume ever did really reach equilibrium, since rising and falling tides continually change the hydrodynamic conditions which govern the flow through the patch. So while this sampling routine may have been sufficient to resolve some of the smaller time scale diffusivity, longer time scale events will not be seen by this technique. As discussed earlier, this may have been the cause of the lower than expected diffusivities seen for the vegetation-free profiles. These longer-term meanderings and alterations of the ambient flow and larger scale turbulence events could contribute significantly to diffusion in the tidal marsh, however, so proper assessment of their contributions would be necessary to more accurately quantify predicted diffusivities. 


\section{Results and Discussion}

\subsection{General Observations}

In general, measured values for transverse and vertical diffusivities were essentially equal to each other and behaved similarly across all ranges of vegetation density and ambient flow. The magnitudes of these values were also on the order of those previously observed in natural settings and laboratory studies (Worcester, 1995, Nepf, et al, 1997). Furthermore, although in many cases there is significant uncertainty in the calculated diffusivities, the overall trend shows a roughly linear increase in diffusivity with ambient flow. This result is not unexpected, since turbulence intensity (and hence turbulent diffusivity) should increase as flow increases. Diffusivities were not found to be dependent on vegetation density, and diffusivities for vegetated conditions compared very well with those for non-vegetated conditions. More specifics on these observations and some thoughts on their causes are presented in what follows.

Table 5-1 and Table 5-2 provide the results of this study in tabular form. The column headings for these tables are as follows: $P$ is percent vegetation coverage, del $x$ refers to the uncertainty in $x, D-M O M$ is the diffusivity calculated by the Method of Moments, and $D-E F$ is the diffusivity calculated by the exponential fit method. Each run is also assigned a three character designator identifying it as either a horizontal or vertical profile, a sequential number, and specifying either low, medium, high, or zero vegetation density. For example, profile $\mathrm{H}-4 \mathrm{~L}$ is the fourth horizontal profile in low vegetation density. Several profiles gave anomalous or questionable diffusivity results, these are discussed further in the notes which follow Tables 5-1 and 5-2. 
Table 5-1: Transverse Diffusivity Results for Field Study

\begin{tabular}{|c|c|c|c|c|c|c|c|c|c|}
\hline Run \# & $\mathbf{P}$ & $\begin{array}{c}\text { Current } \\
(\mathbf{u})\end{array}$ & $\begin{array}{c}\text { del u } \\
(\mathrm{cm} / \mathrm{s})\end{array}$ & $\mathbf{R e - d}$ & $\begin{array}{c}\text { D-MOM } \\
\left(\mathrm{cm}^{\wedge} / \mathrm{s}\right)\end{array}$ & $\begin{array}{c}\text { del D } \\
\left(\mathrm{cm}^{\wedge} / \mathrm{s}\right)\end{array}$ & $\begin{array}{c}\text { D-EF } \\
\left(\mathrm{cm}^{\wedge} / \mathrm{s}\right)\end{array}$ & $\begin{array}{c}\text { del D } \\
\left(\mathrm{cm}^{\wedge} / \mathrm{s}\right)\end{array}$ & $\begin{array}{c}\text { Depth } \\
(\mathrm{cm})\end{array}$ \\
\hline \hline H-1L & 0.36 & 7.40 & 0.43 & 511 & 0.97 & 0.12 & 0.82 & 0.07 & 42 \\
\hline H-2L & 0.36 & 4.62 & 0.33 & 319 & 0.64 & 0.11 & 0.61 & 0.05 & 45 \\
\hline H-3L & 0.36 & 5.48 & 0.40 & 378 & 1.07 & 0.10 & 0.73 & 0.11 & 44 \\
\hline H-4L & 0.36 & 7.37 & 0.53 & 509 & 1.15 & 0.15 & 1.09 & 0.08 & 41 \\
\hline H-5L & 0.36 & 6.94 & 0.83 & 479 & 0.72 & 0.10 & 1.22 & 0.82 & 32 \\
\hline H-1M & 0.73 & 2.96 & 0.21 & 204 & 0.74 & 0.06 & 0.62 & 0.18 & 66 \\
\hline H-2M & 0.73 & 5.04 & 0.28 & 348 & 1.23 & 0.37 & 1.16 & 0.80 & 63 \\
\hline H-3M & 0.73 & 2.07 & 0.19 & 143 & 0.27 & 0.03 & 0.24 & 0.05 & 49 \\
\hline H-4M & 0.73 & 3.22 & 0.19 & 222 & 0.75 & 0.17 & 0.69 & 0.31 & 47 \\
\hline H-5M & 0.73 & 4.30 & 0.28 & 297 & 0.58 & 0.10 & 0.34 & 0.02 & 43 \\
\hline H-1H & 1.38 & 3.01 & 0.19 & 208 & $2.34 * *$ & 0.24 & $1.47 * *$ & 0.54 & 85 \\
\hline H-2H & 1.38 & 3.64 & 0.26 & 251 & 0.86 & 0.07 & 0.53 & 0.09 & 80 \\
\hline H-1Z & 0 & 8.72 & 0.96 & 602 & $2.41^{*}$ & 2.03 & 0.86 & 0.15 & 62 \\
\hline H-2Z & 0 & 9.93 & 0.45 & 685 & 1.80 & 0.43 & 1.98 & 0.31 & 59 \\
\hline H-3Z & 0 & 11.64 & 0.73 & 803 & 3.10 & 1.04 & 2.95 & 0.59 & 30 \\
\hline
\end{tabular}

Table 5-2: Vertical Diffusivity Results for Field Study

\begin{tabular}{|c|c|c|c|c|c|c|c|c|c|}
\hline Run \# & $\mathbf{P}$ & $\begin{array}{c}\text { Current } \\
(\mathbf{u})\end{array}$ & $\begin{array}{c}\text { del u } \\
(\mathrm{cm} / \mathrm{s})\end{array}$ & Re-d & $\begin{array}{c}\text { D-MOM } \\
\left(\mathrm{cm}^{\wedge} / \mathrm{s}\right)\end{array}$ & $\begin{array}{c}\text { del D } \\
\left(\mathrm{cm}^{\wedge} / \mathrm{s}\right)\end{array}$ & $\begin{array}{c}\text { D-EF } \\
\left(\mathrm{cm}^{\wedge} / \mathrm{s}\right)\end{array}$ & $\begin{array}{c}\text { del D } \\
\left(\mathrm{cm}^{\wedge} / \mathrm{s}\right)\end{array}$ & $\begin{array}{c}\text { Depth } \\
(\mathrm{cm})\end{array}$ \\
\hline \hline V-1L & 0.36 & 5.47 & 0.58 & 377 & 0.58 & 0.20 & 0.51 & 0.06 & 45 \\
\hline V-2L & 0.36 & 6.84 & 0.56 & 472 & 1.28 & 0.19 & 0.92 & 0.16 & 43 \\
\hline V-3L & 0.36 & 6.35 & 0.47 & 438 & 1.37 & 0.14 & 1.37 & 0.10 & 44 \\
\hline V-4L & 0.36 & 7.57 & 0.44 & 522 & 1.12 & 0.08 & 1.25 & 0.50 & 38 \\
\hline V-1M & 0.73 & 3.25 & 0.20 & 224 & 0.78 & 0.05 & 0.64 & 0.10 & 66 \\
\hline V-2M & 0.73 & 3.46 & 0.15 & 239 & 0.53 & 0.04 & 0.39 & 0.09 & 61 \\
\hline V-3M & 0.73 & 2.33 & 0.23 & 161 & 0.36 & 0.04 & 0.18 & 0.04 & 49 \\
\hline V-4M & 0.73 & 3.76 & 0.14 & 259 & 0.58 & 0.03 & 0.53 & 0.04 & 46 \\
\hline V-1H & 1.38 & 3.96 & 0.33 & 273 & 0.71 & 0.06 & 0.52 & 0.05 & 77 \\
\hline V-1Z & 0 & 9.52 & 0.89 & 657 & 0.69 & 0.07 & 0.70 & 0.10 & 33 \\
\hline V-2Z & 0 & 10.25 & 0.88 & 707 & 1.19 & 0.49 & 1.07 & 0.55 & 31 \\
\hline V-3Z & 0 & 13.10 & 0.65 & 904 & 1.84 & 0.15 & 1.96 & 0.24 & 29 \\
\hline
\end{tabular}

\section{Notes:}

* - Diffusivity calculated using the Method of Moments for profile $\mathrm{H}-1 \mathrm{Z}$ is anomalously high due to the coordinates of the profile points and the extrapolation technique used. This diffusivity value was not used in trend analysis, although it is plotted in figures.

** - Diffusivities calculated for profile $\mathrm{H}-1 \mathrm{H}$ are also thought to be anomalous based on comparison to other similar flow-vegetation combinations. These values were also not used in trend analysis, but again are plotted in applicable figures. 


\subsection{Vegetated versus Non-Vegetated Diffusivity}

One of the primary focuses of this research was examination of the effects of vegetation on diffusivity. Comparison of diffusivities observed for vegetated and non-vegetated profiles provides a direct means of examining this effect. This section describes the methods used to make this comparison and the conclusions reached.

\subsubsection{Non-Vegetated Diffusivity}

Turbulent diffusivities are known to depend on turbulence intensity and some characteristic turbulent length scale (Fischer, et al, 1979). Flow in non-vegetated open channels has been widely studied, and several empirical relationships relating diffusivity to channel flow and geometry have been developed. Fischer, et al $(1979$, p. 112) give Equation 5-1 as a means of estimating transverse diffusivities in meandering, irregularsided channels. This empirical relation was developed using data from seven separate studies and has a stated accuracy of $\pm 50 \%$. The constant of proportionality in Equation 5-1 is reduced to 0.15 for smooth, rectangular channels and by an order of magnitude (to 0.06) for vertical diffusivities in natural channels (Fischer, et al, 1979).

$$
\varepsilon_{t}=0.6 h u *
$$

Equation 5-1

( $h$ is the mean depth of the channel and $u^{*}$ is the shear velocity at the bed.)

Elder (1959) derived a similar expression for vertical diffusivities in turbulent shear flow over a wide, inclined plane. Equation 5-2 gives this expression. This relation has been widely proven and accepted, and matches well with the expected order of magnitude reduction from the Equation 5-1 expectation as discussed above.

$$
\varepsilon_{v}=0.067 h u *
$$

Equation 5-2

Comparison of measured diffusivities with these empirically expected results was the first analysis undertaken. Shear velocity was not measured during the experiment and so had 
to be estimated. For the seven studies used to develop Equation 5-1 the mean shear velocity was $7 \%$ of mean flow (Fischer, et al, 1979), so this was used as a reasonable estimate of shear flow for the non-vegetated profiles. Using this estimated shear flow and Equations 5-1 and 5-2, the slopes of diffusivity plotted versus $u \cdot h$ were expected to be $0.04 \pm 0.02$ for transverse diffusivity and 0.005 for vertical diffusivity.

Plotting $D$ vs. $u \cdot h$ for unvegetated profiles and then applying a linear least squares fit (with forcing through $(0,0)$ ) resulted in slopes of 0.004 for both transverse and vertical diffusivity. This is within $20 \%$ of the expected value for vertical diffusivity, but is an order of magnitude less than that expected for transverse diffusivity. This discrepancy is believed to be due to the scales involved in the current study. Because the short temporal and spatial scales used were too small to resolve the longer-term variations in currents and turbulence structure which would tend to increase diffusivity, measured transverse diffusivities may have been too small. Transverse and vertical scales were essentially the same in this study, since mean depth was on the order of 0.5 meters and the transverse plume dimensions were roughly the same size. This is a marked difference from the roughly 100:1 width to depth ratio for the studies used to develop Equation 5-1 (Fischer, et al, 1979), and this may account for the lower than expected transverse diffusivities. This argument is further strengthened by reference to another relation from Fischer (1979, p.77) showing how observed diffusivities change with scale. Diffusivities (in $\mathrm{cm}^{2} / \mathrm{s}$ ) are shown to be related to dye cloud size (in $\mathrm{cm}$ ) raised to the $4 / 3$ power by a constant of proportionality between 0.002 and 0.01 (Fischer, et al, 1979). Applying this relation to a 0.5 meter dye cloud provides estimated diffusivities from 0.4 to $1.9 \mathrm{~cm}^{2} / \mathrm{s}$. Again this matches well with measured vertical diffusivities, although measured transverse diffusivities (ranging between 1 and $3 \mathrm{~cm}^{2} / \mathrm{s}$ ) are now slightly higher than these new expected values. These differences are minor and can easily be accounted for by small variations in dye cloud size, however. Measured transverse diffusivities therefore seem to be reasonable based on expected results for the small scales employed. 


\subsubsection{Vegetated Diffusivity}

The technique of relating $D$ to $u \cdot h$ was also applied to vegetated profiles to examine the influence of vegetation on diffusivity. With the addition of vegetation, both the length scale and turbulence intensity which control diffusion are expected to change from the non-vegetated case. The length scale can be expected to change from the channel depth to somewhere on the order of mean stem diameter or mean stem spacing for the vegetation (Ackerman and Okubo, 1993, Anderson and Charters, 1982, Nepf, et al, 1997). If nothing else changes, diffusivities in vegetation would then be expected to be reduced relative to non-vegetated diffusivities based on this change in length scale. There are other changes, however, most notably in the turbulence intensity. In the non-vegetated case, bed-generated turbulence dominates and shear velocity at the bed governs turbulence intensity. In the vegetated case this bed-generated turbulence is supplemented by stem-generated turbulence, however, so it is no longer valid to use shear velocity as a measure of turbulence intensity or as a scaling factor. Both bed-and stem-generated turbulence can be expected to scale on the mean flow, however, so mean flow can be used instead. Turbulence intensity is then given by some constant times the mean flow, and diffusivity is given by another constant of proportionality multiplied by this turbulence intensity and the turbulent length scale. The end result is Equations 5-3 and 5-4, where the two constants of proportionality have been combined into a single $A$ and $A^{\prime}$ depending on whether mean depth $(h)$ or mean stem diameter $(d)$ is used as the representative turbulent length scale. As noted above, previous studies have shown $d$ to be the correct length scale within vegetation, so Equation 5-4 is expected to be more correct.

$$
\begin{aligned}
& D=A \cdot u \cdot h \\
& D=A^{\prime} \cdot u \cdot d
\end{aligned}
$$

Equation 5-3

Equation 5-4

For more direct comparison to the non-vegetated case, Equation 5-3 was first used to analyze data from the vegetated profiles. $D$ was plotted against $u \cdot h$ for all vegetation 
densities separately and in combination, with a linear least squares technique (with forcing through $(0,0))$ used to find the best fit value for $A$ in each case. Data is plotted in Figure 5-1 and Figure 5-2, with results tabulated in Table 5-3.

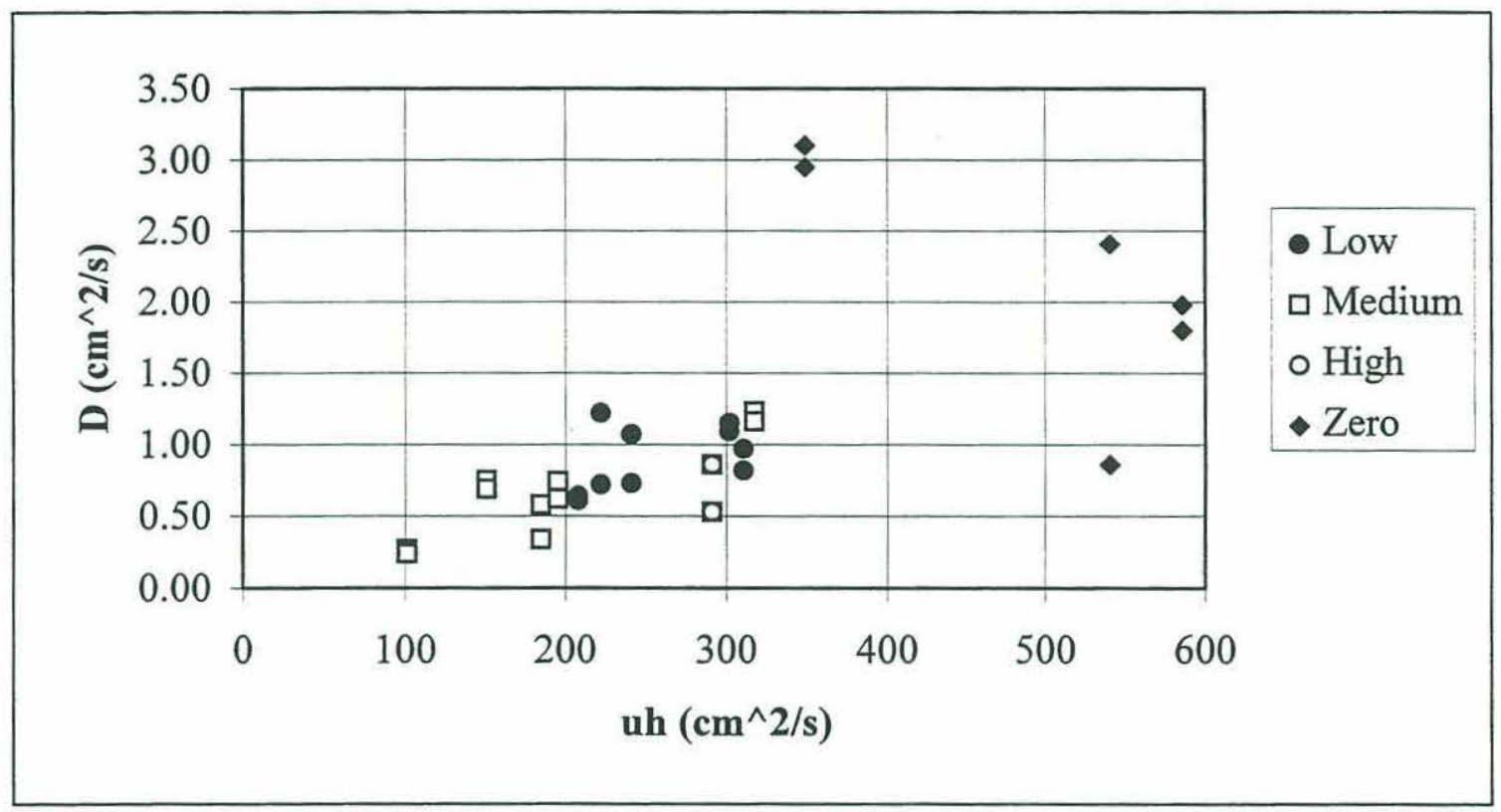

Figure 5-1: D vs. $u \cdot h$ for Transverse Profiles

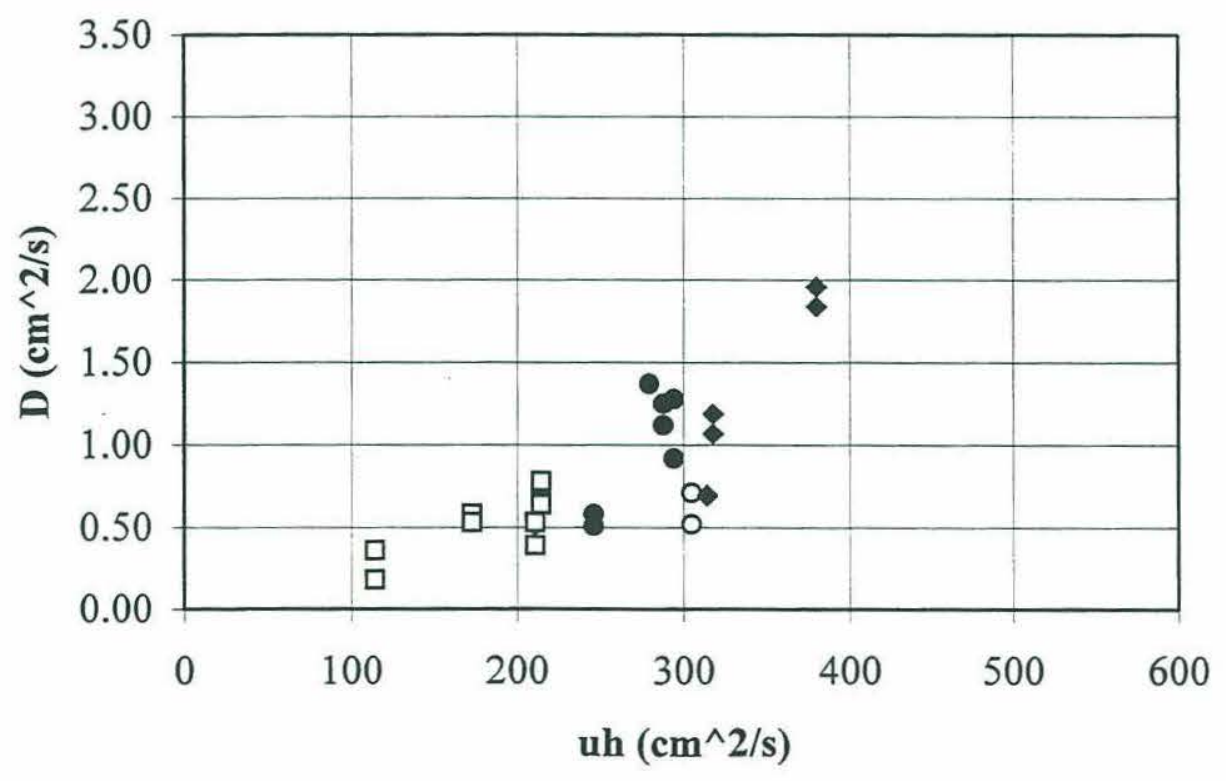

Figure 5-2: D vs. $u \cdot h$ for Vertical Profiles 
Table 5-3: Best Fit Slopes for D vs. u'h Plots

\begin{tabular}{|c|c|c|}
\hline Profiles Used & Transverse Slope & Vertical Slope \\
\hline \hline Unvegetated & 0.0040 & 0.0038 \\
\hline Low Density & 0.0035 & 0.0038 \\
\hline Medium Density & 0.0036 & 0.0028 \\
\hline High Density & 0.0046 & 0.0020 \\
\hline All Vegetated & 0.0035 & 0.0033 \\
\hline
\end{tabular}

This analysis shows that vegetated and non-vegetated diffusivities are very comparable. In general, the computed slopes are smaller for vegetated runs than for non-vegetated runs, meaning that diffusivity in the vegetated areas would be less than for an open channel. This decrease for vegetated conditions is quite small, however, and one slope actually increased while another remained unchanged. Therefore, based on the small differences measured and the uncertainty in the data gathered, it is difficult to say whether any significant difference exists between vegetated and unvegetated diffusivities based on this analysis. This result is based on using water depth as a scaling factor. Similar analysis techniques using different characteristic length scales were used next to further examine any change in diffusivities due to vegetation.

The preceding analysis scaled vegetated diffusivity with mean water depth for ease of comparison with the unvegetated cases, but as noted earlier vegetated diffusivity would be more aptly scaled by mean stem diameter or mean spacing between the stems. Nepf, et al (1997), using vertical wooden dowels to simulate vegetation stems, found that the characteristic length scales for turbulence within the dowels (stems) was on the order of the stem diameter. Mean stem diameter will be examined first as a scaling factor in this study, with analysis using mean stem spacing to follow. Since $d$ in Equation 5-4 is now a constant, analysis based on stem diameter reduces to evaluating diffusivity versus mean flow. Mean flow was converted to a Reynolds number based on mean stem diameter and least squares analyses were conducted as before. The resulting data is plotted in Figure 53 and Figure 5-4 and tabulated in Table 5-4. Uncertainty values given represent the 95\% confidence level, and non-vegetated data is plotted for comparative purposes. 


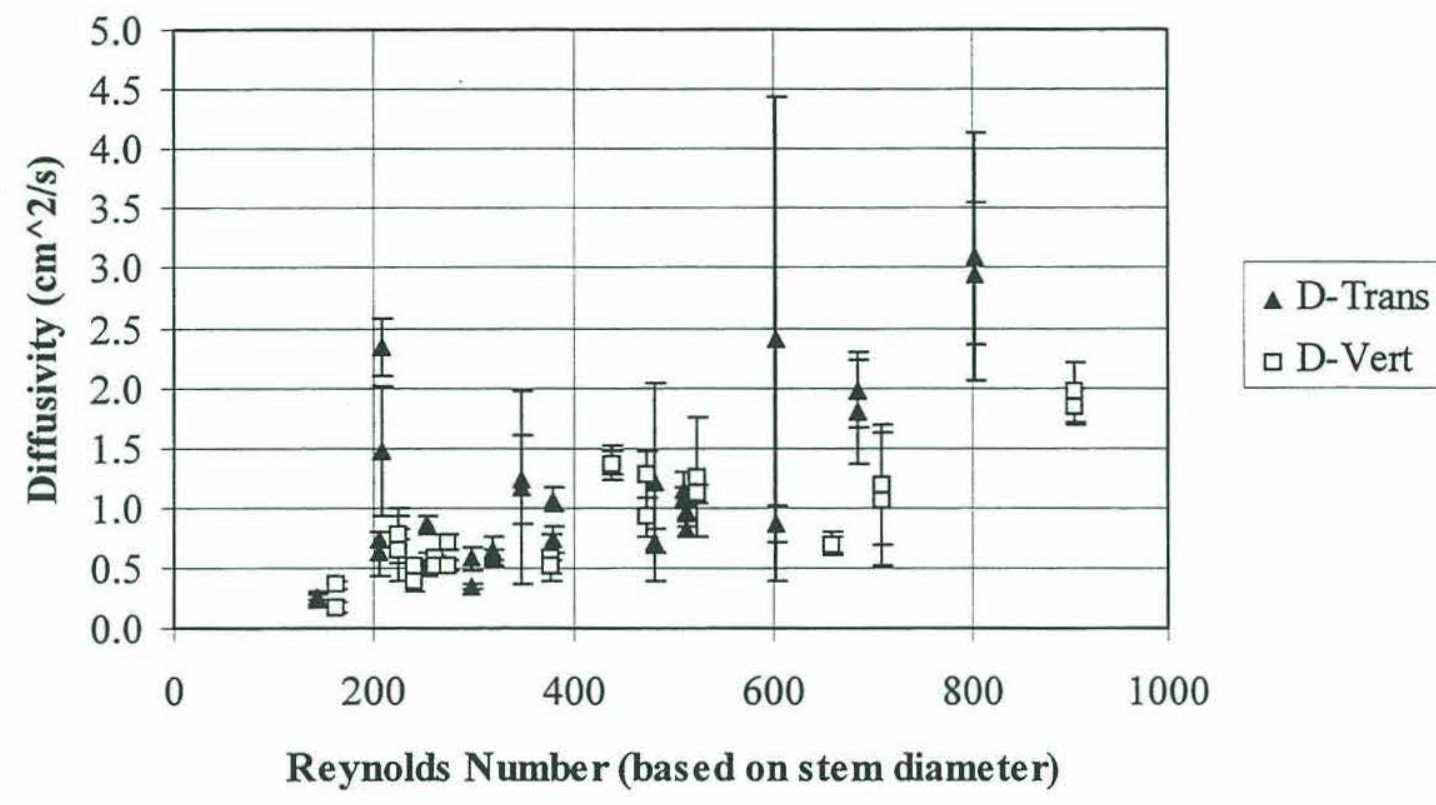

Figure 5-3: Transverse and Vertical Diffusivities vs. Reynolds Number

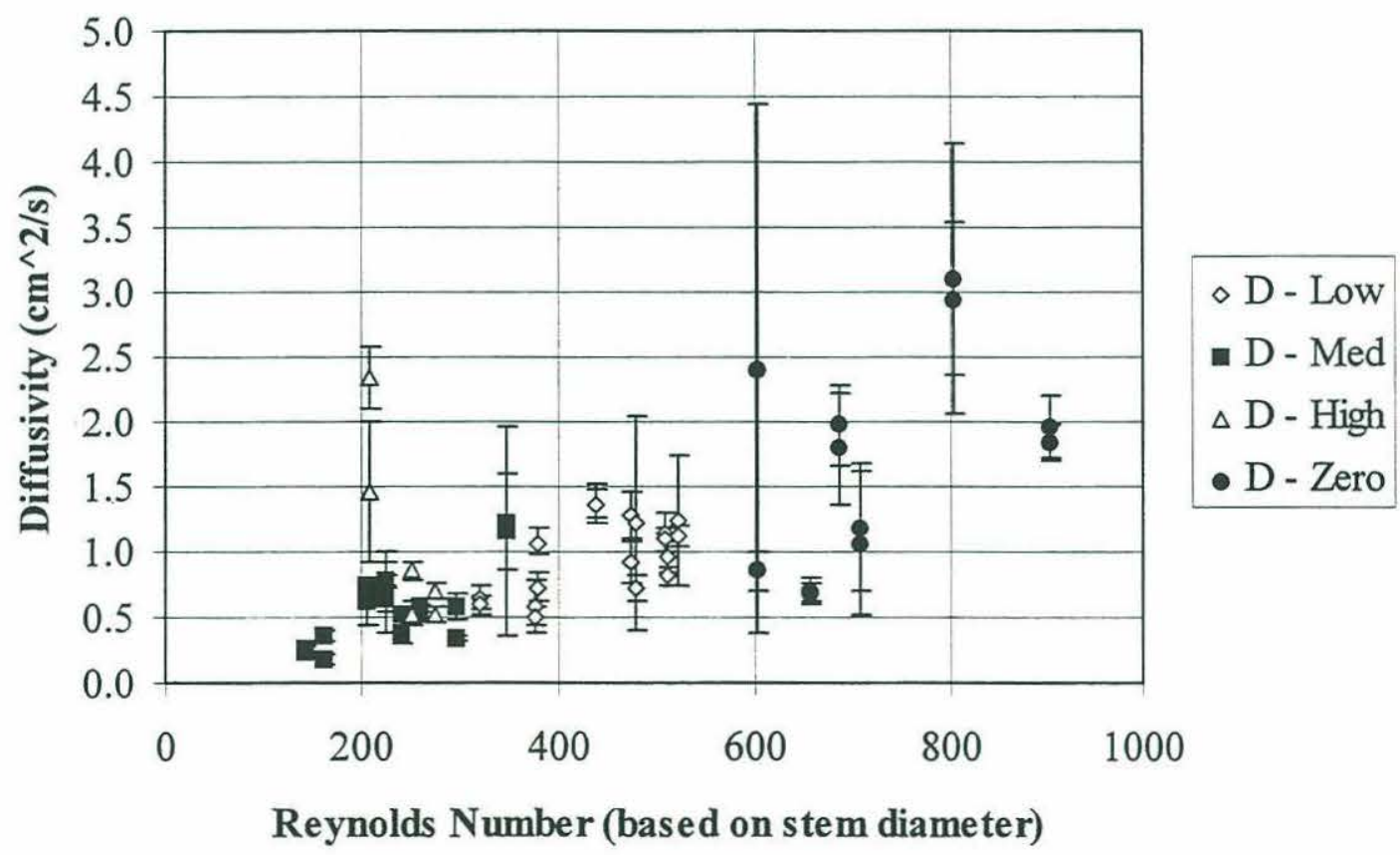

Figure 5-4: Diffusivities vs. Reynolds Number by Vegetation Density 
Table 5-4: Best Fit Slopes for D vs. Re Plots

\begin{tabular}{|l|c|c|c|c|}
\cline { 2 - 5 } \multicolumn{1}{c|}{} & \multicolumn{2}{c|}{ Transverse } & \multicolumn{2}{c|}{ Vertical } \\
\hline Data Points Used & Slope of D vs. Re & Uncertainty & Slope of D vs. Re & Uncertainty \\
\hline All vegetated data & 0.0023 & 0.0005 & 0.0023 & 0.0003 \\
\hline Low density points & 0.0020 & 0.0003 & 0.0024 & 0.0004 \\
\hline Medium density points & 0.0028 & 0.0006 & 0.0023 & 0.0005 \\
\hline High density points & 0.0028 & 0.0013 & 0.0023 & 0.0007 \\
\hline
\end{tabular}

As can be seen, best fit slopes for both transverse and vertical diffusivity were essentially equal to each other over all vegetation densities. Transverse diffusivities at medium and high vegetation densities seem to be slightly higher than other values, but their uncertainty is also higher. From this data, it appears that the vegetation density has little effect on measured diffusivities.

The mean stem spacing was also examined as a turbulence length scale. Stem spacing should be inversely proportional to vegetation density, so diffusivity was plotted versus $u / P$ to examine dependence. Figure 5-5 provides the results. Slopes of the best fit $D$ vs. $u / P$ lines shown are $0.05,0.13$, and 0.24 for low, medium, and high stem densities. These differences may be significant, but the data are perhaps more indicative of the relation between stem density and current velocity. Points for each stem density are clearly clustered in specific $u / P$ ranges, showing that stem density controls flow.

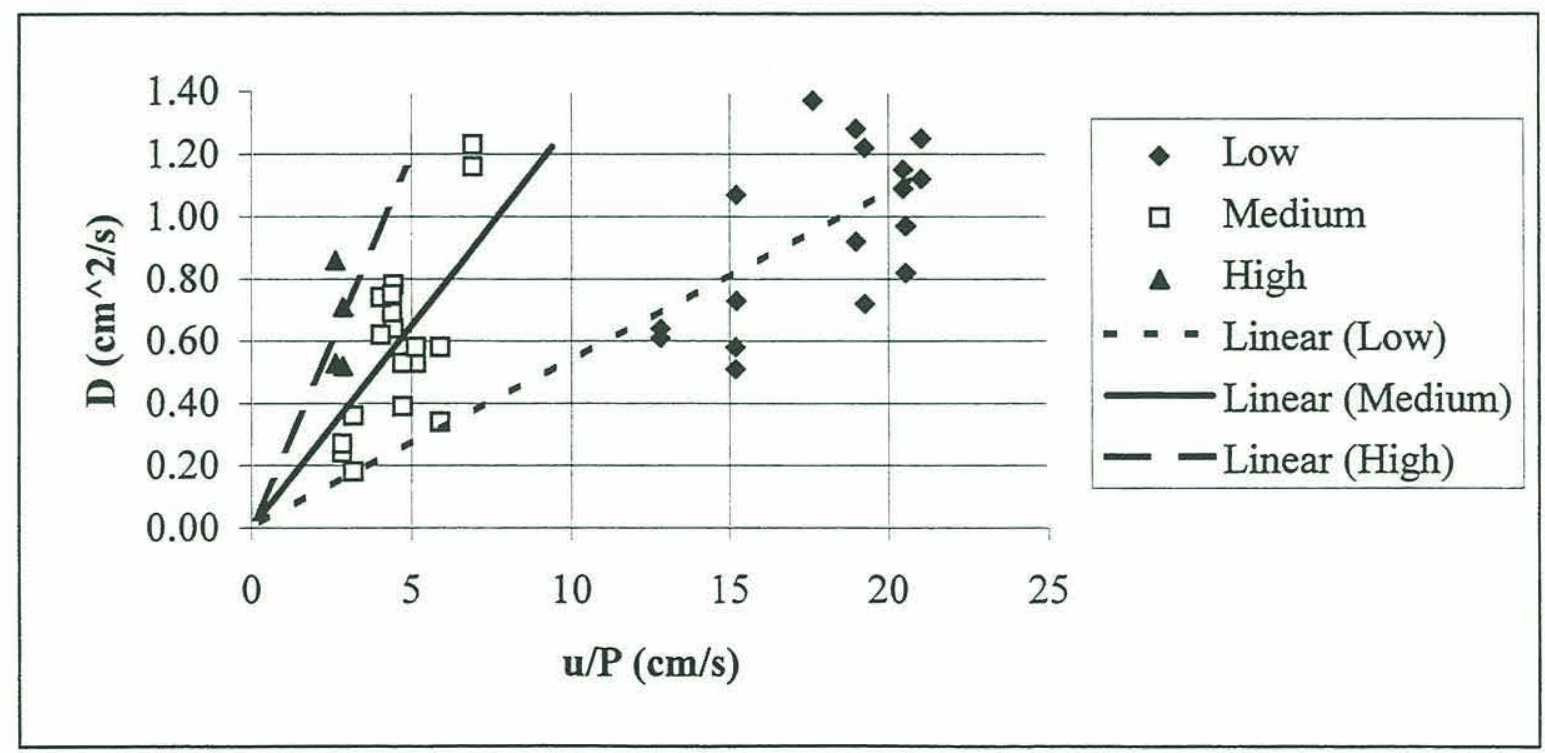

Figure 5-5: Diffusivity vs. u/P for Vegetated Profiles 


\subsection{Transverse versus Vertical Diffusivity}

Figure 5-3, Figure 5-4, and Table 5-4 also show the close agreement between transverse and vertical diffusivities. They both appear to be directly related to ambient flow, and their values at similar flows seem to be comparable across all vegetation densities. As can be seen, there is very little difference in measured transverse and vertical diffusivities, particularly at low Reynolds numbers. Up to a $R e$ of roughly 500 the values fall right on top of one another, although at higher flows some divergence between the two values may be evident. Data in this region is much more sparse and uncertain, however, so this trend may or may not be significant. The slopes computed using data for all vegetated profiles were the same for transverse and vertical diffusivity, and slopes computed for individual vegetation densities all agreed within the $95 \%$ confidence levels given.

This close agreement between the transverse and vertical diffusivities was not necessarily expected, but is also not necessarily too surprising either. A compilation of turbulent diffusion studies made in natural channels (Fischer, et al, 1979) shows that, in general, vertical diffusivities are roughly an order of magnitude less than transverse diffusivities. This difference is due to the different length scales of turbulence in the transverse and vertical directions - in natural channels (with no plants) there is a wide difference in these two length scales. Laboratory studies (Nepf, et al, 1997) using vertical wooden dowels to simulate plants have shown a marked reduction in this length scale difference, and hence in diffusivity. The dowels (plant stems) act to break up the turbulent eddies oriented in the transverse direction, with the characteristic length scale being reduced to on the order of the spacing between the dowels (Nepf, et al, 1997). Transverse and vertical diffusivities differ by roughly a factor of four in these laboratory studies, a significant reduction from the factor of ten found in natural, plant-free, systems (Fischer, et al, 1979).

In this study, the plant stems should act much like the dowels to reduce the transverse turbulent length scale. Unlike the dowels, however, in the natural setting the stems (and leaves) grow in many directions centered around the vertical. This spreading of the stem matrix should produce wakes with a wide variety of orientations, therefore reducing the 
2-D bias of the flume experiment and leading to reduced anisotropy in the transverse and vertical directions. Additionally, the natural stems are quite flexible and move under the influence of the wind and the current. This should enhance the stirring effect and lead to more similar transverse and vertical turbulence scales. These reasons, coupled with the scale discussion presented earlier, makes the close agreement between the transverse and vertical diffusivity values seems reasonable.

\subsection{Vegetation Density Effects}

As seen from Figure 5-4 and Table 4-3, there is very little difference in the diffusivities observed at different vegetation densities. One must be careful in making the statement that diffusivity is not dependent on vegetation density from this data, however, since there are very few cases where different vegetation densities are sampled at similar or overlapping Reynolds numbers.

These results differ somewhat from those obtained in the laboratory study discussed earlier (Nepf, et al, 1997). Figure 5-6 presents data from this laboratory study, and shows quite clearly that increasing the dowel (stem) density increases diffusivity for a given Reynolds number in that experiment. Diffusivity appears to increase linearly with Reynolds number from these results, similar to the conclusions reached in the current study. The increase in diffusivity for a given increase in dowel density is also seen to fall as the dowel density increases due to shading effects. Again, this increase in diffusivity with increasing stem density was not seen in the field study. (For reference, High vegetation density in this field study was $1.4 \%$, Medium was $0.7 \%$, and Low was $0.35 \%$ ). 


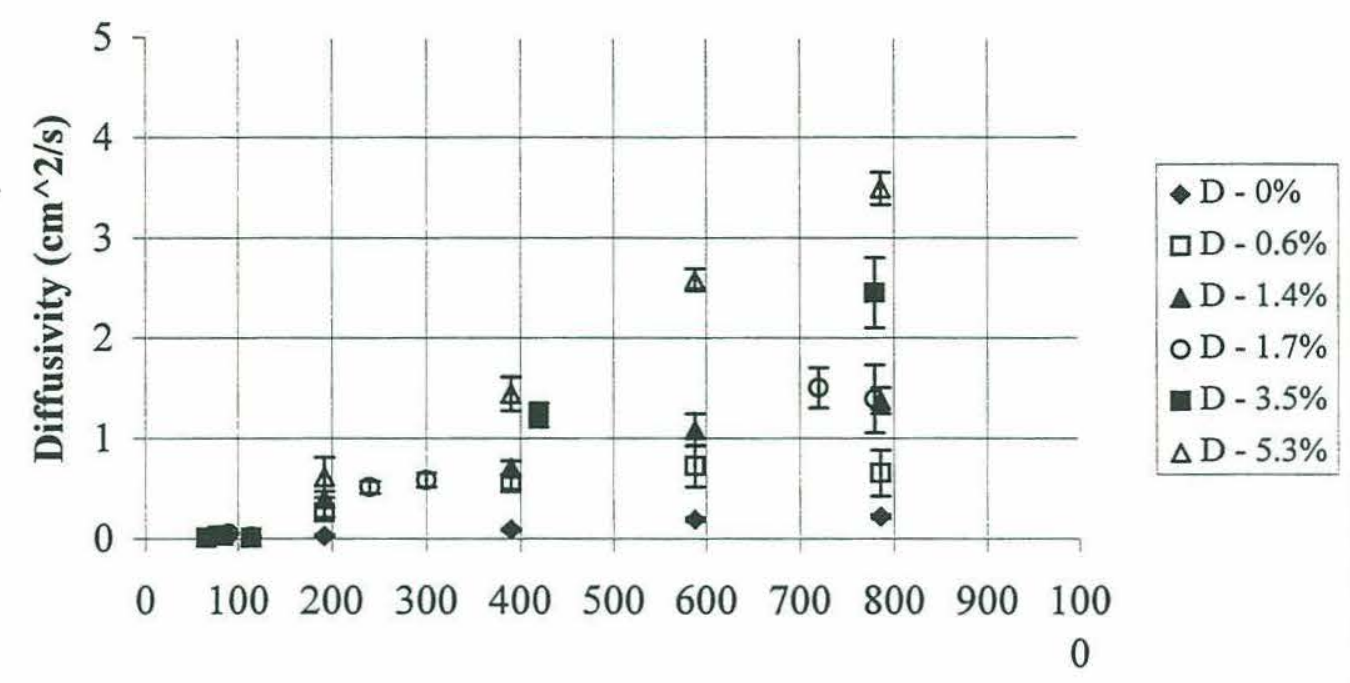

Reynolds Number

Figure 5-6: Transverse Diffusivity versus Reynolds Number - Laboratory Study (data from Nepf, et al, 1997)

There are several explanations as to why results from this study do not show the dependence of diffusivity on vegetation density evident in the laboratory study. The laboratory study was able to measure diffusivity for different stem densities at similar Reynolds numbers, but in the field this was not done to any great extent. The added flow restriction imposed by the additional vegetation was sufficient to re-route flow around the vegetation patch, so any diffusivity-enhancing effect of the increased stem density tended to be counterbalanced by the concurrent flow reduction within the patch. These two effects essentially cancel each other out, and little diffusivity dependence on stem density is noted. Vegetation density seems to control flow, and this flow then determines diffusivity.

Alternately, it could be possible that the flexibility and the more random orientation of the natural stems (relative to the dowels) magnifies the shading effect seen in the laboratory data at increasing dowel density. Since only a few stems (and leaves) would then be necessary to effectively cover the full cross section for flow, it may be that there indeed is 
not much diffusivity enhancement as vegetation density is increased. If this were true, the presence of only a few plants would increase the diffusivity significantly, but addition of more plants would have little effect.

Another possible explanation for the seeming independence on vegetation density is that, at least for this site, other factors dominate. The site was chosen so as to minimize turbulence induced by means other than the vegetation, but assessment of these other turbulence sources may have underestimated their contribution. Although the region around the vegetation patch did have a fairly smooth bed, some roughness and unevenness was still present, so bed-generated turbulence may have been more important than originally thought. In addition, the patch lay roughly 25-30 meters downstream of a major channel bend on both incoming and outgoing tides. Turbulent mixing coefficients have been measured at 2-25 times their normal value downstream of bends in natural channels (Fischer, et al, 1979), so perhaps significant residual turbulence from these bends still existed at the sampling point. Contributing to the effects of both these concerns, only roughly 1.5 meters of vegetation existed as a zone of transition between the free stream and the dye injection point. This distance was the maximum available at this particular vegetation patch, but was perhaps not sufficient to fully smooth the flow before beginning the experiment. These three effects; turbulence contributed by the bed, the natural turbulence enhancement due to the bends in the channel, and insufficient smoothing of the flow within the patch; when taken together may have overwhelmed the contribution of the differing plant densities, making it seem that diffusivity is independent of vegetation density.

To examine the dependence of diffusivity on vegetation density a little more closely, the non-dimensional parameter $\mathrm{D} / \mathrm{u} \cdot \mathrm{d}$ was plotted versus percent stem coverage. Figures 5-7 and 5-8 show these relationships, with the open symbols being the individual data points and the solid symbols being the mean value at each vegetation density. Although they may not be significant due to the uncertainties involved, the results from this examination seem to support the conclusions reached earlier. D/u $d$ is essentially constant across all vegetation densities for transverse diffusivity, although there may be a slight reduction in 
the vegetated versus the unvegetated cases. For vertical diffusivity, there is somewhat of an increase in $\mathrm{D} / \mathrm{u} \cdot \mathrm{d}$ when going from unvegetated to low density, but then the value remains constant as vegetation density is increased. These results support the enhancement of vertical diffusivity by addition of a few stems, followed by little change as more stems are added, and the slight reduction in horizontal diffusivity found in the previous analysis. Values of $\mathrm{D} / \mathrm{u} \cdot \mathrm{d}$ between transverse and vertical diffusivities also were quite comparable to one another, again confirming earlier results.

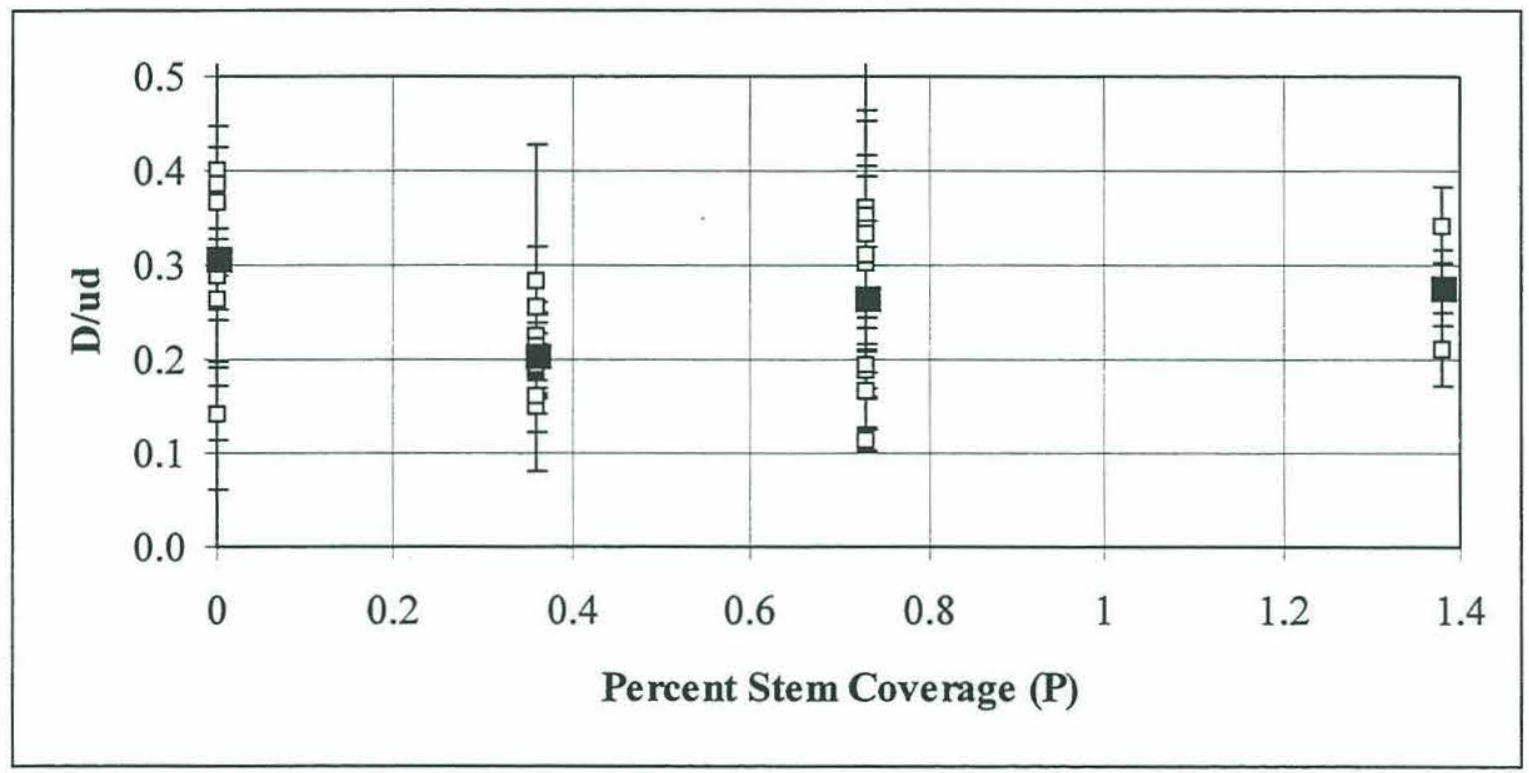

Figure 5-7: D/ud vs. Percent Stem Coverage - Transverse Diffusivity

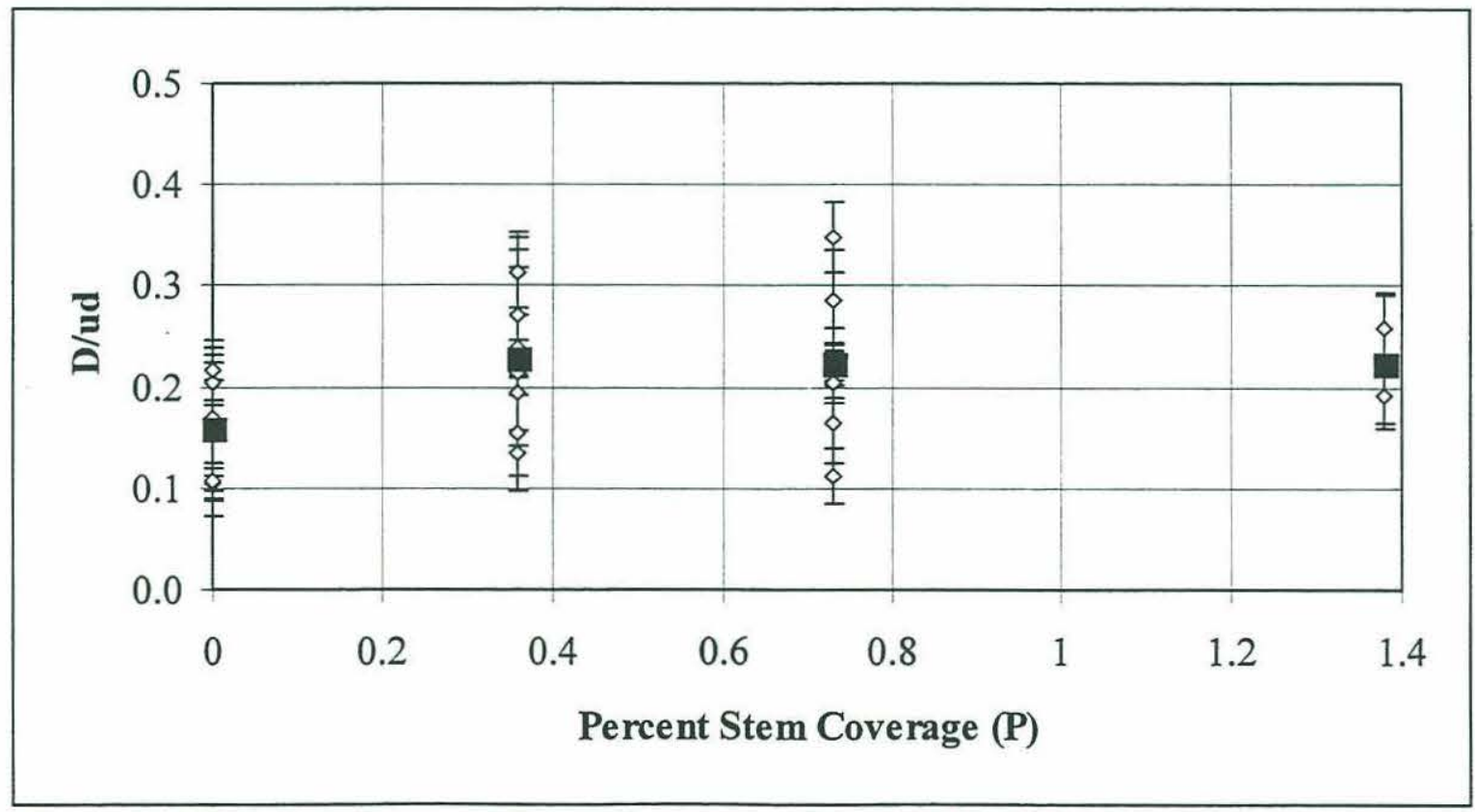

Figure 5-8: D/ud vs. Percent Stem Coverage - Vertical Diffusivity 
As a further examination of the influence of vegetation density on diffusivity, $D$ was also plotted as a function of $P \cdot \operatorname{Re}$ for vegetated profiles. These relationships for horizontal and vertical diffusivity are shown in Figures 5-9 and 5-10, respectively, with the solid line being a least squares fit to the data. Although there is again much uncertainty, it appears that diffusivity values for $P \cdot R e$ greater than about 200 begin to fall off from the best fit line. It appears the initial slope is roughly 0.005 for both cases, but that slopes obtained using only the higher $P \cdot \operatorname{Re}$ points would be much lower. This observation is likely due to the shading effects discussed earlier, and could come about as either vegetation density or flow is increased sufficiently. Increasing the stem density obviously increases the chances of shading as there are more stems to interact with. Increasing the flow causes an increase in turbulence and vortex shedding, and the enlarged vortices have a higher chance of interacting with other stems. $P \cdot R e=200$ appears to be the breaking point for reduction of diffusivity, although further study would be necessary to say this with any certainty. 


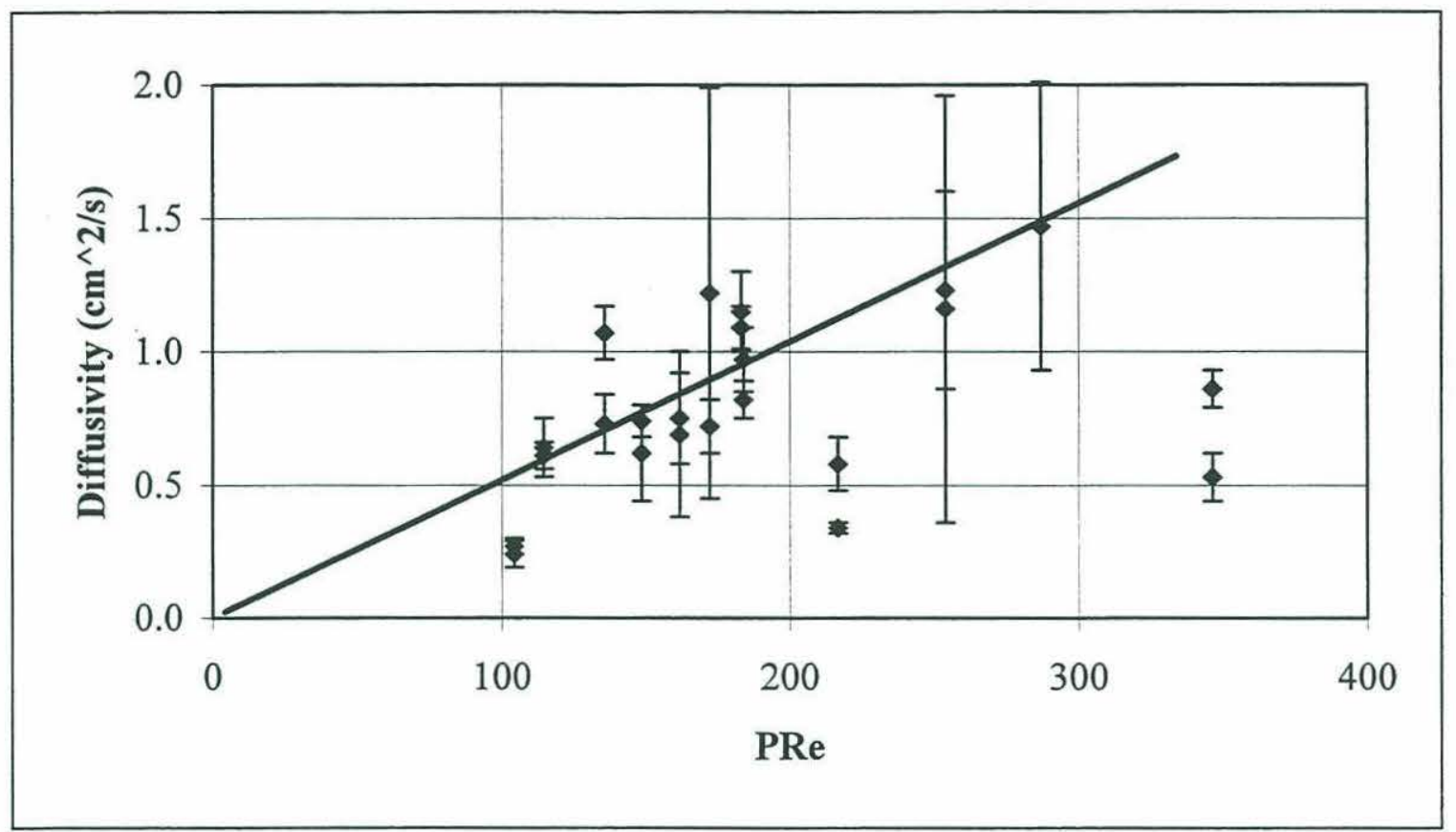

Figure 5-9: D vs. P·Re for Transverse Profiles

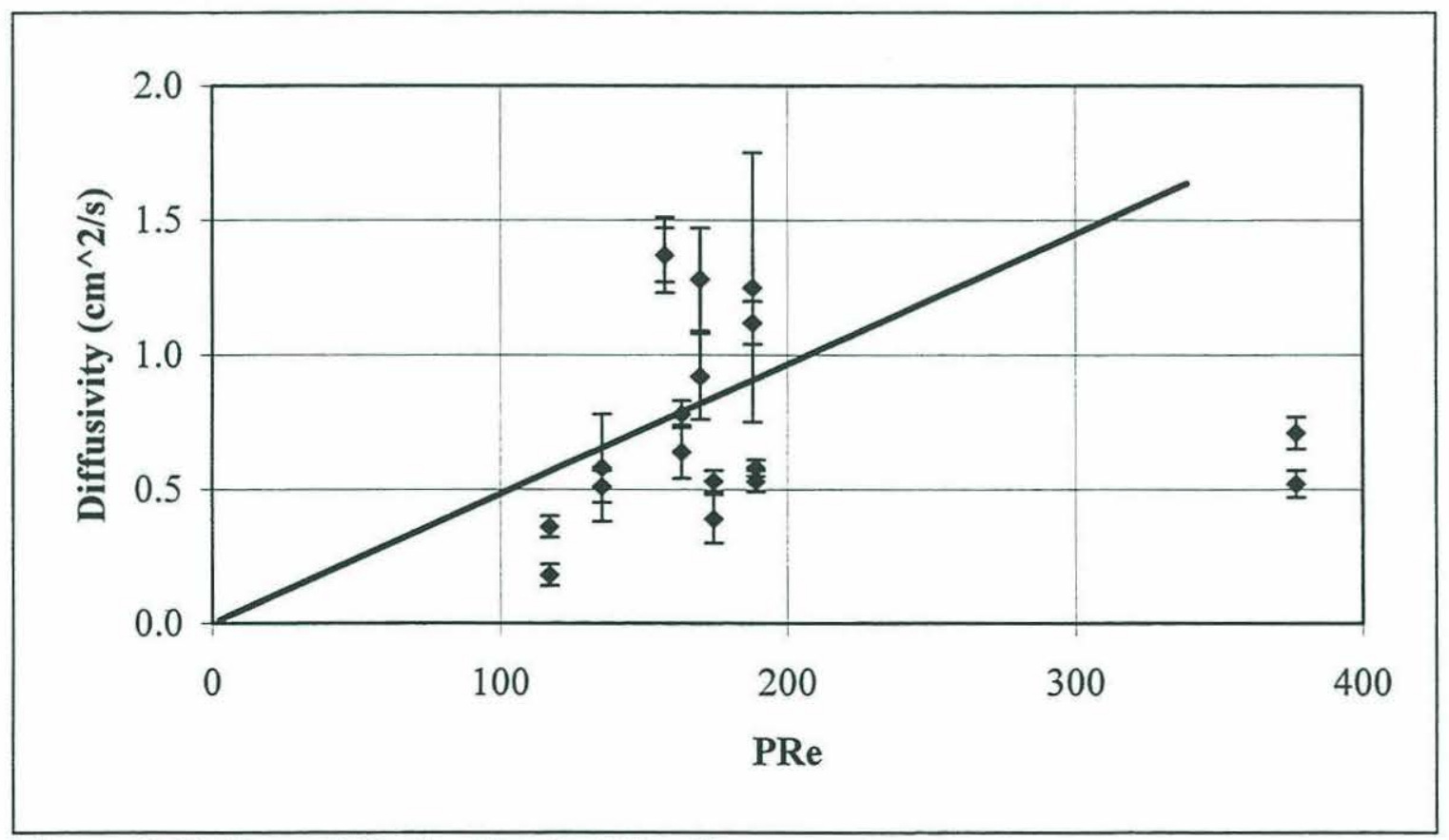

Figure 5-10: D vs. P·Re for Vertical Profiles 


\subsection{Other Comparisons}

Diffusivity values obtained for vegetated profiles do compare well with other field and laboratory experiments done in vegetation. A mixing study done at low flow in eelgrass beds found a mixing coefficient of roughly $0.5 \pm 0.4 \mathrm{~cm}^{2} / \mathrm{sec}$ at current velocities within the bed of $2 \mathrm{~cm} / \mathrm{sec}$ (Worcester, 1995). This flow is equivalent to a Reynolds number of 170 based on mean stem diameter, and the diffusivity value above matches well with those presented in Figure 5-3. The dye patch scales used in that study were $0.1 \mathrm{~m}$ to several meters and little difference was noted between vegetated and non-vegetated diffusivities (Worcester, 1995), again matching well with this experiment. Measured values from the current field experiment also match well with the laboratory values obtained by Nepf, et al, in their dowel-flume experiment (see Figure 5-6). Although the uncertainty in the data from this field experiment is much greater, the magnitudes of the individual points agree fairly well, at least for the vegetated profiles. The diffusivity found in this experiment for the unvegetated profiles is much greater than that found in the lab, but there are important differences in the two studies as well. The flume was a limited size in width and height, therefore the eddy-scale is much smaller than in the field. Also, the bed in the field is much less smooth than in the laboratory, so additional contributions from bed-generated turbulence can be expected.

\subsection{Summary and Recommendations}

In summary, the results obtained for diffusivity appear to be reasonable based on intuition and previously released results. The goal of this study was to examine the effects of vegetation density on diffusion, but the results showed little such dependence.

Diffusivities were found to be much more dependent on flow than on vegetation density. Increased vegetation density does cause a reduction in flow, thereby reducing diffusivity as a secondary effect. Diffusivity within vegetated regions is therefore expected to be reduced relative to non-vegetated regions. Transverse and vertical diffusivities were also found to be isotropic across all ranges of vegetation density, a departure from earlier published results. This isotropy is accomplished even at low stem densities and is 
believed to be due to the nearly random orientation of the stems. Laboratory studies and models, such as those by Nepf, et al, (1997), need to be revised to account for this result. Additionally, techniques used in this study were partially ineffective in that sampling times were too small to resolve longer time scale variations in diffusion. To address these issues, suggestions for improvements in further studies include:

- Future studies should be done at a site which provides a longer time period for sampling. This could be done by finding a tidal marsh where the water level does not rise and fall as quickly as it did at this location, or perhaps even by locating an alternate spot in Great Sippewissett Marsh closer to the inlet channel. These options are likely to offer only limited improvement, however, so a better option may be to conduct a study in a vegetated creek or river channel. This would provide consistent study conditions over the period necessary to resolve longerterm variability.

- Alternately, a different sampling technique could be used to effectively gather more data at each point over the same available time period. This would entail sampling from several locations concurrently, significantly increasing the time, effort, and equipment required for sampling. One possible approach is to simultaneously collect water samples from a number of points using a number of small pumps, and then analyzing these water samples for fluorescence either in the lab or in the field in discrete sample mode. This technique would provide a longer-term average fluorescence value, but all time dependence would be lost. Another possibility is to use several fluorometers simultaneously, but again this significantly expands the effort and expenditure required. Fluorescence readings in the field would also be much more preferable, since transporting large water samples would be quite difficult.

- Additionally, some provision needs to be made for ensuring comparable flows through the study site at different vegetation densities. In this study, even relatively sparse vegetation coverage was sufficient to reroute flow around the vegetation patch, so that increased diffusivity due to increased stem density was 
masked by the concurrent flow reduction. This made it difficult to assess the effect of the vegetation coverage, since very few points at similar flows but differing vegetation densities were gathered. To adequately measure the true effects of vegetation density on diffusivity, a site where the water is constrained to flow through the vegetated area would be much better. Again, a vegetated creek or river channel would work well, particularly one vegetated from bank to bank.

- Finally, more and better instrumentation and recording is probably warranted in future studies. Currents obtained in this study were adequate for the calculations which were done, but were quite crudely obtained. Use of a continuously operating, low-flow current measurement device, such as a BASS (Benthic Acoustic Stress Sensor) instrument, would allow better resolution of current variability and magnitude over the course of a profile. This would enable better and more detailed analysis of the results, and may help in correlation between current variability and fluorescence fluctuations. Provisions should also be made for more carefully recording water depth during the course of the experiment, perhaps by the use of a floating tidal height gauge. Finally, more careful measurement of the vertical coordinates involved (such as dye injection height and sample port location) would allow more full use of the data obtained for proper curve fitting. Since vertical coordinates were not well resolved in the current study, use of two-dimensional contouring and analysis of the leading constant in the one-dimensional exponential curve fitting were not done. Addition of these capabilities would greatly enhance future studies. 


\section{Bibliography}

Ackerman, J. and Okubo, A. (1993). Reduced Mixing in a Marine Macrophyte Canopy. Functional Ecology, 7, 305-309.

Anderson, S.M. and Charters, A.C. (1982). A Fluid Dynamics Study of Seawater Flow Through Gelidium nudifrons. Limnology and Oceanography 27(3):399-412.

Burke, R.W. and Stolzenbach, K.D. (1983). Free Surface Flow Through Salt Marsh Grass. MIT Sea Grant Report MITSG 83-16, Cambridge, MA.

Butman, C.A., Fréchette, M., Geyer, W.R., and Starczak, V.R. (1994). Flume experiments on food supply to the blue mussel Mytilus edulis L. as a function of the boundary-layer flow. Limnology and Oceanography 39(7):1755-1768.

Capone, D.G. and Bautista, M.F. (1985). A Groundwater Source of Nitrate in Nearshore Marine Sediments. Nature 313: 214-6.

El-Hakim, O. and Salama, M.M. (1992). Velocity Distribution Inside and Above Branched Flexible Roughness. Journal of Irrigation and Drainage Engineering 118(6):914-927.

Elder, J.W. (1959). The Dispersion of Marked Fluid in Turbulent Shear Flow. Journal of Fluid Mechanics 5: 544.

Fréchette, M., Butman, C.A., and Geyer, W.R. (1989). The importance or boundary-layer flows in supplying phytoplankton to the benthic suspension feeder, Mytilus edulis L. Limnology and Oceanography 34(1):19-36.

Gambi, M.C., Nowell, A.R.M., and Jumars, P.A. (1990). Flume Observations on Flow Dynamics in Zostera marina (eelgrass) Beds. Marine Ecology Progress Series 61:159-69.

Giblin, A.E. and Gaines, A.G. (1990). Nitrogen Inputs to a Marine Embayment: The Importance of Groundwater. Biogeochemistry 10: 309-328.

Harvey, J.W. and Odum, W.E. (1990). The Influence of Tidal Marshes on Upland Groundwater Discharge to Estuaries. Biogeochemistry 10: 217-236.

Johannes, R.E. (1980). The Ecological Significance of the Submarine Discharge of Groundwater. Marine Ecology Progress Series 3: 365-73. 
Kadlec, R.H. (1990). Overland Flow in Wetlands: Vegetation Resistance. Journal of Hydraulic Engineering 116(5):691-706.

Kadlec, R.H. and Hey, D.L. (1994). Constructed Wetlands for River Water Quality Improvement. Water Science Technology 29(4):159-168.

Kaplan, W., Valiela, I., and Teal, J.M. (1979). Denitrification in a Salt Marsh Ecosystem. Limnology and Oceanography 24(4): 726-34.

Koch, E. W. (1993). Currents, Sea Grass Morphology, and Sediment Geochemistry. $12^{\text {th }}$ Biennial International Estuarine Research Conference. Nov. 14-18, Hilton Head.

Land Margins Ecosystems Research (LMER) Coordinating Committee (1992). Understanding Changes in Coastal Environments: The LMER Program. Eos 73(45):481-5.

Leonard, L.A. and Luther, M.E. (1995). Flow Hydrodynamics in Tidal Marsh Canopies. Limnology and. Oceanography 40(8):1474-1484.

Matse, K. (1995). Mother Nature's Pump and Treat. Civil Engineering. Oct.

McLaughlin, R. (1994). Are Golf Courses Handicapping Coastal Water Quality?. Water Environment and Technology 6(7): 21.

Millham, N.P. and Howes, B.L. (1994). Freshwater Flow into a Coastal Embayment: Groundwater and Surface Water Inputs. Limnology and Oceanography 39(8): 1928-44.

Mitsch, W.J. (1993). Ecological Engineering - A Cooperative Role with the Planetary Life-Support System. Environmental Science and Technology 27(3):438-45.

Mitsch, W.J. (1995). Restoration of Our Lakes and Rivers with Wetlands - An Important Application of Ecological Engineering. Water Science and Technology 31(8):167-77.

National Oceanic and Atmospheric Administration (1990). 50 Years of Population Change Along the Nation's Coasts (1960-2010). Silver Spring, MD. Office of Oceanography and Marine Assessment. 41p.

National Oceanic and Atmospheric Administration (1991). Coastal Wetlands of the United States: An Accounting of a Valuable Natural Resource. Silver Spring, MD. Office of Oceanography and Marine Assessment. 59p. 
National Oceanic and Atmospheric Administration (1996). NOAA's Estuarine

Eutrophication Survey. Vol. 1: Mid-Atlantic Region. Silver Spring, MD. Office of Ocean Resources Conservation Assessment. 50p.

National Oceanic and Atmospheric Administration (1997). NOAA's Estuarine

Eutrophication Survey. Vol. 2: Mid-Atlantic Region. Silver Spring, MD. Office of Ocean Resources Conservation Assessment. 50p.

National Research Council (1993). "Managing Wastewater in Coastal Urban Areas". National Academy Press, Washington D.C.

National Research Council (1994). "Priorities for Coastal Ecosystem Science." National Academy Press, Washington D.C.

Nepf, H., Sullivan, J. and Zavistovski, R. (1997). A Model for Diffusion Within Emergent Vegetation. Limnology and Oceanography, accepted.

Reed, S.C., Middlebrooks, E.J., and Crites, R.W. (1988). 'Natural Systems for Wastewater Management and Treatment". McGraw-Hill, New York.

Shi, Z., Pethick, J.S., Burd, F. and Murphy, B. (1996). Velocity Profiles in a Salt Marsh Canopy. Geo-Marine Letters (16):319-323.

Simmons, G.M. Jr. (1992). Importance of Submarine Groundwater Discharge and Seawater Cycling to Material Flux Across Sediment/Water Interfaces in Marine Environments. Marine Ecology Progress Series 84: 173-84.

Smart, P.L., and Laidlaw, I.M.S. (1977). An Evaluation of Some Fluorescent Dyes for Water Tracing. Water Resources Research 13(1): 15-33.

Valiela, I., Teal, J.M., and Carpenter, E.J. (1978). Nutrient and Particulate Fluxes in a Salt Marsh Ecosystem: Tidal Exchanges and Inputs by Precipitation and Groundwater. Limnology and Oceanography 23(4): 798-812.

Valiela, I, and Teal, J.M. (1979). The Nitrogen Budget of a Salt Marsh Ecosystem. Science 280: 652-6.

Valiela, I., Costa, J., Foreman, K., Teal, J.M., Howes, B.L., and Aubrey, D. (1990). Transport of Groundwater-Borne Nutrients and Their Effects on Coastal Waters. Biogeochemistry 10: 177-97.

Valiela, I., Foreman, K., LaMontague, M., Hersh, D., Costa, J., Peckol, P., DeMeoAndreson, B., D'Avanzo, C., Babione, M., Sham, C-H, Brawley, J., Lajtha, K. (1992). Couplings of Watersheds and Coastal Waters: Sources and Consequences of Nutrient Enrichment in Waquoit Bay, Massachusetts. Estuaries 15(4): 443-57. 
Weiskel, P.K. and Howes, B.L. (1991). Quantifying Dissolved Nitrogen Flux Through a Coastal Watershed. Water Resources Research 27(11): 2929-39.

Weiskel, P.K. and Howes, B.L. (1992). Differential Transport of Sewage-Derived Nitrogen and Phosphorus through a Coastal Watershed. Environmental Science and Technology 26: 352-360.

Worcester, S.E. (1995). Effects of Eelgrass Beds on Advection and Turbulent Mixing in Low Current and Shoot Density Environments. Marine Ecology Progress Series 126:223-32.

Young, P. (1996). The 'New Science' of Wetland Restoration. Environmental Science and Technology 30(7):292A-296A. 


\section{Appendix A - Detailed Results}

This appendix presents more detailed data and results for the study. Detailed tables showing data points used and intermediate results for each profile are included first, followed by plots of the individual fluorescence profiles.

Each profile presented here is identified by a three character 'Run Number' designation. This designation begins with ' $\mathrm{H}$ ' for horizontal profiles and with ' $\mathrm{V}$ ' for vertical profiles. The second character is an incremental counter, starting at ' 1 ' for horizontal and vertical profiles at each plant density and increasing for each successive horizontal or vertical profile. The third character identifies the vegetation density associated with the profile, and is either an ' $L$ ', ' $M$ ', ' $H$ ', or ' $Z$ ' depending on whether the profile is for low, medium, high, or zero plant density. All profiles were analyzed using the techniques described in the thesis, with the exception of the following variations:

- Profile H-1Z - The mean fluorescence values for the first and second data point in this profile were very nearly equal. These fluorescence readings also had uncertainties quite large relative to their actual value. These two things acting together made using these points to extrapolate to zero fluorescence impossible - fluorescence never reached zero when using certain combinations of these points. The combinations which caused this problem were not included in the analysis of this profile.

- Profiles V-1Z, V-2Z, and V-3Z - These profiles were all taken in relatively shallow water and with the dye source at or above the water surface. Because the dye was distributed only in the water, however, only half of the plume described by the equations used actually developed for these profiles. In these cases, a sample was taken as close to the water's surface as possible (roughly $2 \mathrm{~cm}$ ) without drawing air into the sample pump. The water surface was then set as a mirror at zero elevation and the measured points were reflected in the 
mirror to give a full profile. The measured point closest to the water was given a coordinate of $2 \mathrm{~cm}$ displacement from the mirror, with other coordinates adjusted similarly. The resulting full profiles were then analyzed with the standard methods described above. Transformed coordinates were converted back to their original values for plotting, with only the lower half of the profile (the portion actually in the water) being plotted. 
Table A-1: Profile Data for Low Plant Density

\begin{tabular}{|c|c|c|c|c|c|c|c|}
\hline Run Number & Data Set & Data Points & Mean Time & $\begin{array}{c}\text { Current }(\boldsymbol{u}) \\
(\mathrm{cm} / \mathrm{sec})\end{array}$ & $\begin{array}{c}\text { del } \boldsymbol{u} \\
(\mathrm{cm} / \mathrm{sec})\end{array}$ & $\begin{array}{c}\text { Distance }(\boldsymbol{l}) \\
(\mathrm{cm})\end{array}$ & Re-d \\
\hline \hline V-1L & Aug 6, Set B & 7 to 9 & $3: 36: 00$ & 5.36 & 0.04 & 145 & 370 \\
\hline V-2L & Aug 6, Set C & 1 to 4 & $3: 46: 30$ & 6.80 & 0.11 & 145 & 469 \\
\hline H-1L & Aug 6, Set C & 6 to 11 & $3: 52: 30$ & 7.35 & 0.05 & 145 & 507 \\
\hline H-2L & Aug 7, Set A & 1 to 4 & $4: 26: 30$ & 4.53 & 0.33 & 134 & 313 \\
\hline H-3L & Aug 7, Set A & 5 to 10 & $4: 31: 30$ & 5.40 & 0.40 & 134 & 373 \\
\hline V-3L & Aug 7, Set A & 11 to 14 & $4: 36: 30$ & 6.26 & 0.49 & 134 & 432 \\
\hline H-4L & Aug 7, Set B & 1 to 5 & $4: 48: 00$ & 7.35 & 0.52 & 134 & 507 \\
\hline V-4L & Aug 7, Set B & 6 to 9 & $4: 57: 00$ & 7.55 & 0.68 & 134 & 521 \\
\hline H-5L & Aug 7, Set B & 11 to 14 & $5: 18: 00$ & 7.06 & 0.42 & 134 & 487 \\
\hline
\end{tabular}

Table A-2: Profile Data for Medium Plant Density

\begin{tabular}{|c|c|c|c|c|c|c|c|}
\hline Run Number & Data Set & Data Points & Mean Time & $\begin{array}{c}\text { Current }(\boldsymbol{u}) \\
(\mathrm{cm} / \mathrm{sec})\end{array}$ & $\begin{array}{c}\text { del } \boldsymbol{u} \\
(\mathrm{cm} / \mathrm{sec})\end{array}$ & $\begin{array}{c}\text { Distance }(\boldsymbol{l}) \\
(\mathrm{cm})\end{array}$ & Re-d \\
\hline \hline H-1M & Aug 2, Set A & 5 to 10 & $11: 44: 30$ & 2.93 & 0.34 & 135 & 202 \\
\hline V-1M & Aug 2, Set A & 10 to 14 & $11: 49: 00$ & 3.22 & 0.24 & 135 & 222 \\
\hline H-2M & Aug 2, Set B & 3 to 6 & $12: 12: 45$ & 4.88 & 0.30 & 135 & 337 \\
\hline V-2M & Aug 2, Set B & 9 to 13 & $12: 30: 00$ & 3.77 & 0.12 & 135 & 260 \\
\hline H-3M & Aug 5, Set A & 1 to 4 & $2: 26: 30$ & 2.04 & 0.19 & 127 & 141 \\
\hline V-3M & Aug 5, Set A & 5 to 8 & $2: 30: 53$ & 2.30 & 0.23 & 127 & 159 \\
\hline H-4M & Aug 5, Set B & 1 to 5 & $2: 44: 00$ & 3.15 & 0.25 & 127 & 217 \\
\hline V-4M & Aug 5, Set B & 5 to 9 & $2: 52: 00$ & 3.69 & 0.29 & 127 & 255 \\
\hline H-5M & Aug 5, Set C & 1 to 3 & $3: 06: 00$ & 4.28 & 0.22 & 127 & 295 \\
\hline
\end{tabular}


Table A-3: Profile Data for High Plant Density

\begin{tabular}{|c|c|c|c|c|c|c|c|}
\hline Run Number & Data Set & Data Points & Mean Time & $\begin{array}{c}\text { Current }(\boldsymbol{u}) \\
(\mathrm{cm} / \mathrm{sec})\end{array}$ & $\begin{array}{c}\text { del } \boldsymbol{u} \\
(\mathrm{cm} / \mathrm{sec})\end{array}$ & $\begin{array}{c}\text { Distance }(\boldsymbol{l}) \\
(\mathrm{cm})\end{array}$ & Re-d \\
\hline \hline H-1H & July 31, Set B & 2 to 6 & $9: 47: 30$ & 3.01 & 0.21 & 152.5 & 208 \\
\hline H-2H & July 31, Set C & 1 to 5 & $10: 06: 30$ & 3.64 & 0.26 & 152.5 & 251 \\
\hline V-1H & July 31, Set C & 5 to 9 & $10: 16: 00$ & 3.96 & 0.36 & 152.5 & 273 \\
\hline
\end{tabular}

Table A-4: Profile Data for Zero Plant Density

\begin{tabular}{|c|c|c|c|c|c|c|c|}
\hline Run Number & Data Set & Data Points & Mean Time & $\begin{array}{c}\text { Current }(\boldsymbol{u}) \\
(\mathrm{cm} / \mathrm{sec})\end{array}$ & $\begin{array}{c}\text { del } \boldsymbol{u} \\
(\mathrm{cm} / \mathrm{sec})\end{array}$ & $\begin{array}{c}\text { Distance }(\boldsymbol{l}) \\
(\mathrm{cm})\end{array}$ & Re-d \\
\hline \hline H-1Z & Jul 24, Set C & 2 to 5 & $4: 08: 30$ & 8.72 & 0.97 & 203 & 602 \\
\hline H-2Z & Jul 24, Set C & 6 to 10 & $4: 17: 45$ & 9.93 & 1.07 & 203 & 685 \\
\hline V-1Z & Aug 8, Set A & 10 to 12 & $5: 44: 00$ & 9.52 & 0.23 & 134 & 657 \\
\hline V-2Z & Aug 8, Set A & 12 to 14 & $5: 48: 30$ & 10.25 & 0.25 & 134 & 707 \\
\hline H-3Z & Aug 8, Set A & 15 to 19 & $5: 57: 00$ & 11.64 & 0.29 & 134 & 803 \\
\hline V-3Z & Aug 8, Set A & 20 to 23 & $6: 06: 00$ & 13.10 & 0.34 & 134 & 904 \\
\hline
\end{tabular}


Table A-5: Diffusivity Results for Low Plant Density

\section{Horizontal Diffusivity}

\begin{tabular}{|c|c|c|c|c|c|c|c|c|c|c|c|c|}
\hline & & \multicolumn{5}{|c|}{ Method of Moments } & \multicolumn{6}{|c|}{ Exponential Fit Method } \\
\hline $\begin{array}{c}\text { Run } \\
\text { Number }\end{array}$ & Re-d & $\begin{array}{c}\text { Xbar } \\
(\mathrm{cm})\end{array}$ & $\begin{array}{c}\text { Variance } \\
\left(\mathrm{cm}^{\wedge} 2\right)\end{array}$ & $\begin{array}{c}\text { del Var } \\
\left(\mathrm{cm}^{\wedge} 2\right)\end{array}$ & $\begin{array}{c}D \\
\left(\mathrm{~cm}^{\wedge} 2 / \mathrm{s}\right)\end{array}$ & $\begin{array}{c}\operatorname{del} \boldsymbol{D} \\
\left(\mathrm{cm}^{\wedge} 2 / \mathrm{s}\right)\end{array}$ & $\begin{array}{c}\text { Xbar } \\
(\mathrm{cm})\end{array}$ & $\begin{array}{c}\text { Variance } \\
\left(\mathrm{cm}^{\wedge} 2\right)\end{array}$ & $\begin{array}{c}\text { del Var } \\
\left(\mathrm{cm}^{\wedge} 2\right)\end{array}$ & $\begin{array}{c}D \\
\left(\mathrm{~cm}^{\wedge} 2 / \mathrm{s}\right)\end{array}$ & $\begin{array}{l}\operatorname{del} \boldsymbol{D} \\
\left(\mathrm{cm}^{\wedge} 2 / \mathrm{s}\right)\end{array}$ & $\mathbf{R}^{\wedge} 2$ \\
\hline $\mathrm{H}-1 \mathrm{~L}$ & 507 & 134.9 & 38.02 & 5.40 & 0.96 & 0.14 & 135.2 & 31.96 & 1.98 & 0.81 & 0.05 & 0.996 \\
\hline $\mathrm{H}-2 \mathrm{~L}$ & 313 & 129.6 & 37.35 & 7.31 & 0.63 & 0.13 & 130.4 & 35.25 & 1.51 & 0.60 & 0.05 & 0.999 \\
\hline $\mathrm{H}-3 \mathrm{~L}$ & 373 & 130.7 & 52.22 & 3.82 & 1.05 & 0.11 & 132.2 & 35.90 & 4.51 & 0.72 & 0.11 & 0.986 \\
\hline $\mathrm{H}-4 \mathrm{~L}$ & 507 & 143.1 & 41.78 & 6.73 & 1.15 & 0.20 & 144.0 & 39.61 & 0.52 & 1.09 & 0.08 & 1.000 \\
\hline $\mathrm{H}-5 \mathrm{~L}$ & 487 & 141.6 & 27.71 & 2.07 & 0.73 & 0.07 & 145.8 & 47.22 & 31.12 & 1.24 & 0.82 & 0.884 \\
\hline
\end{tabular}

\section{Vertical Diffusivity}

\begin{tabular}{|c|c|c|c|c|c|c|c|c|c|c|c|c|}
\hline & & \multicolumn{5}{|c|}{ Method of Moments } & \multicolumn{6}{|c|}{ Exponential Fit Method } \\
\hline $\begin{array}{c}\text { Run } \\
\text { Number }\end{array}$ & Re-d & $\begin{array}{l}\text { Ybar } \\
(\mathrm{cm})\end{array}$ & $\begin{array}{c}\text { Variance } \\
\left(\mathrm{cm}^{\wedge} 2\right)\end{array}$ & $\begin{array}{c}\text { del Var } \\
\left(\mathrm{cm}^{\wedge} 2\right)\end{array}$ & $\underset{\left(\mathrm{cm}^{\wedge} 2 / \mathrm{s}\right)}{\boldsymbol{D}}$ & $\begin{array}{c}\operatorname{del} \boldsymbol{D} \\
\left(\mathrm{cm}^{\wedge} 2 / \mathrm{s}\right)\end{array}$ & $\begin{array}{l}\text { Ybar } \\
(\mathrm{cm})\end{array}$ & $\begin{array}{c}\text { Variance } \\
\left(\mathrm{cm}^{\wedge} 2\right)\end{array}$ & $\begin{array}{c}\text { del Var } \\
\left(\mathrm{cm}^{\wedge} 2\right)\end{array}$ & $\begin{array}{c}\boldsymbol{D} \\
\left(\mathrm{cm}^{\wedge} 2 / \mathrm{s}\right)\end{array}$ & $\begin{array}{c}\operatorname{del} \boldsymbol{D} \\
\left(\mathrm{cm}^{\wedge} 2 / \mathrm{s}\right)\end{array}$ & $\mathbf{R}^{\wedge} \mathbf{2}$ \\
\hline $\mathrm{V}-1 \mathrm{~L}$ & 370 & 48.2 & 30.70 & 12.16 & 0.57 & 0.22 & 47.7 & 27.24 & 0.24 & 0.50 & 0.01 & 1.000 \\
\hline V-2L & 469 & 49.1 & 54.42 & 6.47 & 1.28 & 0.15 & 50.0 & 38.98 & 5.72 & 0.91 & 0.14 & 0.990 \\
\hline V-3L & 432 & 49.4 & 57.75 & 6.24 & 1.35 & 0.18 & 50.1 & 57.83 & 0.47 & 1.35 & 0.11 & 1.000 \\
\hline $\mathrm{V}-4 \mathrm{~L}$ & 521 & 52.7 & 39.61 & 2.66 & 1.12 & 0.13 & 52.3 & 44.24 & 17.35 & 1.25 & 0.50 & 0.939 \\
\hline
\end{tabular}


Table A-6: Diffusivity Results for Medium Plant Density

\section{Horizontal Diffusivity}

\begin{tabular}{|c|c|c|c|c|c|c|c|c|c|c|c|c|}
\hline & & \multicolumn{5}{|c|}{ Method of Moments } & \multicolumn{6}{|c|}{ Exponential Fit Method } \\
\hline $\begin{array}{c}\text { Run } \\
\text { Number }\end{array}$ & Re-d & $\begin{array}{c}\text { Xbar } \\
(\mathrm{cm})\end{array}$ & $\begin{array}{c}\text { Variance } \\
\left(\mathrm{cm}^{\wedge} 2\right)\end{array}$ & $\begin{array}{c}\text { del Var } \\
\left(\mathrm{cm}^{\wedge} 2\right)\end{array}$ & $\underset{\left(\mathrm{cm}^{\wedge} 2 / \mathrm{s}\right)}{D}$ & $\begin{array}{c}\text { del } \boldsymbol{D} \\
\left(\mathrm{cm}^{\wedge} 2 / \mathrm{s}\right)\end{array}$ & $\begin{array}{l}\text { Xbar } \\
(\mathrm{cm})\end{array}$ & $\begin{array}{c}\text { Variance } \\
\left(\mathrm{cm}^{\wedge} 2\right)\end{array}$ & $\begin{array}{c}\text { del Var } \\
\left(\mathrm{cm}^{\wedge} 2\right)\end{array}$ & $\underset{\left(\mathrm{cm}^{\wedge} 2 / \mathrm{s}\right)}{D}$ & $\begin{array}{l}\operatorname{del} \boldsymbol{D} \\
\left(\mathrm{cm}^{\wedge} 2 / \mathrm{s}\right)\end{array}$ & $\mathbf{R}^{\wedge} \mathbf{2}$ \\
\hline $\mathrm{H}-1 \mathrm{M}$ & 202 & 48.4 & 67.79 & 2.79 & 0.74 & 0.09 & 45.8 & 56.46 & 15.47 & 0.61 & 0.18 & 0.965 \\
\hline $\mathrm{H}-2 \mathrm{M}$ & 337 & 56.0 & 66.36 & 22.89 & 1.20 & 0.42 & 55.0 & 62.23 & 42.91 & 1.12 & 0.78 & 0.878 \\
\hline $\mathrm{H}-3 \mathrm{M}$ & 141 & 111.1 & 32.80 & 1.53 & 0.26 & 0.03 & 110.1 & 29.36 & 5.29 & 0.24 & 0.05 & 0.991 \\
\hline $\mathrm{H}-4 \mathrm{M}$ & 217 & 125.4 & 59.15 & 14.10 & 0.73 & 0.18 & 124.3 & 54.33 & 24.42 & 0.67 & 0.31 & 0.888 \\
\hline $\mathrm{H}-5 \mathrm{M}$ & 295 & 132.6 & 34.09 & 5.88 & 0.57 & 0.10 & 133.4 & 19.88 & 0.36 & 0.33 & 0.02 & 1.000 \\
\hline
\end{tabular}

\section{Vertical Diffusivity}

\begin{tabular}{|c|c|c|c|c|c|c|c|c|c|c|c|c|}
\hline \multirow{2}{*}{$\begin{array}{c}\text { Run } \\
\text { Number }\end{array}$} & \multirow[b]{2}{*}{$\operatorname{Re}-d$} & \multicolumn{5}{|c|}{ Method of Moments } & \multicolumn{6}{|c|}{ Exponential Fit Method } \\
\hline & & $\begin{array}{l}\text { Ybar } \\
(\mathrm{cm})\end{array}$ & $\begin{array}{c}\text { Variance } \\
\left(\mathrm{cm}^{\wedge} 2\right)\end{array}$ & $\begin{array}{c}\text { del Var } \\
\left(\mathrm{cm}^{\wedge} 2\right)\end{array}$ & $\begin{array}{c}D \\
\left(\mathrm{~cm}^{\wedge} 2 / \mathrm{s}\right)\end{array}$ & $\begin{array}{c}\text { del } \boldsymbol{D} \\
\left(\mathrm{cm}^{\wedge} 2 / \mathrm{s}\right)\end{array}$ & $\begin{array}{l}\text { Ybar } \\
(\mathrm{cm})\end{array}$ & $\begin{array}{c}\begin{array}{c}\text { Variance } \\
\left(\mathrm{cm}^{\wedge} 2\right)\end{array} \\
\end{array}$ & $\begin{array}{c}\text { del Var } \\
\left(\mathrm{cm}^{\wedge} 2\right)\end{array}$ & $\begin{array}{c}D \\
\left(\mathrm{~cm}^{\wedge} 2 / \mathrm{s}\right)\end{array}$ & $\begin{array}{c}\operatorname{del} \boldsymbol{D} \\
\left(\mathrm{cm}^{\wedge} 2 / \mathrm{s}\right)\end{array}$ & $\mathbf{R}^{\wedge} \mathbf{2}$ \\
\hline $\mathrm{V}-1 \mathrm{M}$ & 222 & 39.4 & 64.96 & 1.14 & 0.77 & 0.06 & 39.1 & 53.34 & 7.65 & 0.64 & 0.10 & 0.993 \\
\hline $\mathrm{V}-2 \mathrm{M}$ & 260 & 33.1 & 41.24 & 3.46 & 0.58 & 0.05 & $34: 2$ & 30.63 & 7.11 & 0.43 & 0.10 & 0.972 \\
\hline $\mathrm{V}-3 \mathrm{M}$ & 159 & 36.7 & 39.57 & 2.05 & 0.36 & 0.04 & 37.6 & 19.54 & 3.44 & 0.18 & 0.04 & 0.993 \\
\hline $\mathrm{V}-4 \mathrm{M}$ & 255 & 45.2 & 39.22 & 2.23 & 0.57 & 0.06 & 45.4 & 35.64 & 2.07 & 0.52 & 0.05 & 0.998 \\
\hline
\end{tabular}


Table A-7: Diffusivity Results for High Plant Density

Horizontal Diffusivity

\begin{tabular}{|c|c|c|c|c|c|c|c|c|c|c|c|c|}
\hline & & \multicolumn{5}{|c|}{ Method of Moments } & \multicolumn{6}{|c|}{ Exponential Fit Method } \\
\hline $\begin{array}{c}\text { Run } \\
\text { Number }\end{array}$ & Re-d & $\begin{array}{l}\text { Xbar } \\
(\mathrm{cm})\end{array}$ & $\begin{array}{c}\text { Variance } \\
\left(\mathrm{cm}^{\wedge} 2\right)\end{array}$ & $\begin{array}{c}\text { del Var } \\
\left(\mathrm{cm}^{\wedge} 2\right)\end{array}$ & $\begin{array}{c}\boldsymbol{D} \\
\left(\mathrm{cm}^{\wedge} 2 / \mathrm{s}\right)\end{array}$ & $\begin{array}{c}\operatorname{del} \boldsymbol{D} \\
\left(\mathrm{cm}^{\wedge} 2 / \mathrm{s}\right)\end{array}$ & $\begin{array}{l}\text { Xbar } \\
(\mathrm{cm})\end{array}$ & $\begin{array}{c}\text { Variance } \\
\left(\mathrm{cm}^{\wedge} 2\right)\end{array}$ & $\begin{array}{c}\text { del Var } \\
\left(\mathrm{cm}^{\wedge} 2\right)\end{array}$ & $\begin{array}{c}\boldsymbol{D} \\
(\mathrm{cm} \wedge 2 / \mathrm{s})\end{array}$ & $\begin{array}{c}\operatorname{del} \boldsymbol{D} \\
(\mathrm{cm} \wedge 2 / \mathrm{s})\end{array}$ & $\mathbf{R}^{\wedge} \mathbf{2}$ \\
\hline$=\mathrm{H}-1 \mathrm{H}$ & 208 & 80.6 & 237.44 & 26.37 & 2.34 & 0.31 & 80.3 & 149.00 & 54.36 & 1.47 & 0.55 & 0.947 \\
\hline $\mathrm{H}-2 \mathrm{H}$ & 251 & 102.3 & 72.22 & 5.53 & 0.86 & 0.09 & 102.8 & 44.79 & 6.97 & 0.53 & 0.09 & 0.988 \\
\hline
\end{tabular}

\section{Vertical Diffusivity}

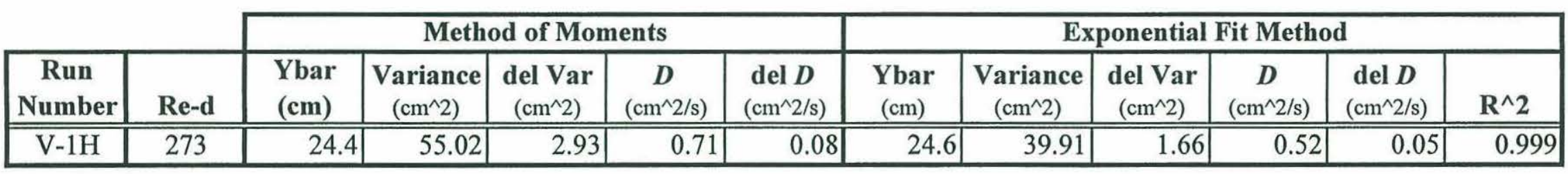


Table A-8: Diffusivity Results for Zero Plant Density

Horizontal Diffusivity

\begin{tabular}{|c|c|c|c|c|c|c|c|c|c|c|c|c|}
\hline \multirow[b]{2}{*}{$\begin{array}{c}\text { Run } \\
\text { Number }\end{array}$} & \multirow[b]{2}{*}{ Re-d } & \multicolumn{5}{|c|}{ Method of Moments } & \multicolumn{6}{|c|}{ Exponential Fit Method } \\
\hline & & $\begin{array}{l}\text { Xbar } \\
(\mathrm{cm})\end{array}$ & \begin{tabular}{|c|}
$\begin{array}{c}\text { Variance } \\
\left(\mathrm{cm}^{\wedge} 2\right)\end{array}$ \\
\end{tabular} & $\begin{array}{c}\text { del Var } \\
\left(\mathrm{cm}^{\wedge} 2\right)\end{array}$ & $\begin{array}{c}D \\
\left(\mathrm{~cm}^{\wedge} 2 / \mathrm{s}\right) \\
\end{array}$ & $\begin{array}{c}\operatorname{del} \boldsymbol{D} \\
\left(\mathrm{cm}^{\wedge} 2 / \mathrm{s}\right) \\
\end{array}$ & $\begin{array}{l}\text { Xbar } \\
(\mathrm{cm})\end{array}$ & $\begin{array}{c}\text { Variance } \\
\left(\mathrm{cm}^{\wedge} 2\right)\end{array}$ & $\begin{array}{c}\begin{array}{c}\text { del Var } \\
\left(\mathrm{cm}^{\wedge} 2\right)\end{array} \\
\end{array}$ & $\begin{array}{c}D \\
\left(\mathrm{~cm}^{\wedge} 2 / \mathrm{s}\right)\end{array}$ & $\begin{array}{c}\operatorname{del} \boldsymbol{D} \\
\left(\mathrm{cm}^{\wedge} 2 / \mathrm{s}\right) \\
\end{array}$ & $\mathbf{R}^{\wedge} 2$ \\
\hline $\mathrm{H}-1 \mathrm{Z}$ & 602 & 85.1 & 113.03 & 76.85 & 2.43 & 1.67 & 87.9 & 40.22 & 5.68 & 0.86 & 0.16 & 0.994 \\
\hline $\mathrm{H}-2 \mathrm{Z}$ & 685 & 84.2 & 73.84 & 28.92 & 1.81 & 0.73 & 83.1 & 81.15 & 12.13 & 1.98 & 0.37 & 0.988 \\
\hline $\mathrm{H}-3 \mathrm{Z}$ & 803 & 123.0 & 71.80 & 33.50 & 3.12 & 1.46 & 122.0 & 68.00 & 13.00 & 2.95 & 0.57 & 0.979 \\
\hline
\end{tabular}

Vertical Diffusivity

\begin{tabular}{|c|c|c|c|c|c|c|c|c|c|c|c|c|}
\hline \multirow[b]{2}{*}{$\begin{array}{c}\text { Run } \\
\text { Number }\end{array}$} & \multirow[b]{2}{*}{ Re-d } & \multicolumn{5}{|c|}{ Method of Moments } & \multicolumn{6}{|c|}{ Exponential Fit Method } \\
\hline & & $\begin{array}{l}\text { Ybar } \\
\text { (cm) }\end{array}$ & $\begin{array}{c}\text { Variance } \\
\left(\mathrm{cm}^{\wedge} 2\right)\end{array}$ & $\begin{array}{c}\text { del Var } \\
\left(\mathrm{cm}^{\wedge} 2\right)\end{array}$ & $\begin{array}{c}D \\
\left(\mathrm{~cm}^{\wedge} 2 / \mathrm{s}\right)\end{array}$ & $\begin{array}{c}\operatorname{del} \boldsymbol{D} \\
\left(\mathrm{cm}^{\wedge} 2 / \mathrm{s}\right)\end{array}$ & $\begin{array}{l}\text { Ybar } \\
(\mathrm{cm})\end{array}$ & $\begin{array}{c}\text { Variance } \\
\left(\mathrm{cm}^{\wedge} 2\right)\end{array}$ & $\begin{array}{c}\text { del Var } \\
\left(\mathrm{cm}^{\wedge} 2\right)\end{array}$ & $\begin{array}{c}D \\
\left(\mathrm{~cm}^{\wedge} 2 / \mathrm{s}\right)\end{array}$ & $\begin{array}{c}\text { del } \boldsymbol{D} \\
\left(\mathrm{cm}^{\wedge} 2 / \mathrm{s}\right)\end{array}$ & $\mathbf{R}^{\wedge} 2$ \\
\hline $\mathrm{V}-1 \mathrm{Z}$ & 657 & 0.0 & 19.53 & 2.10 & 0.69 & 0.08 & 0.0 & 19.69 & 1.95 & 0.70 & 0.07 & 0.992 \\
\hline $\mathrm{V}-2 \mathrm{Z}$ & 707 & -0.1 & 31.30 & 29.80 & 1.20 & 1.14 & 0.0 & 28.00 & 14.10 & 1.07 & 0.54 & 0.843 \\
\hline $\mathrm{V}-3 \mathrm{Z}$ & 904 & -0.1 & 37.59 & 5.38 & 1.84 & 0.27 & 0.0 & 40.01 & 4.50 & 1.96 & 0.23 & 0.986 \\
\hline
\end{tabular}




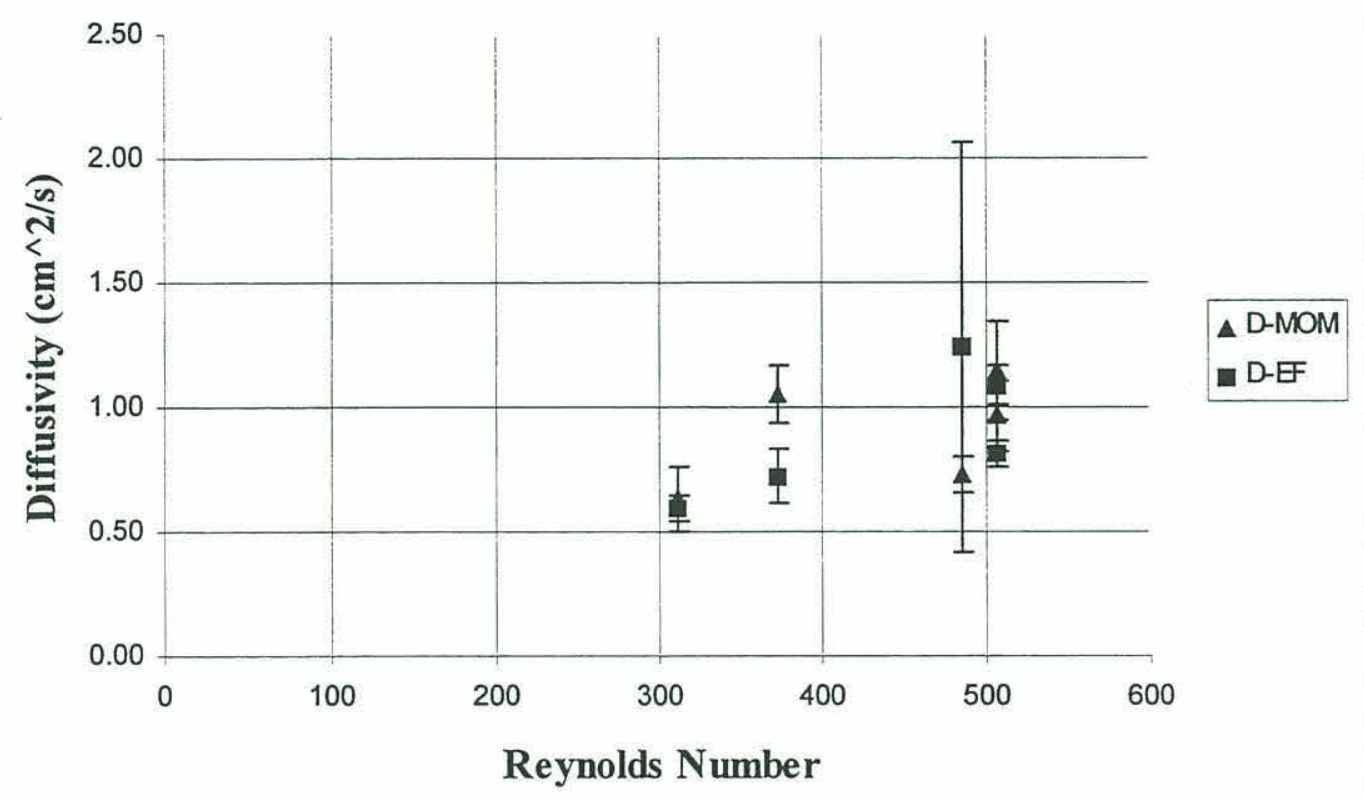

Figure A-1: Horizontal Diffusivity Results - Low Plant Density

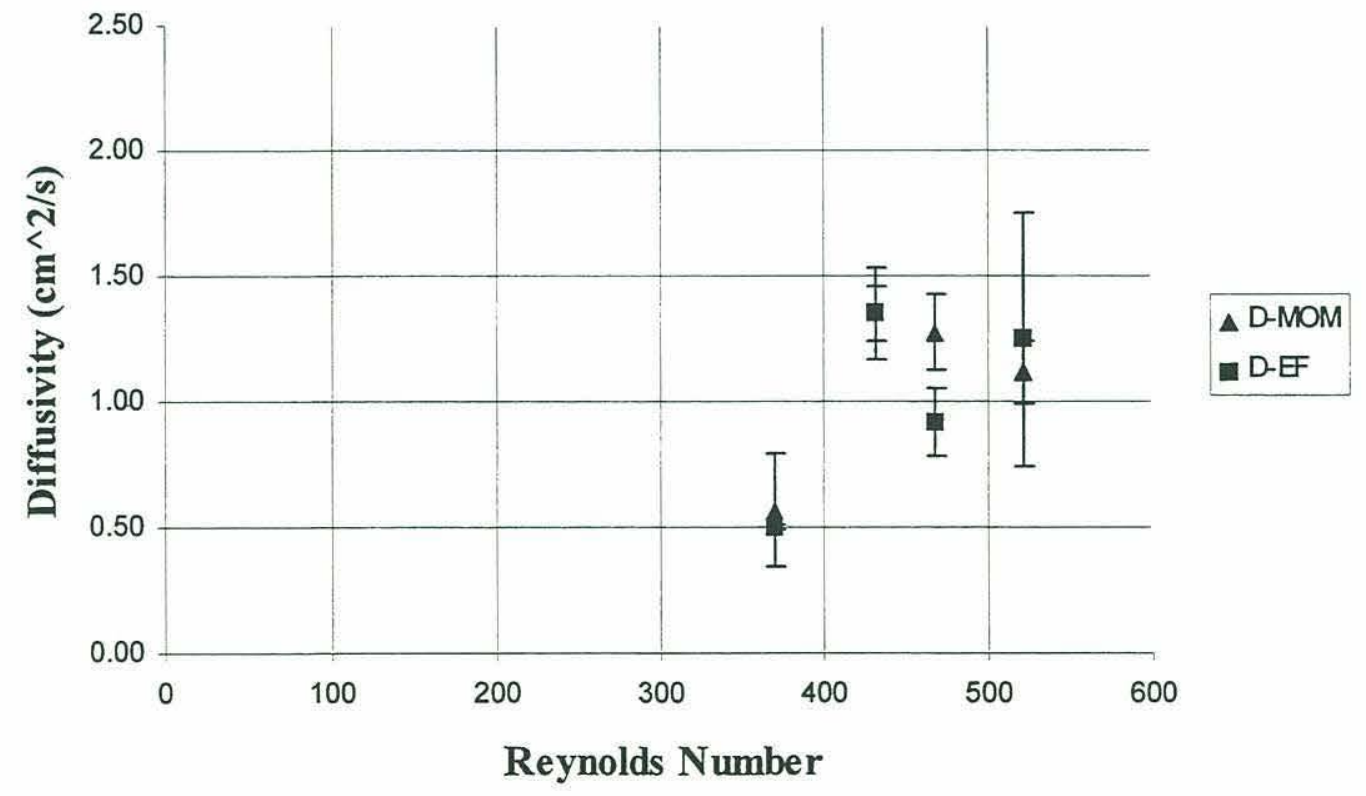

Figure A-2: Vertical Diffusivity Results - Low Plant Density 


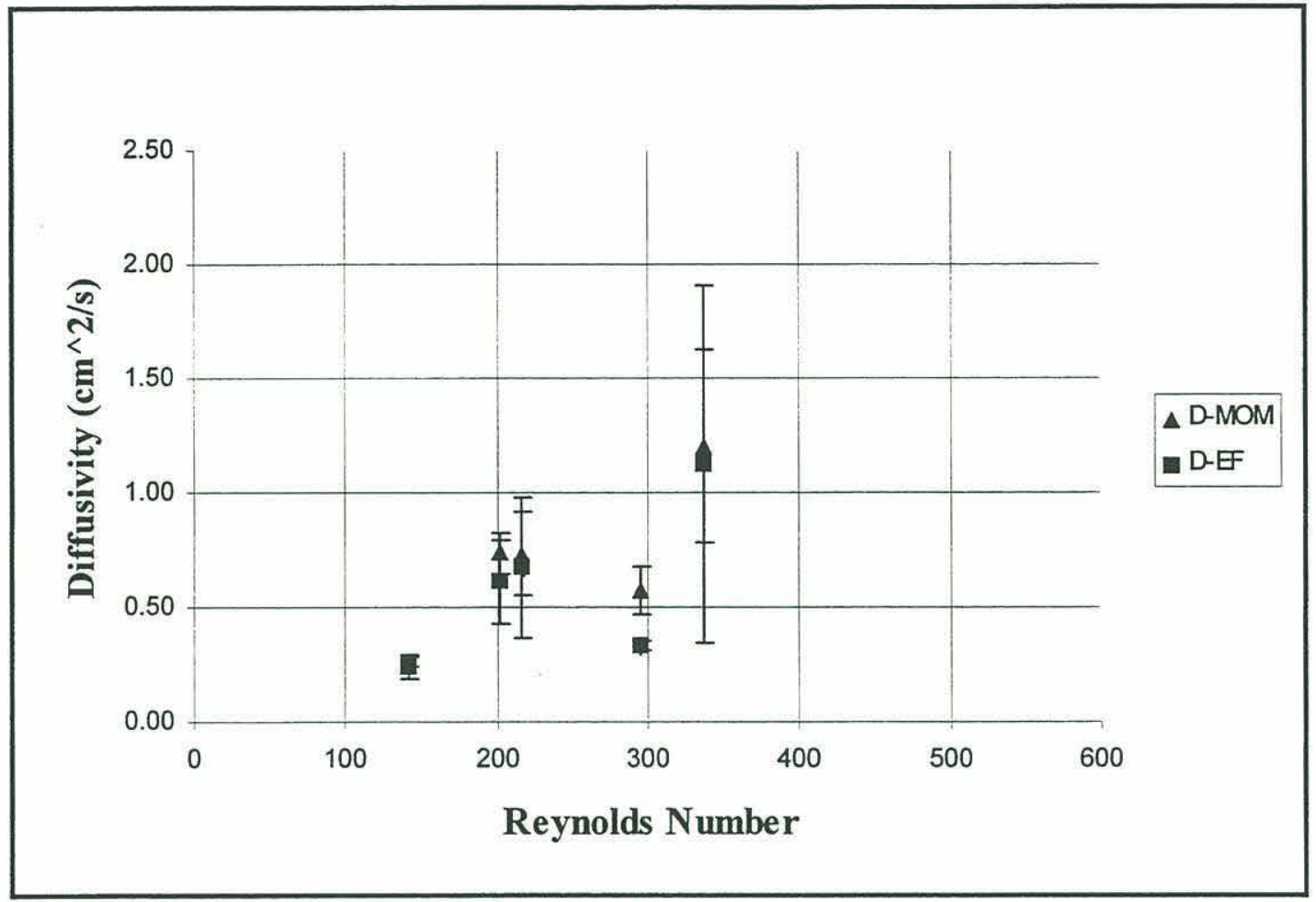

Figure A-3: Horizontal Diffusivity Results - Medium Plant Density

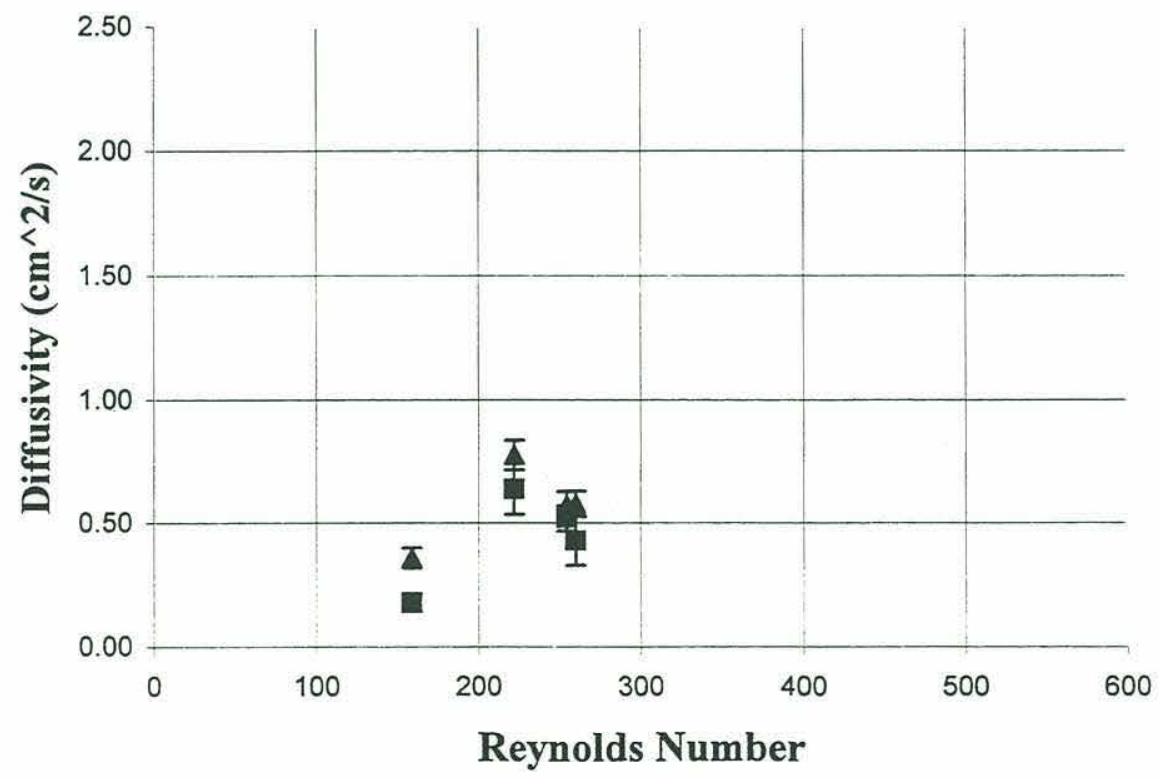

$\triangle \mathrm{D}-\mathrm{MOM}$ DD-EF

Figure A-4: Vertical Diffusivity Results - Medium Plant Density 


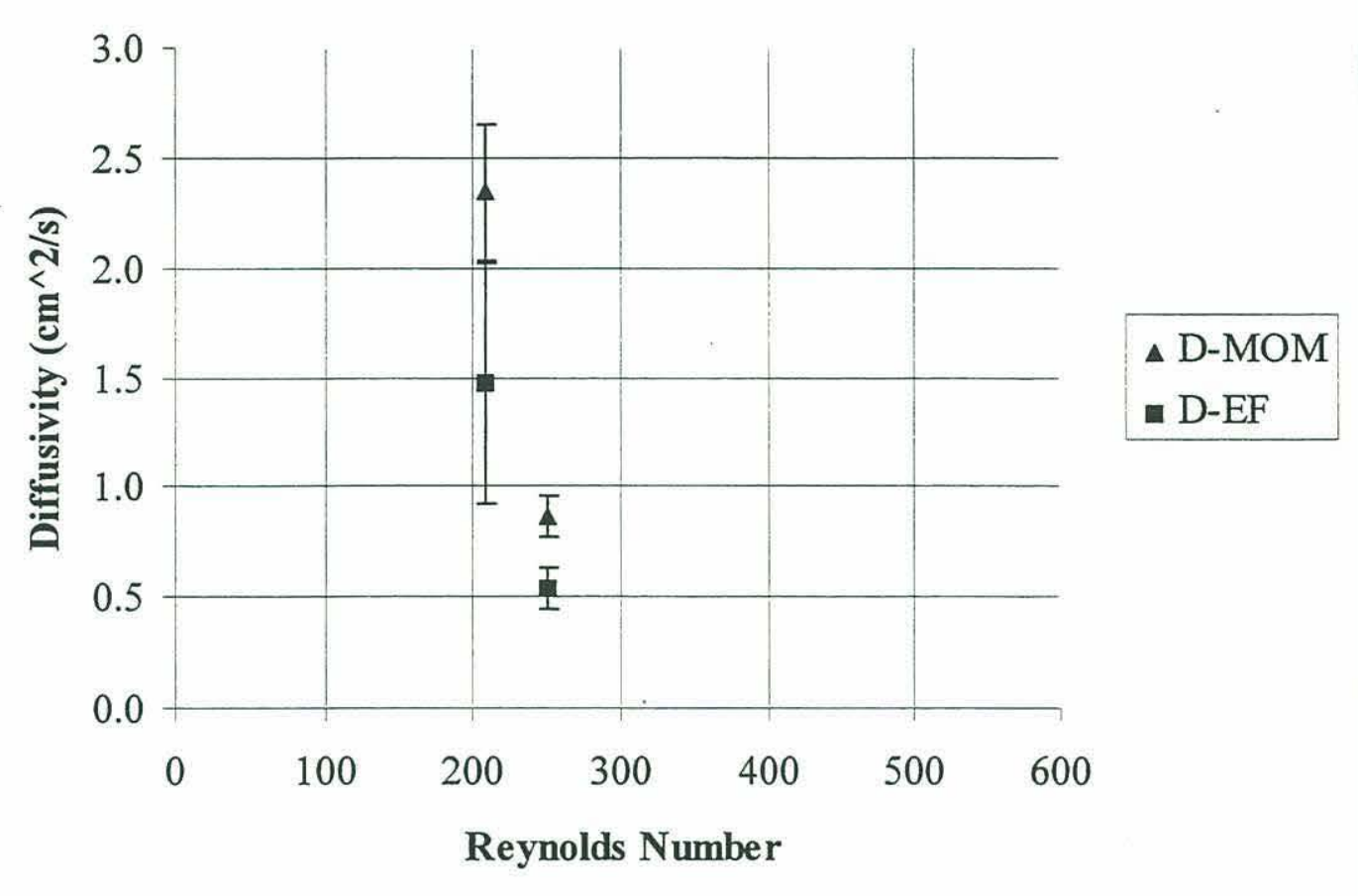

Figure A-5: Horizontal Diffusivity Results - High Plant Density

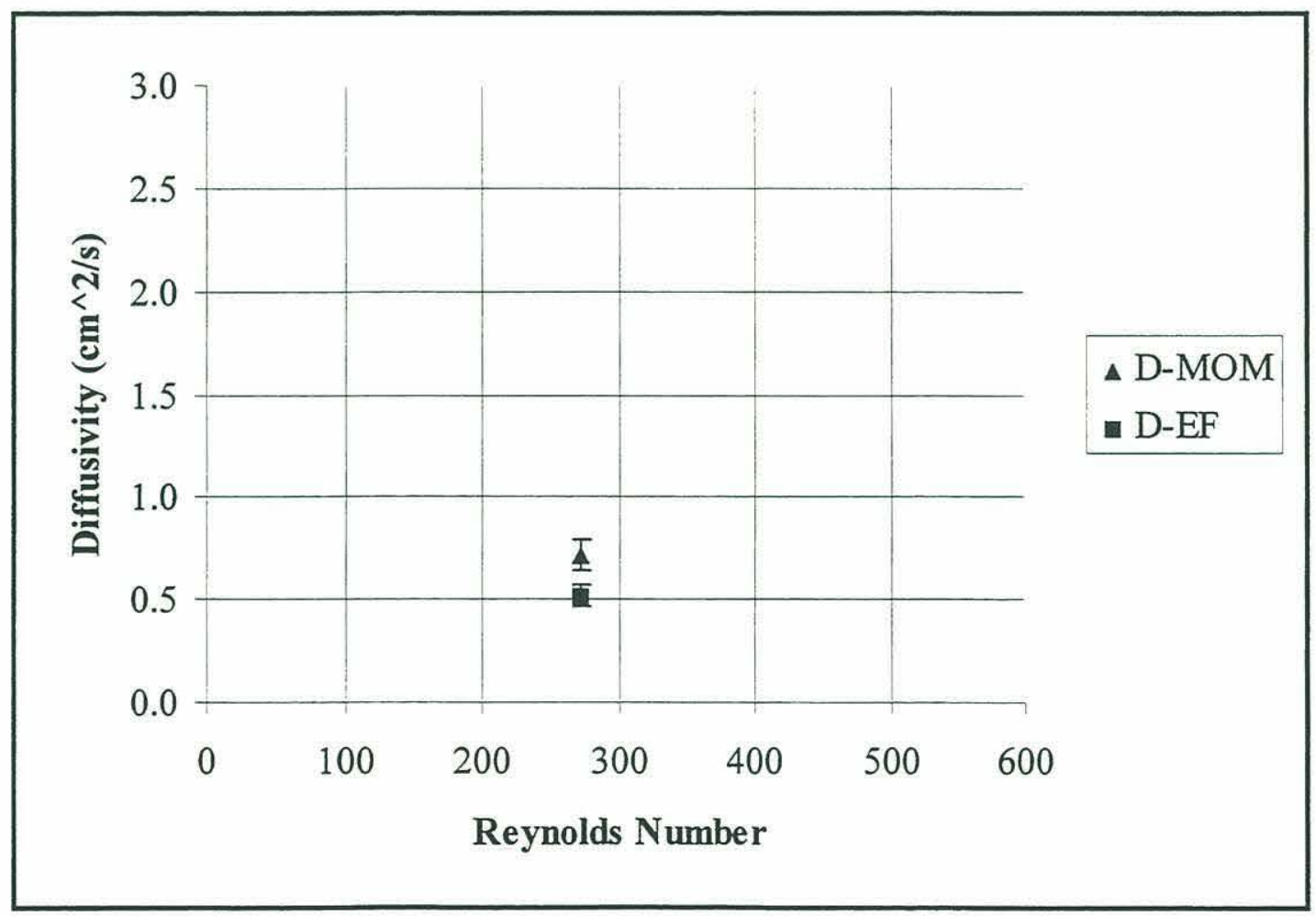

Figure A-6: Vertical Diffusivity Results - High Plant Density 


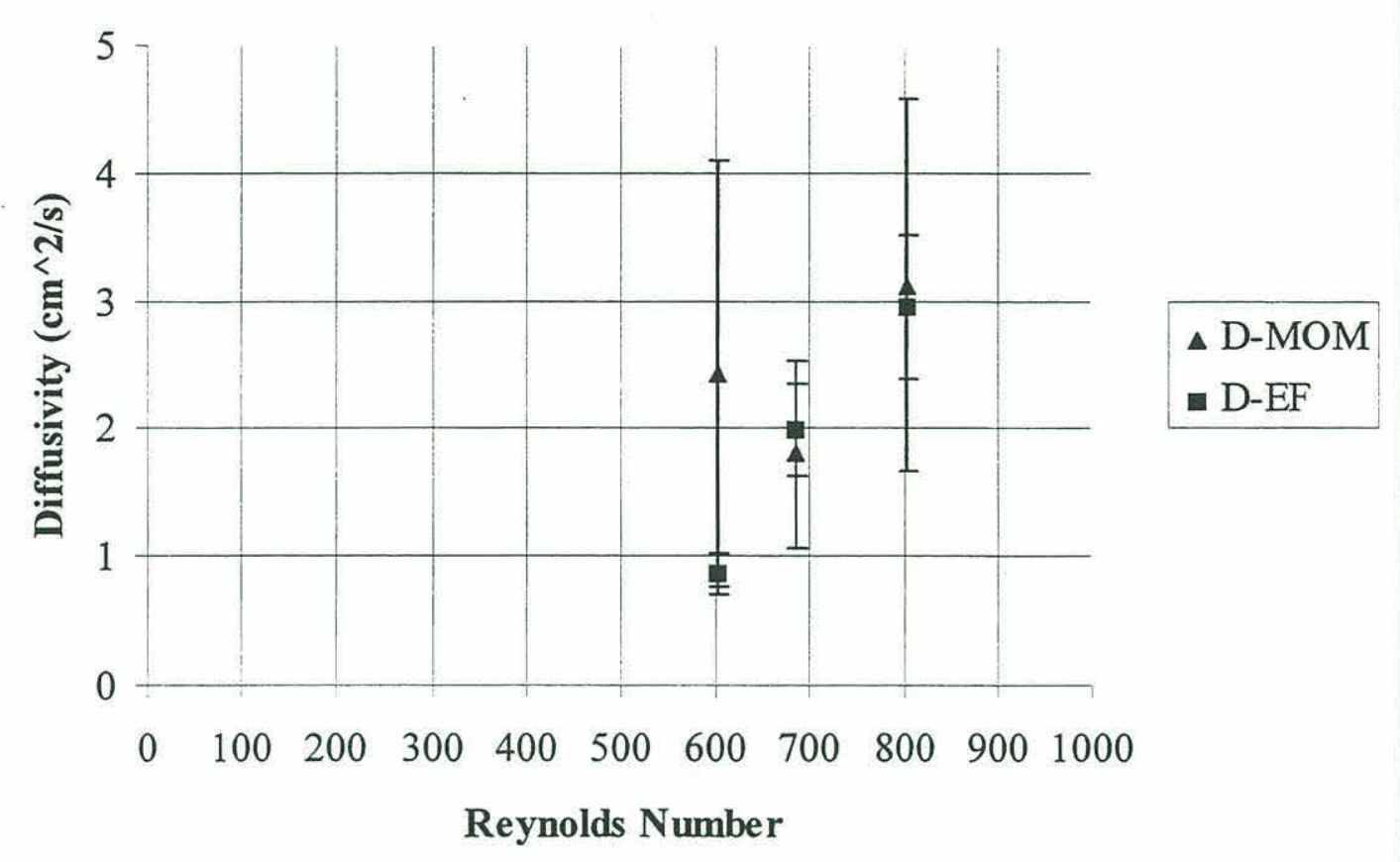

Figure A-7: Horizontal Diffusivity Results - Zero Plant Density

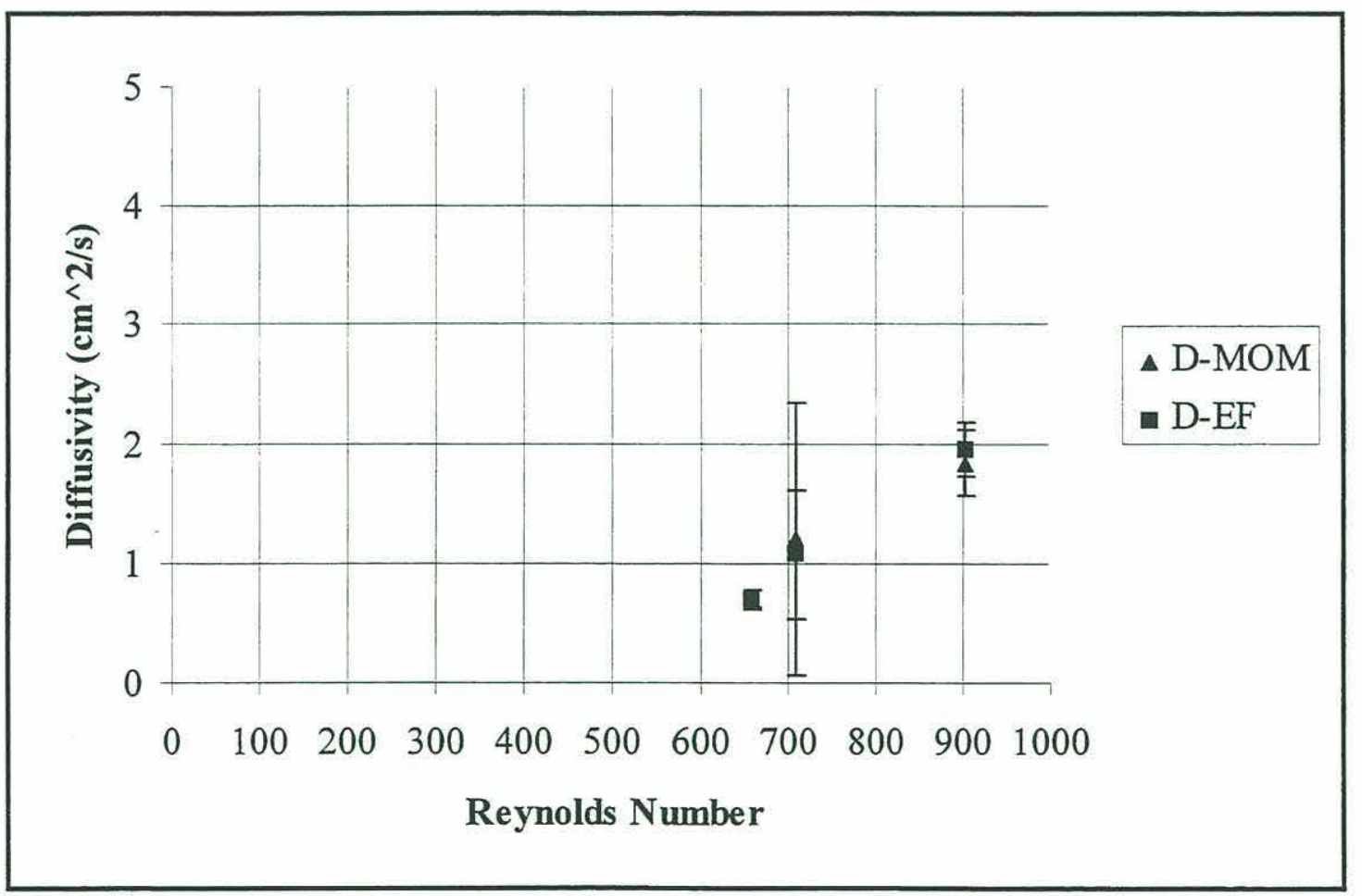

Figure A-8: Vertical Diffusivity Results - Zero Plant Density 


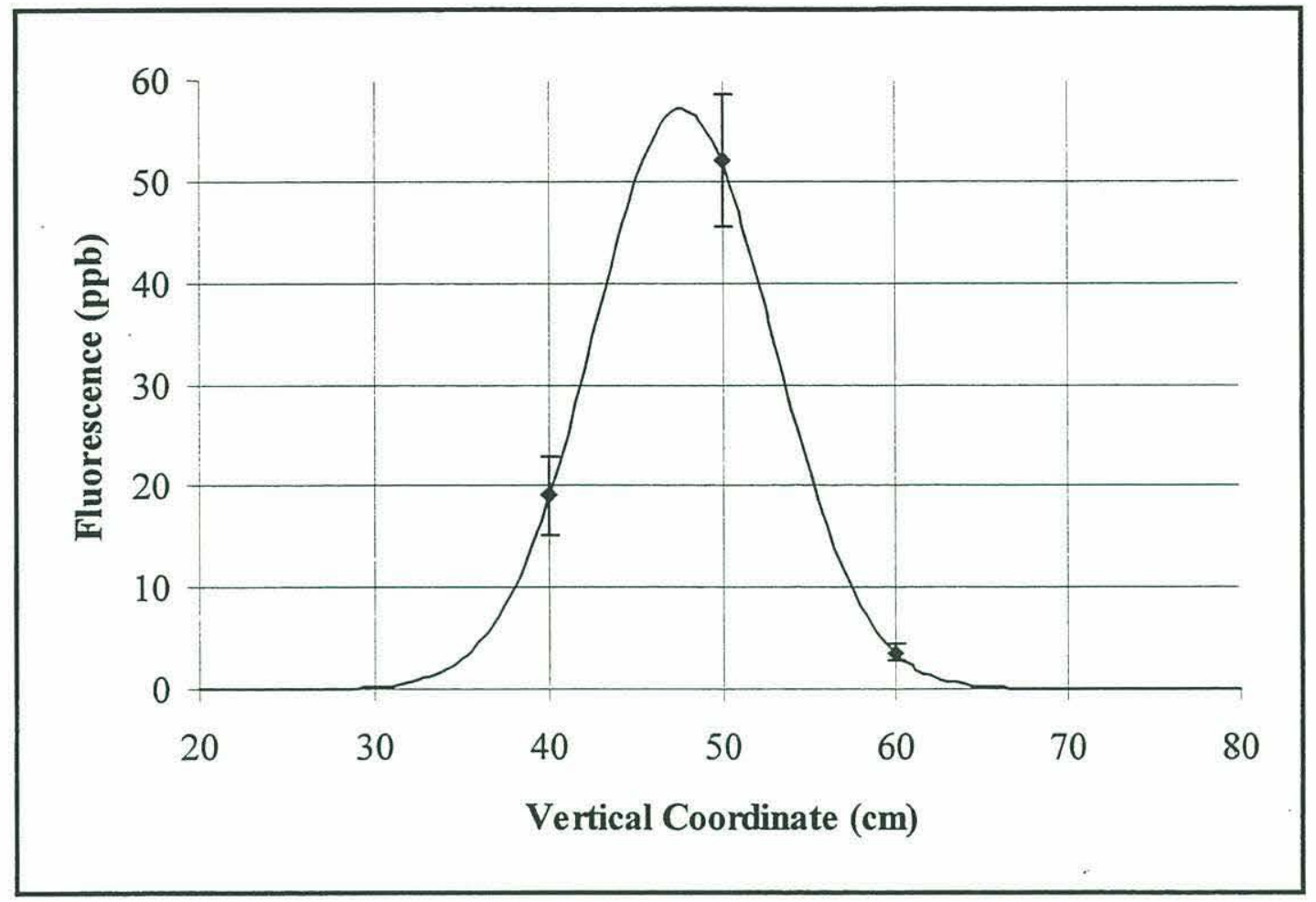

Figure A-9: Profile V-1L - August 6th, Set B, Points 7-9

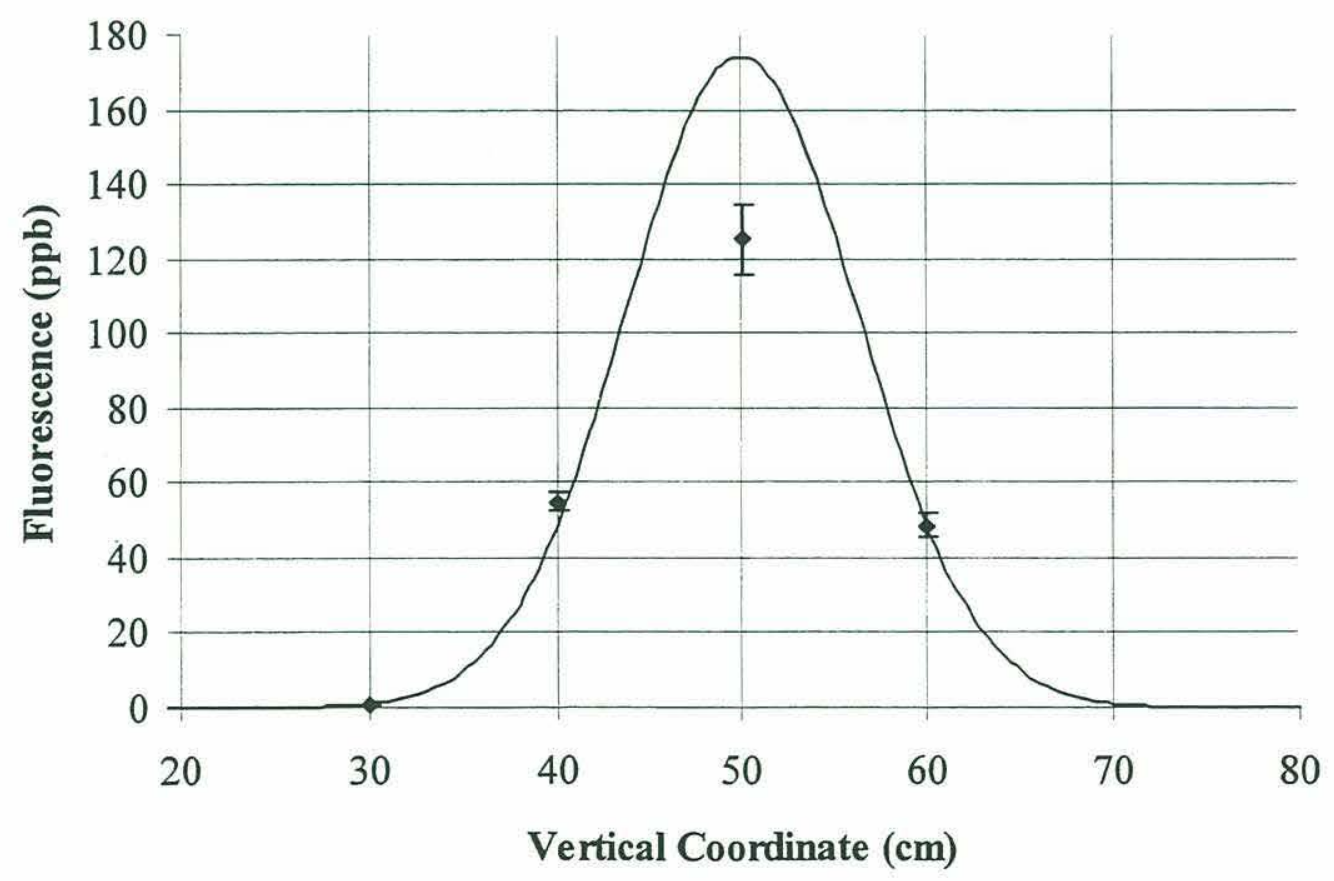

Figure A-10: Profile V-2L - August 6th, Set C, Points 1-4 


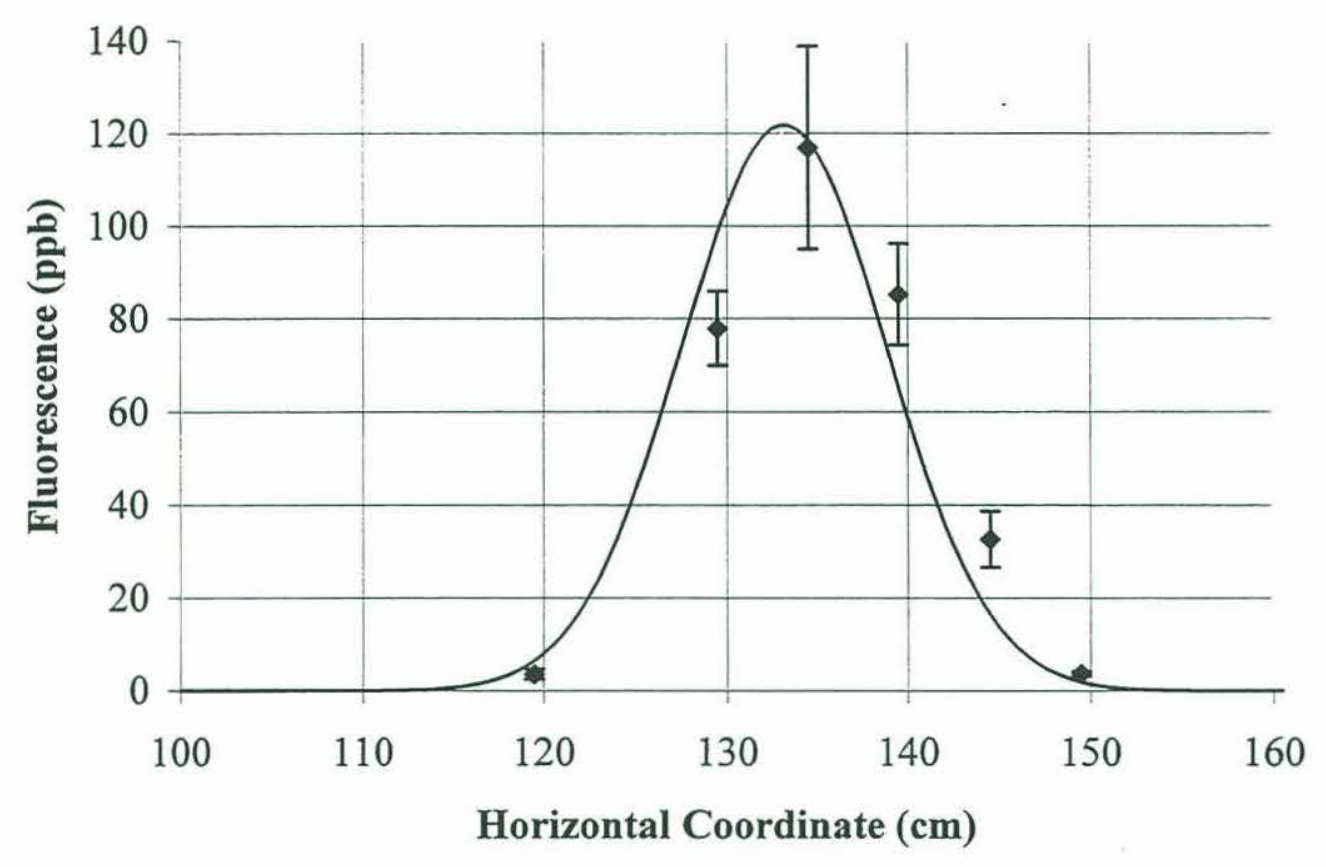

Figure A-11: Profile H-1L - August 6th, Set C, Points 6-11

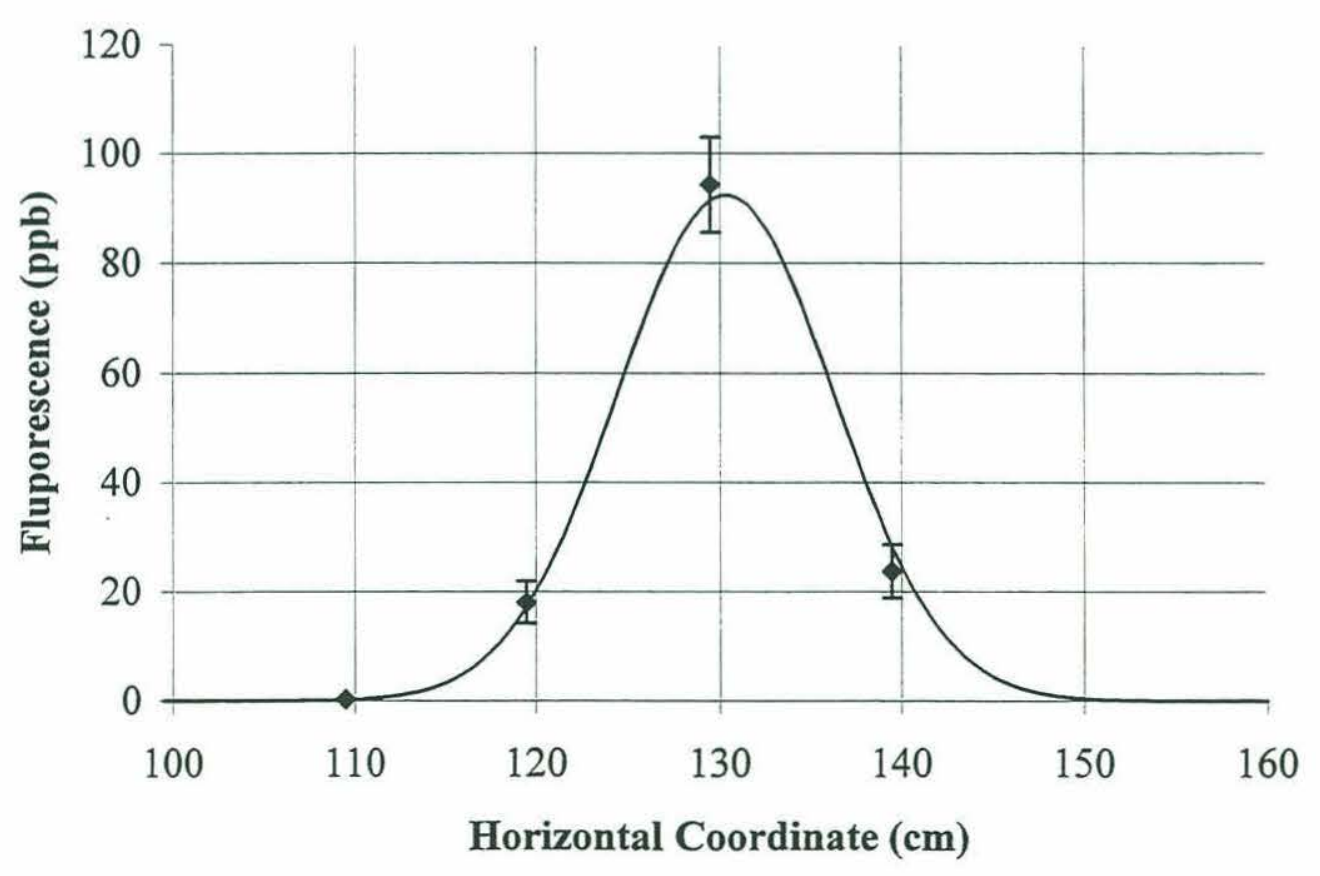

Figure A-12: Profile H-2L - August 7th, Set A, Points 1-4 


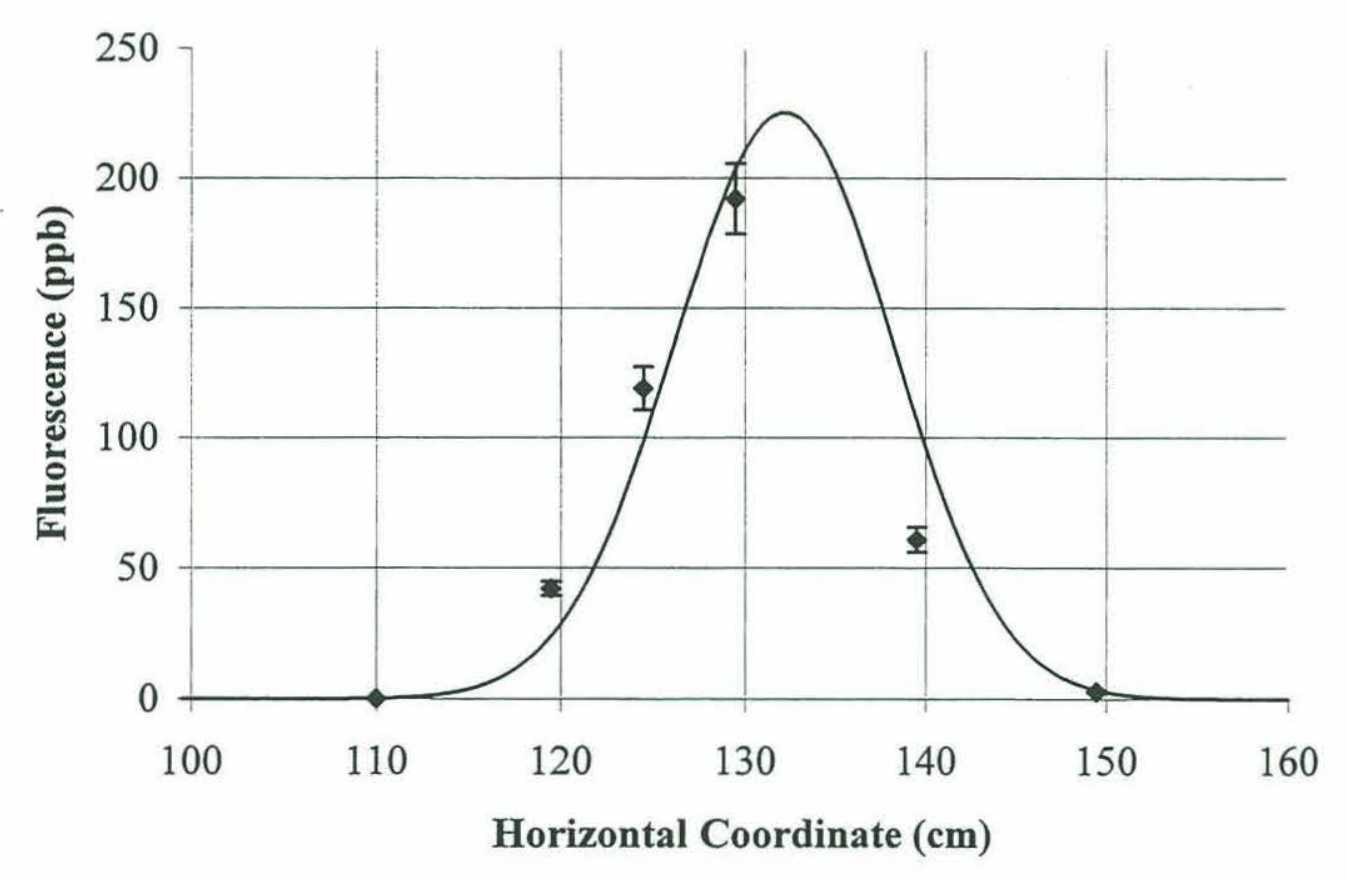

Figure A-13: Profile H-3L - August 7th, Set A, Points 5-10

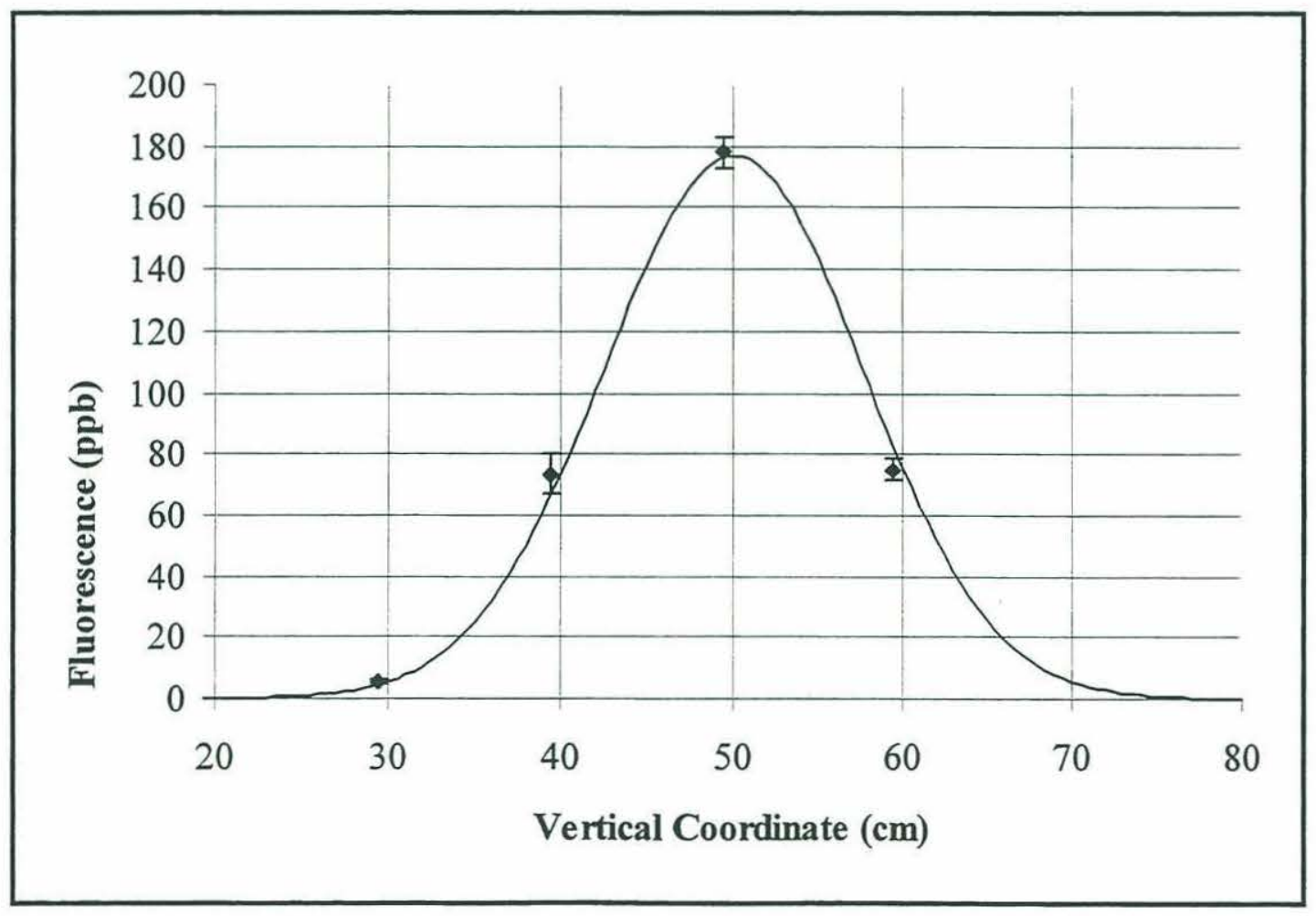

Figure A-14: Profile V-3L - August 7th, Set A, Points 11-14 


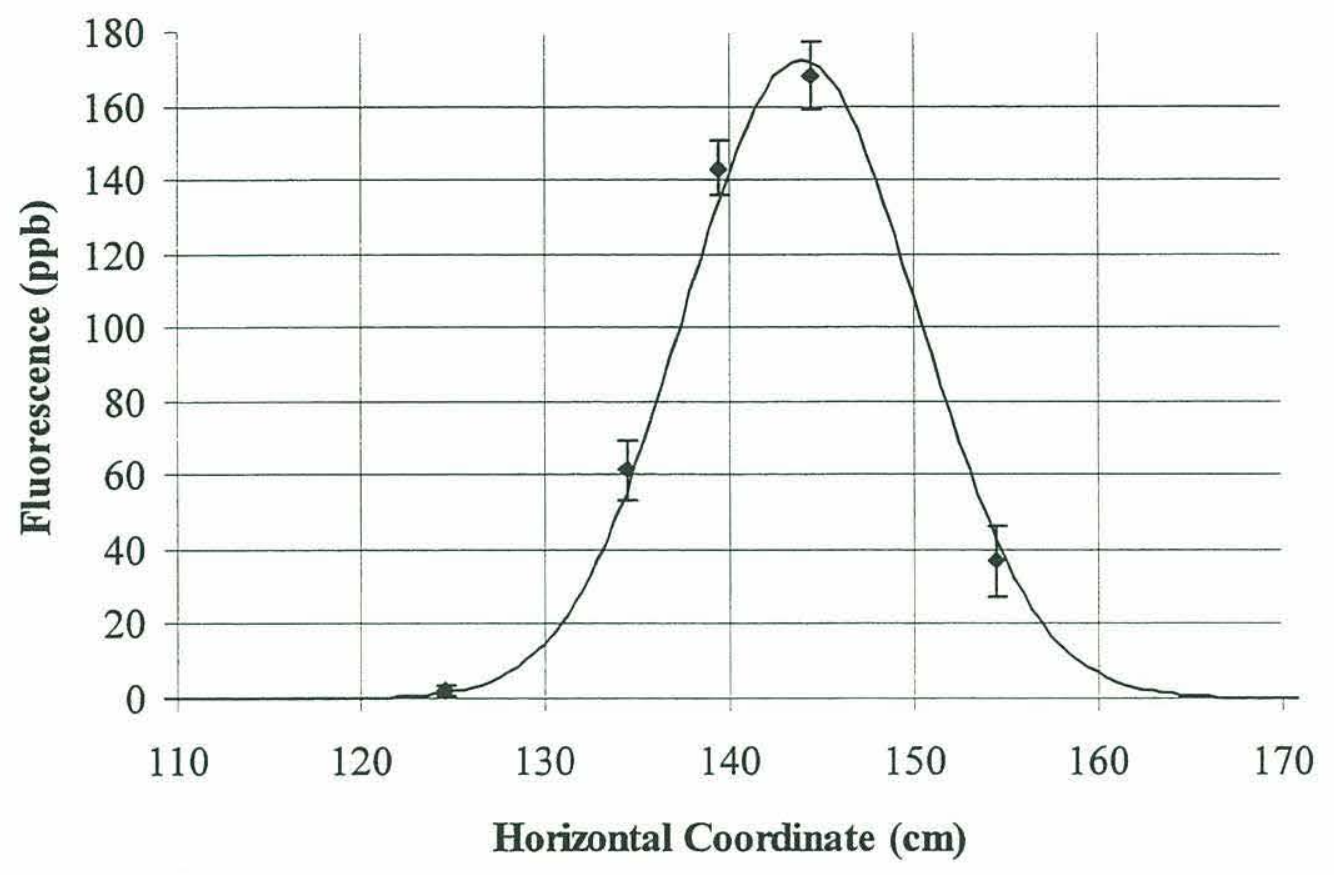

Figure A-15: Profile H-4L - August 7th, Set B, Points 1-5

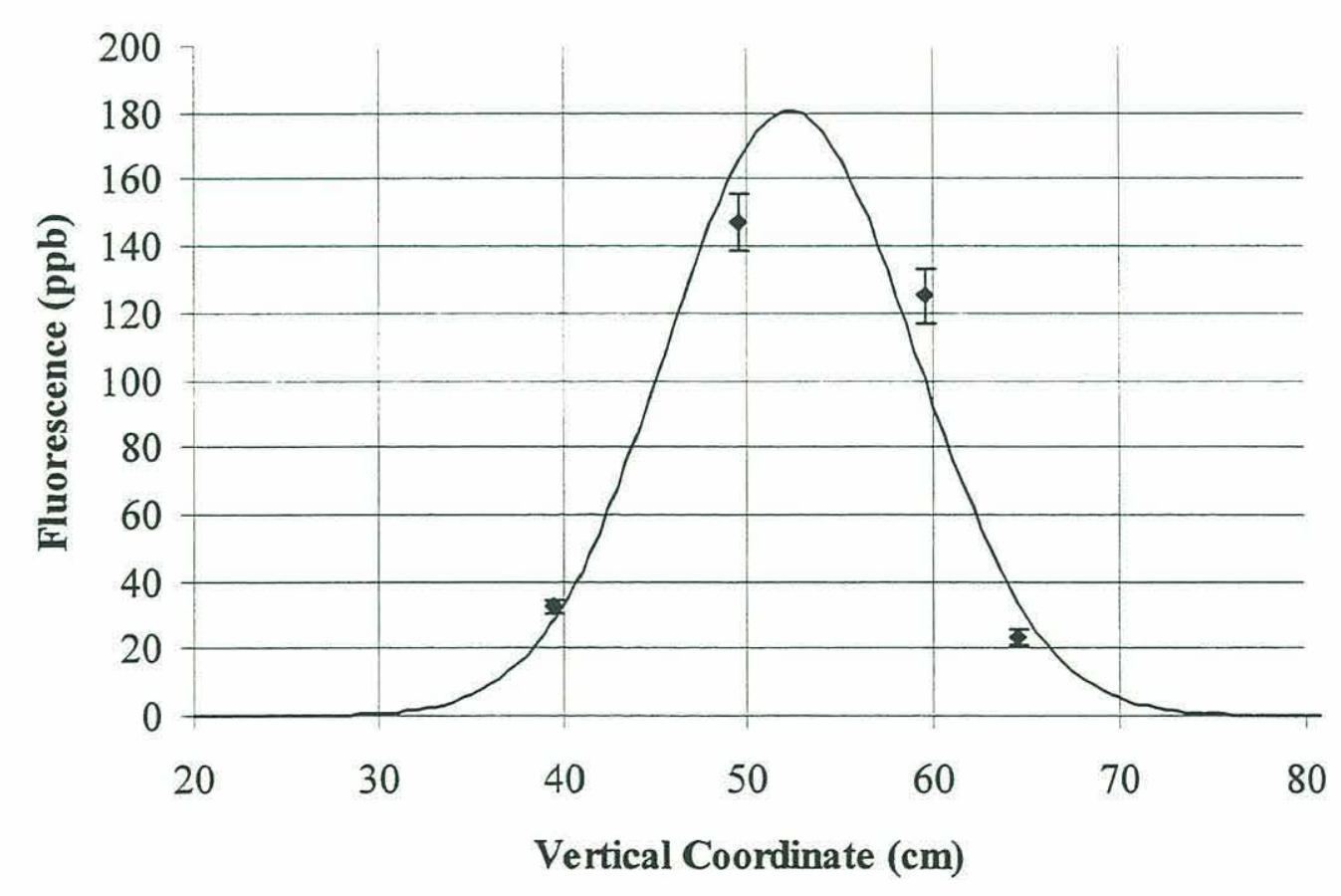

Figure A-16: Profile V-4L - August 7th, Set B, Points 6-9 


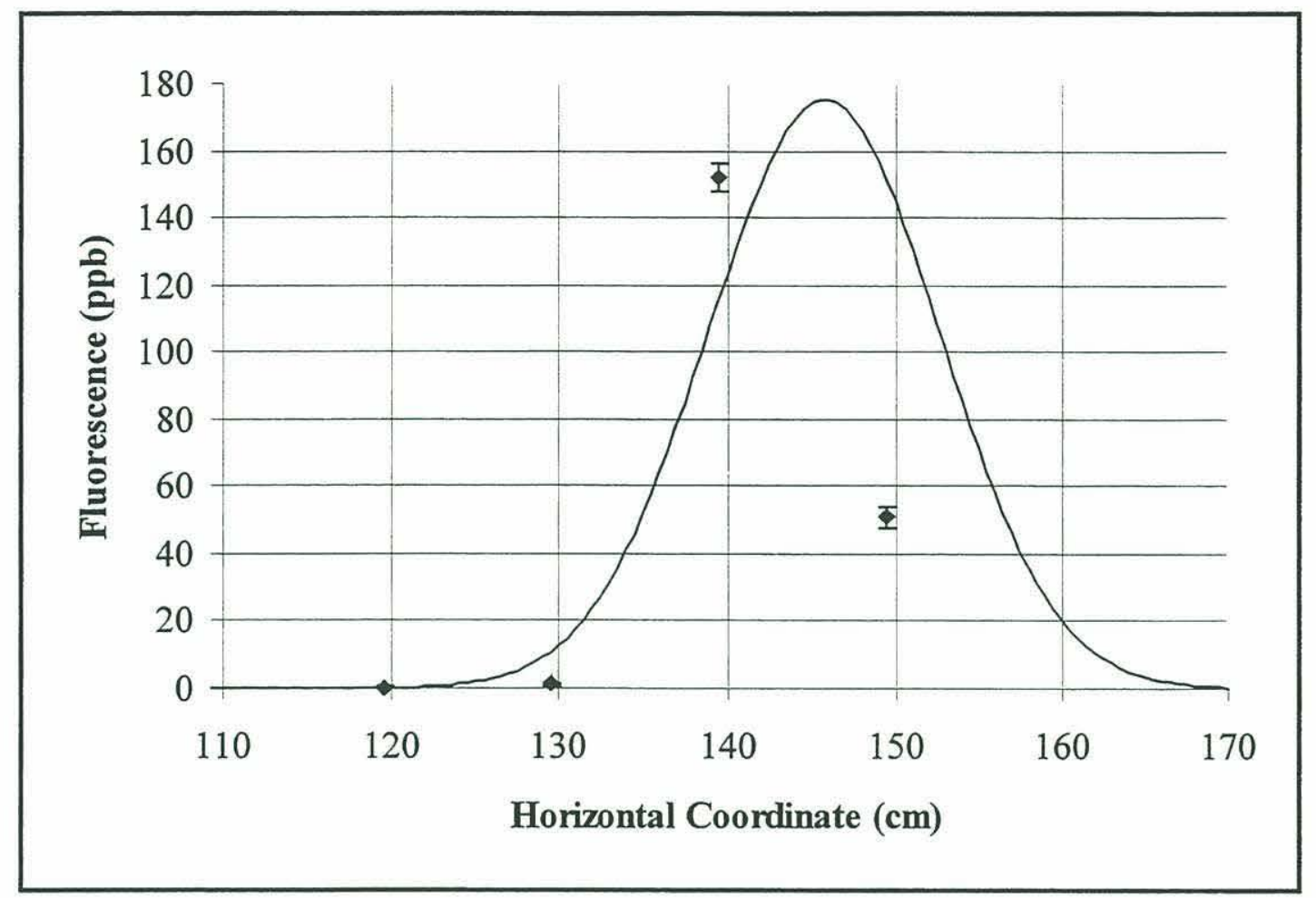

Figure A-17: Profile H-5L - August 7th, Set B, Points 11-14

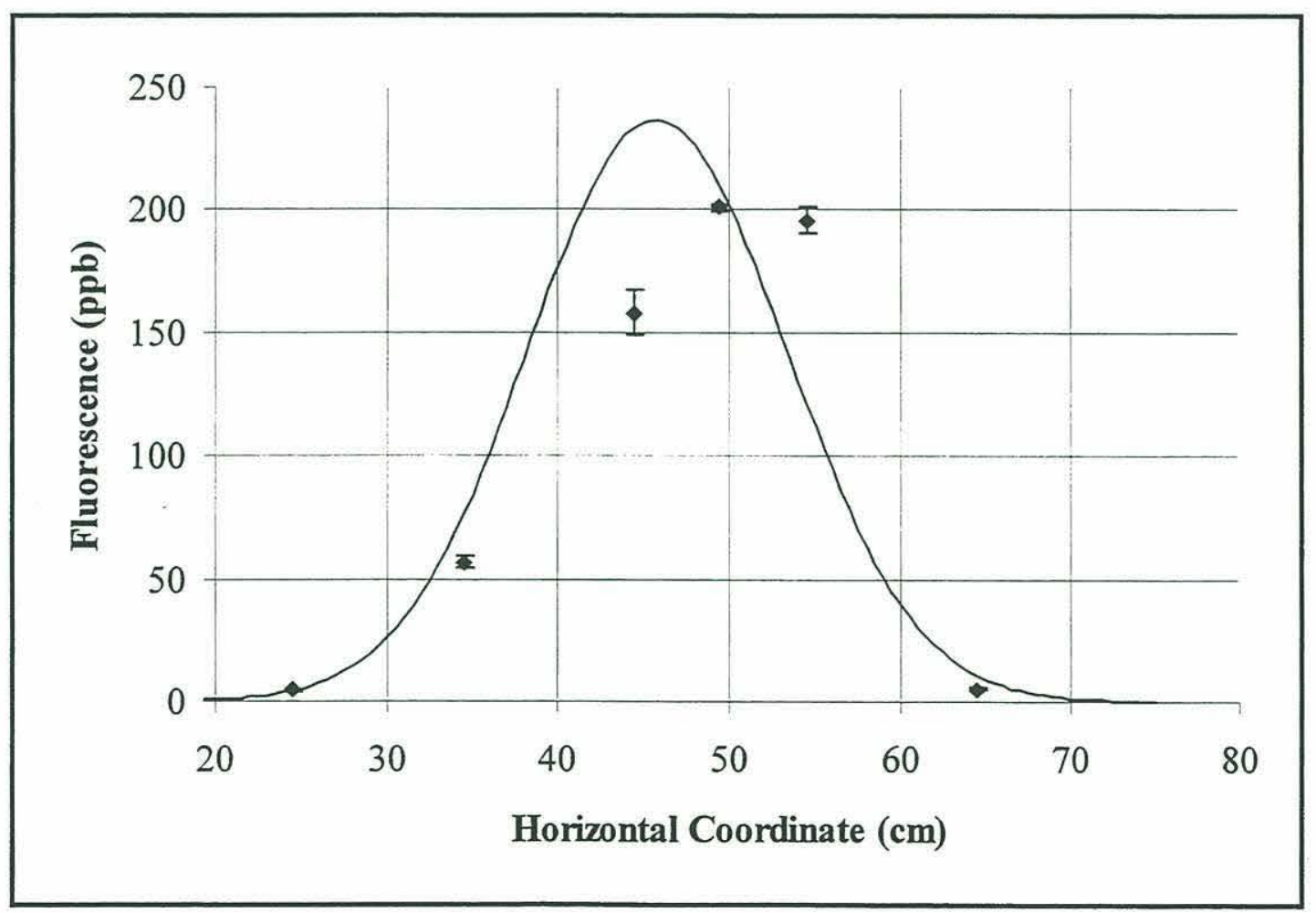

Figure A-18: Profile H-1M - August 2nd, Set A, Points 5-10 


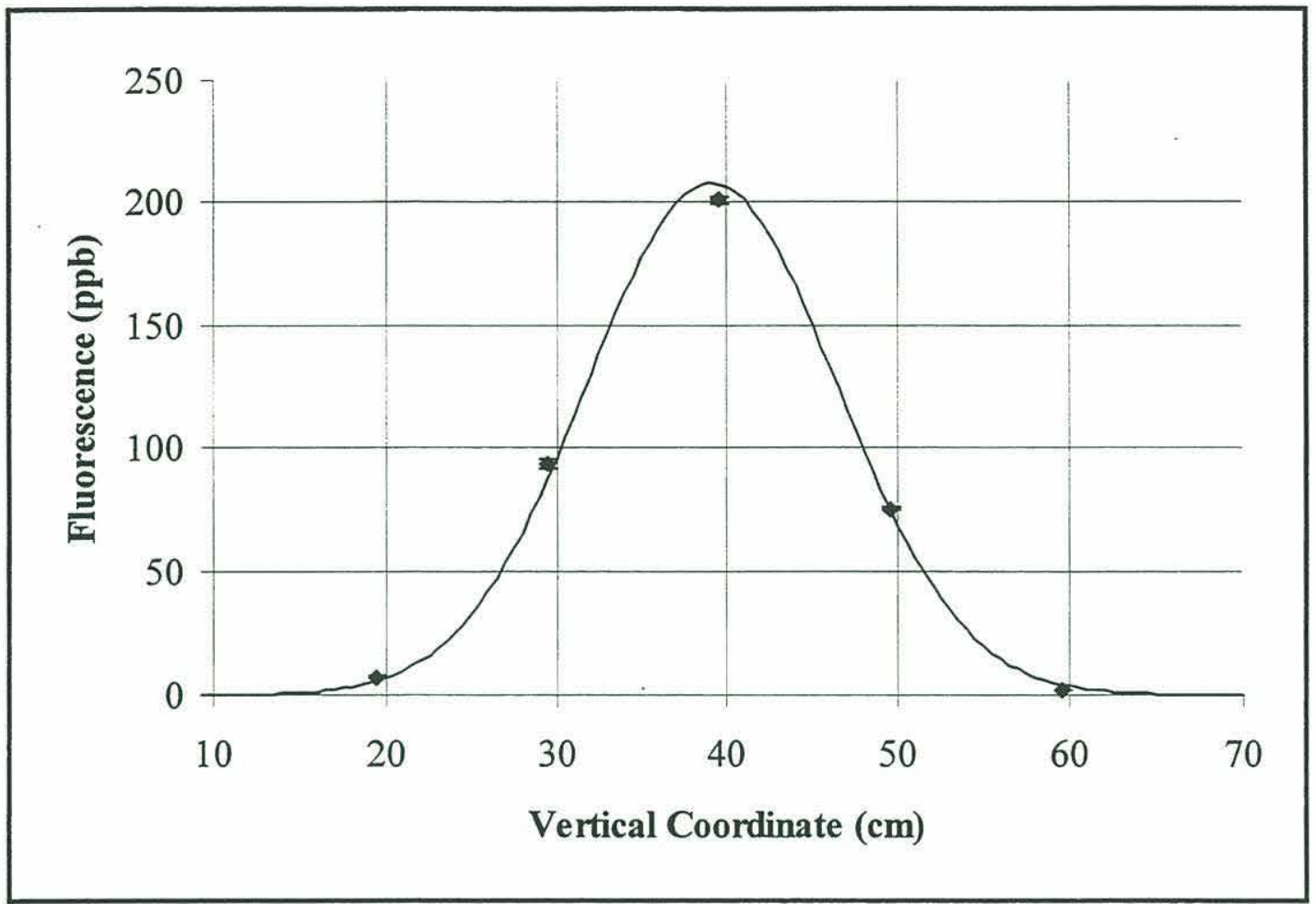

Figure A-19: Profile V-1M - August 2nd, Set A, Points 10-14

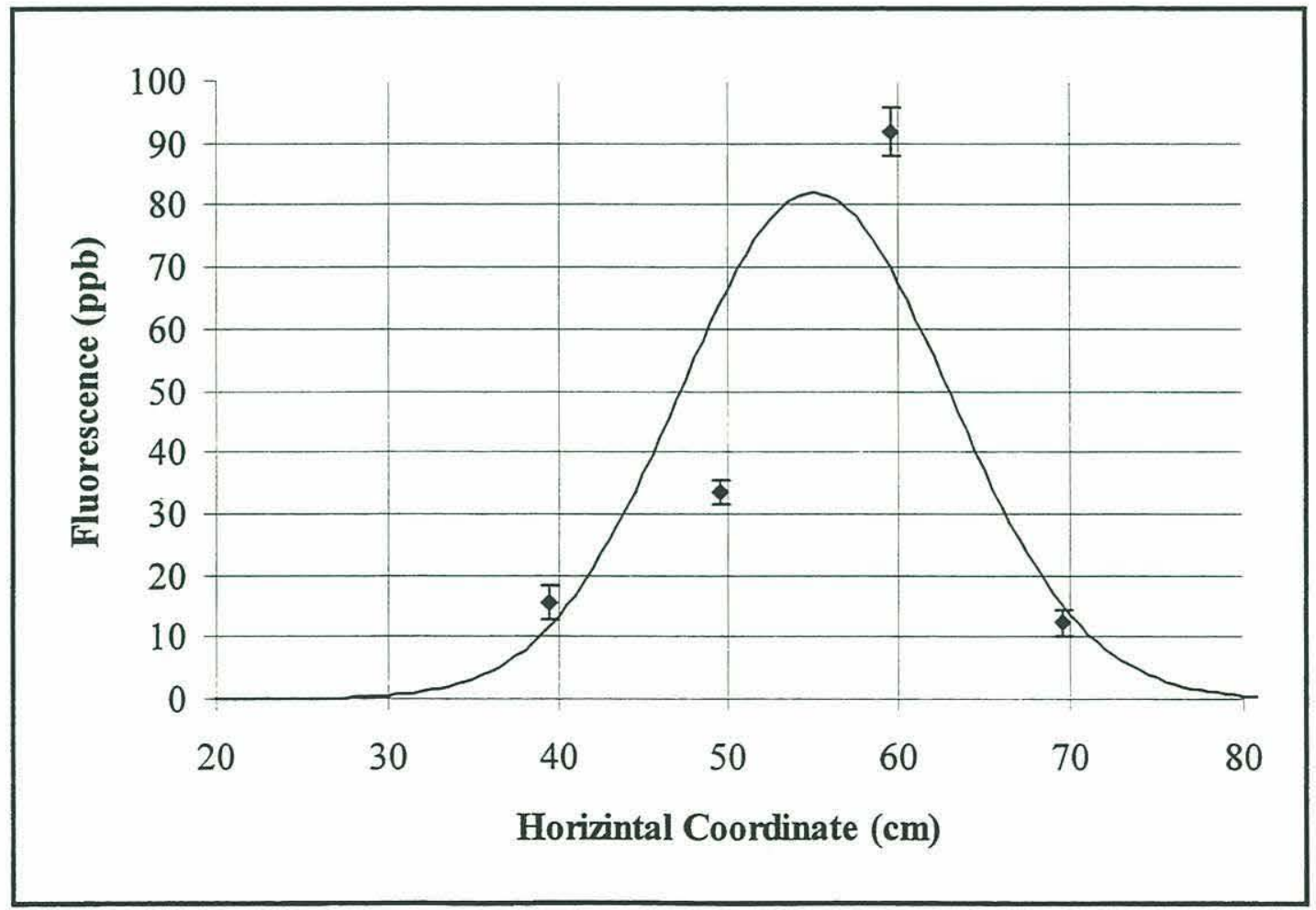

Figure A-20: Profile H-2M - August 2nd, Set B, Points 3-6 


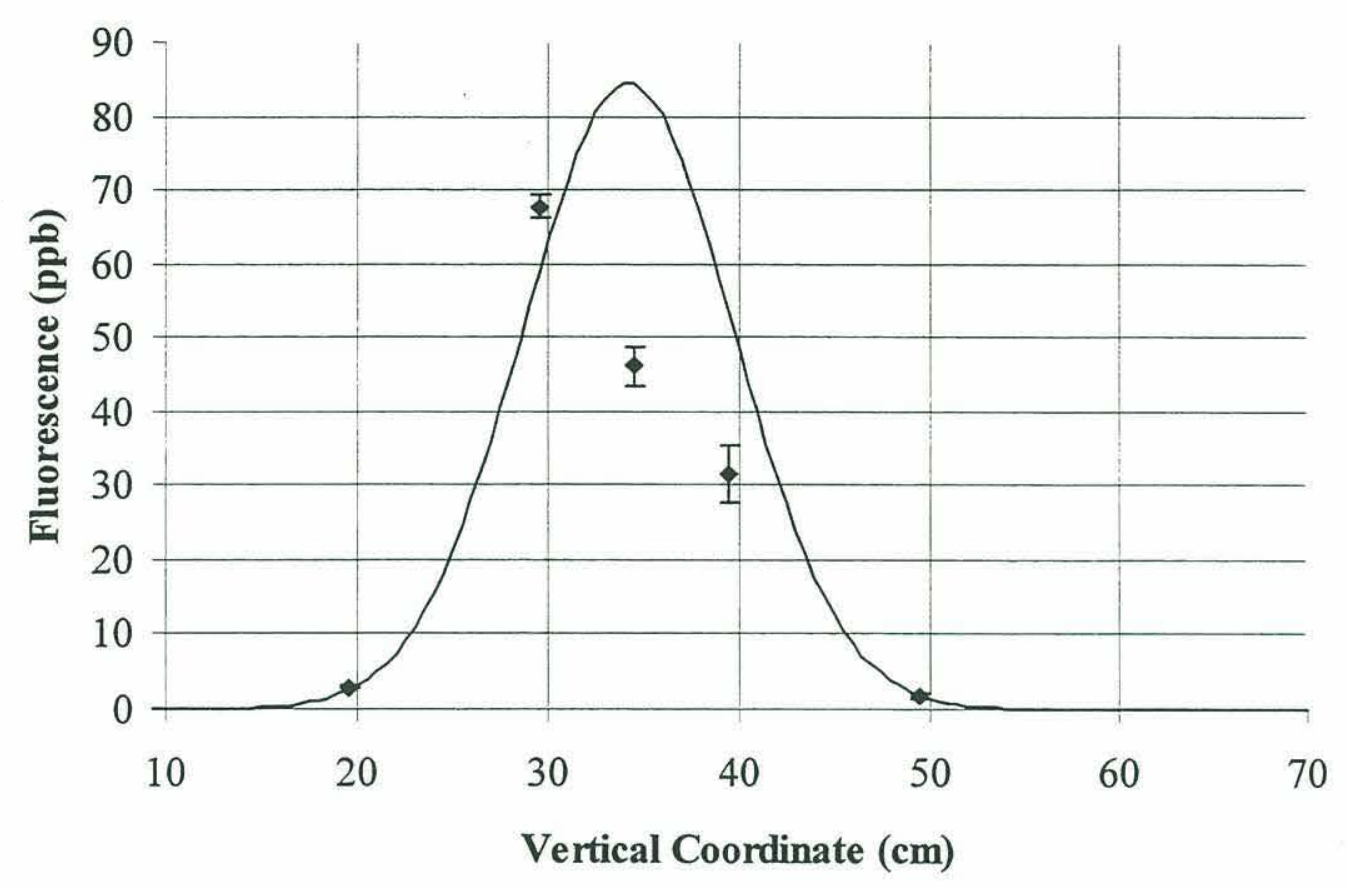

Figure A-21: Profile V-2M - August 2nd, Set B, Points 9-13

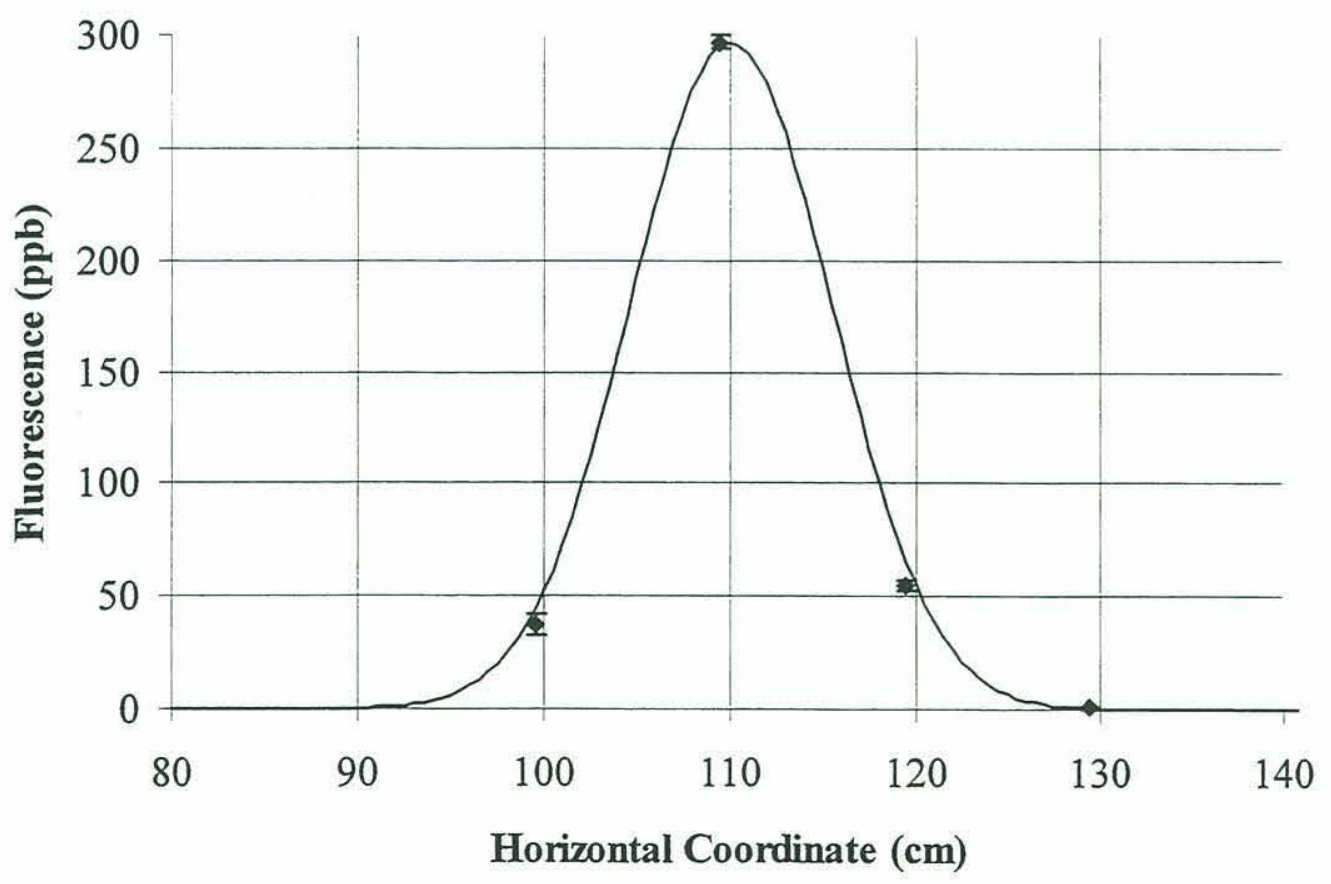

Figure A-22: Profile H-3M - August 5th, Set A, Points 1-4 


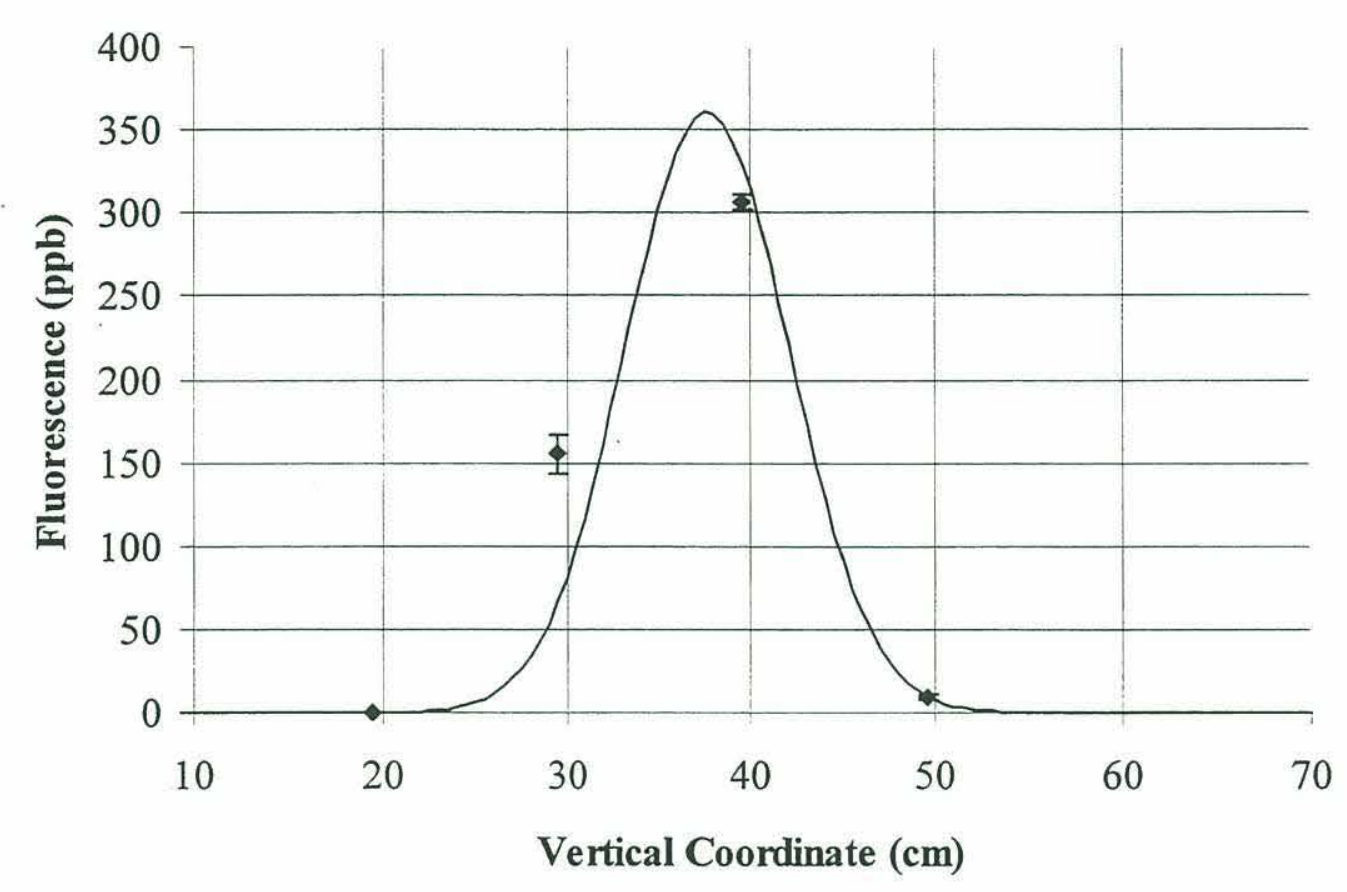

Figure A-23: Profile V-3M - August 5th, Set A, Points 5-8

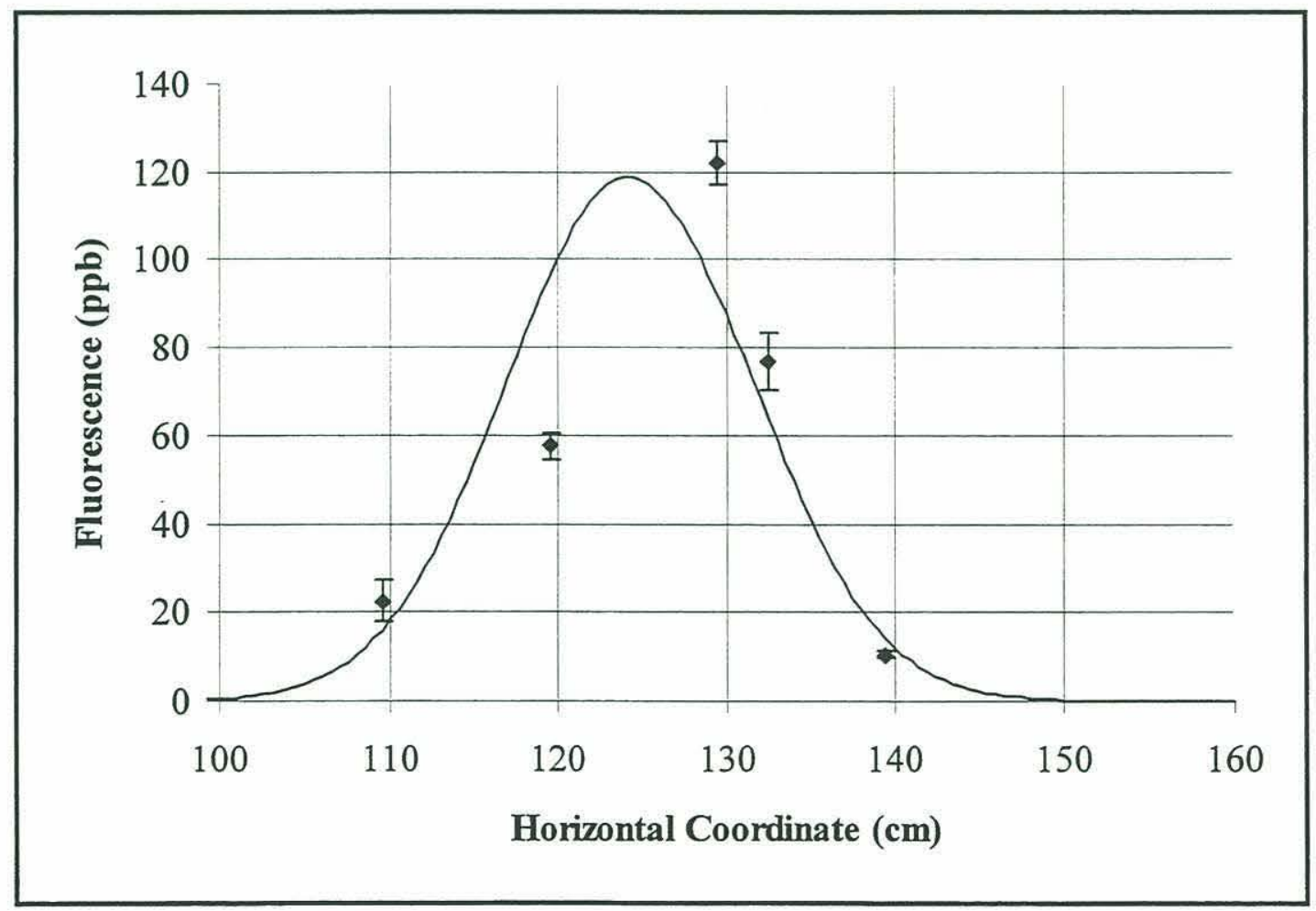

Figure A-24: Profile H-4M - August 5th, Set B, Points 1-5 


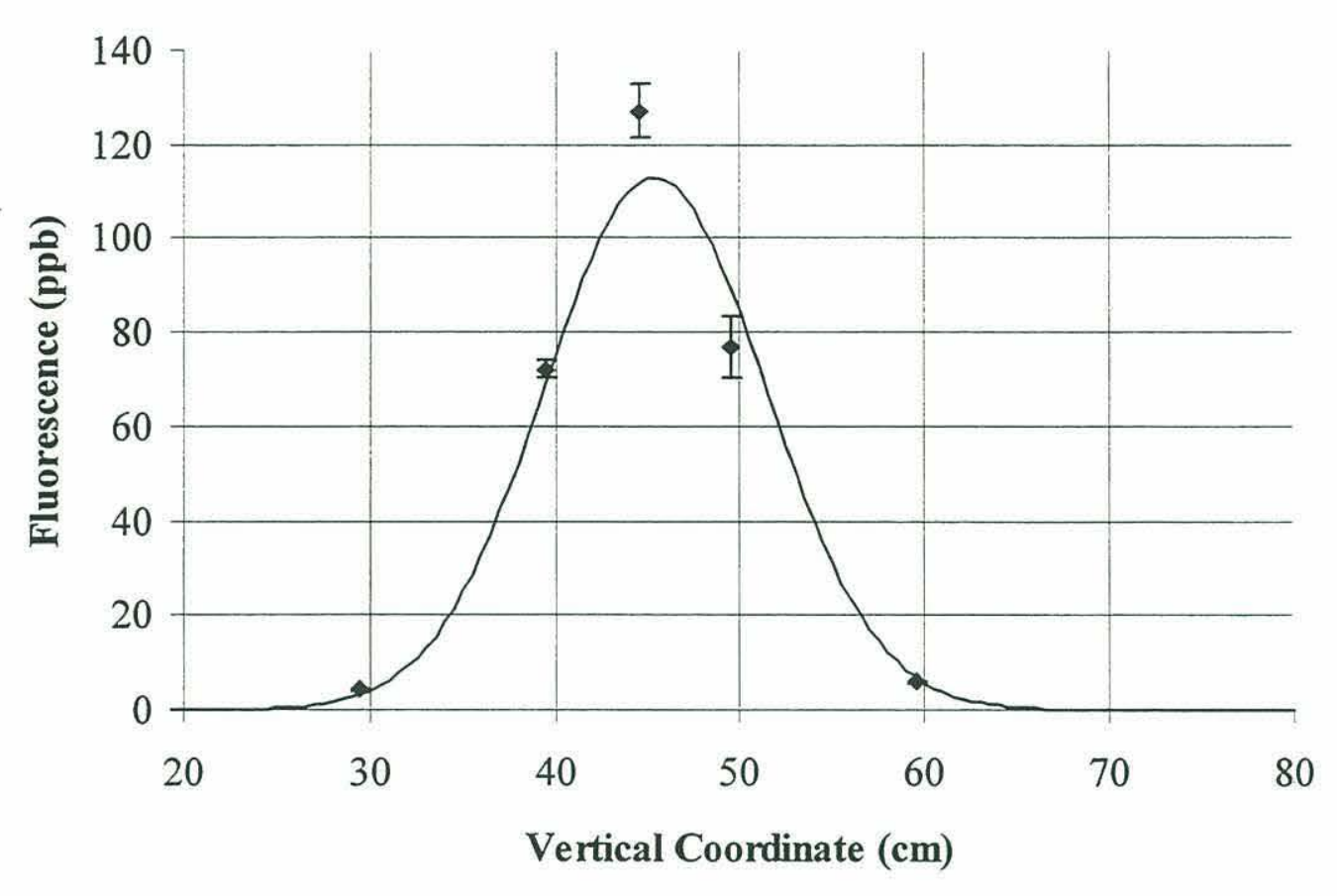

Figure A-25: Profile V-4M - August 5th, Set B, Points 5-9

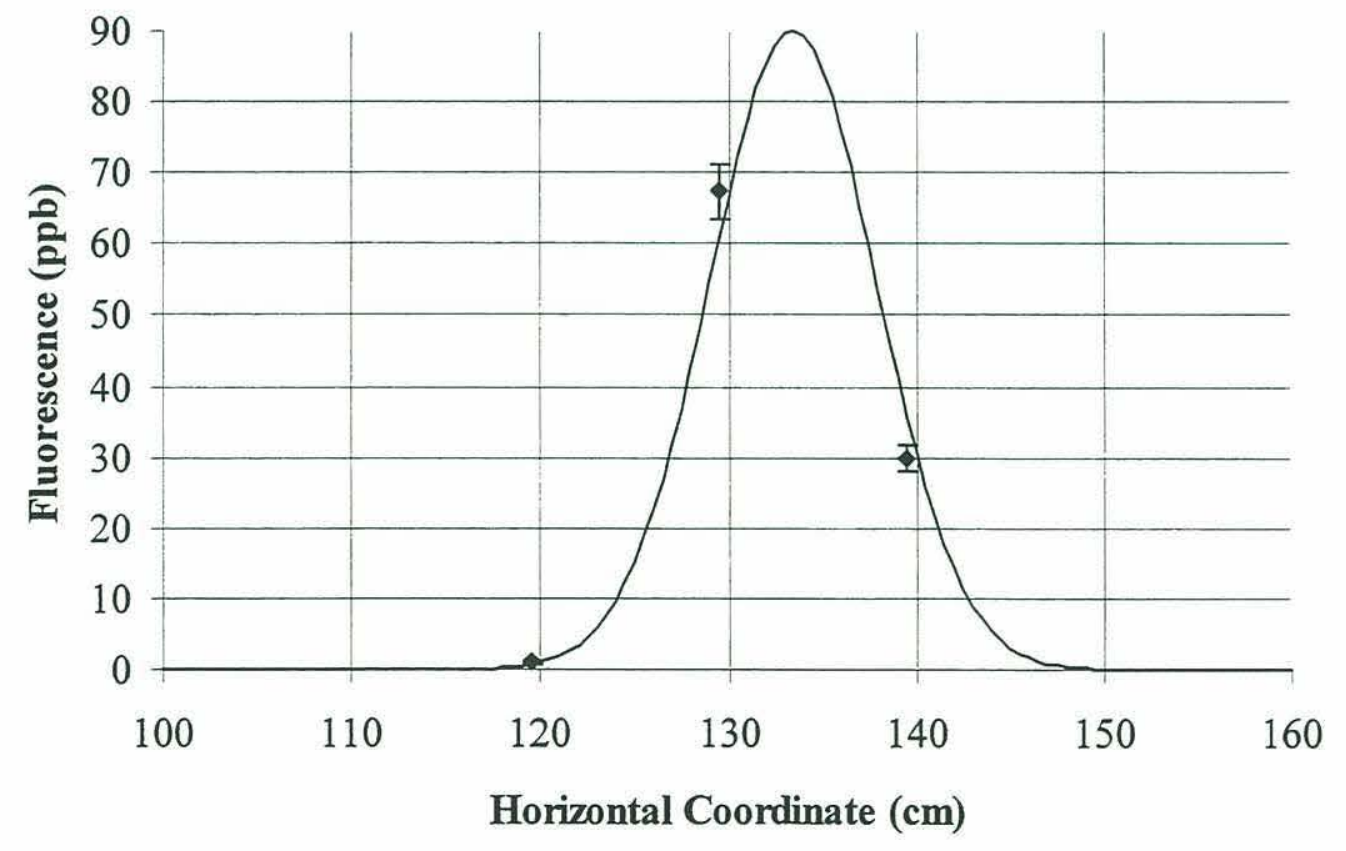

Figure A-26: Profile H-5M - August 5th, Set C, Points 1-3 


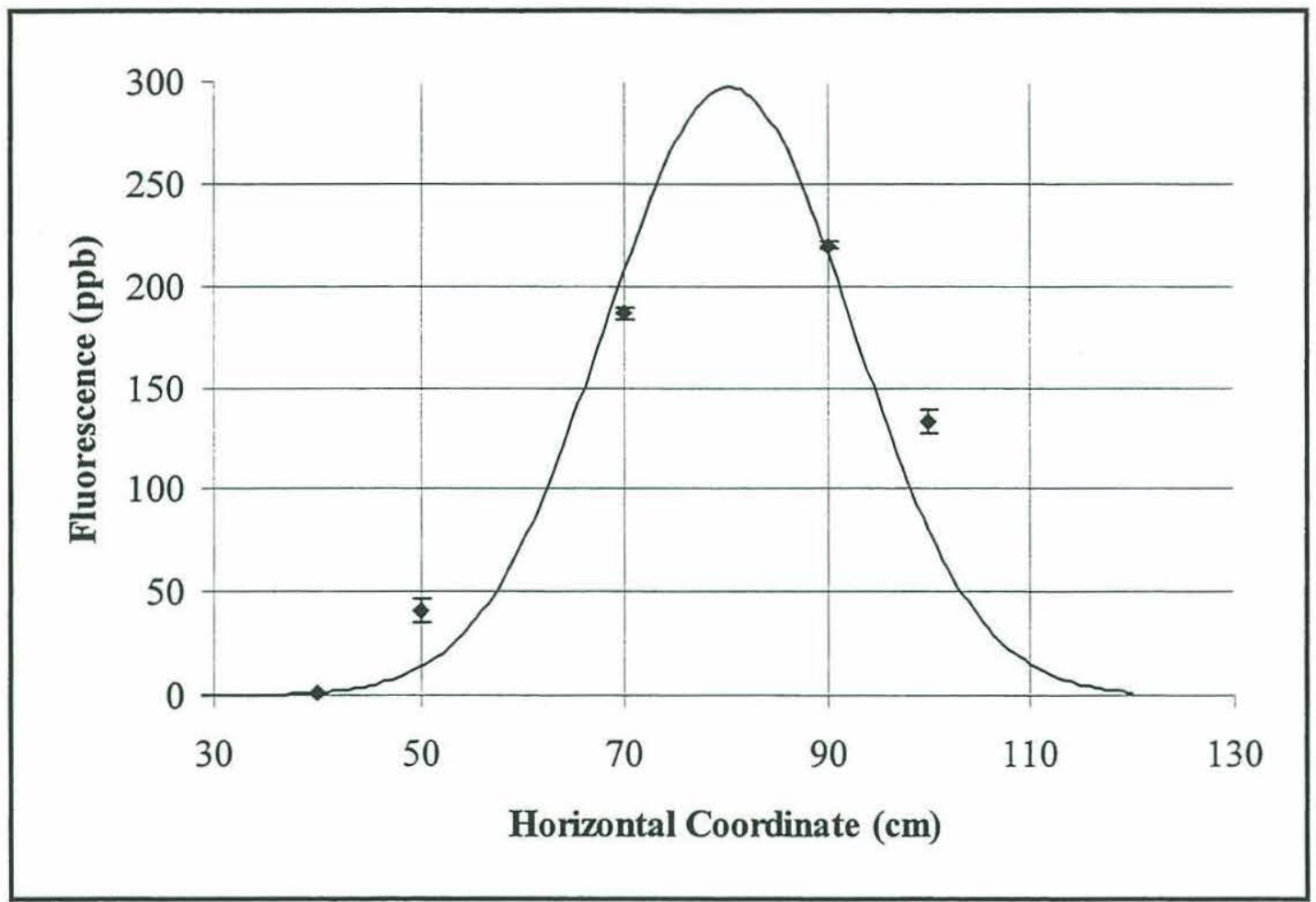

Figure A-27: Profile H-1H - July 31st, Set B, Points 2-6

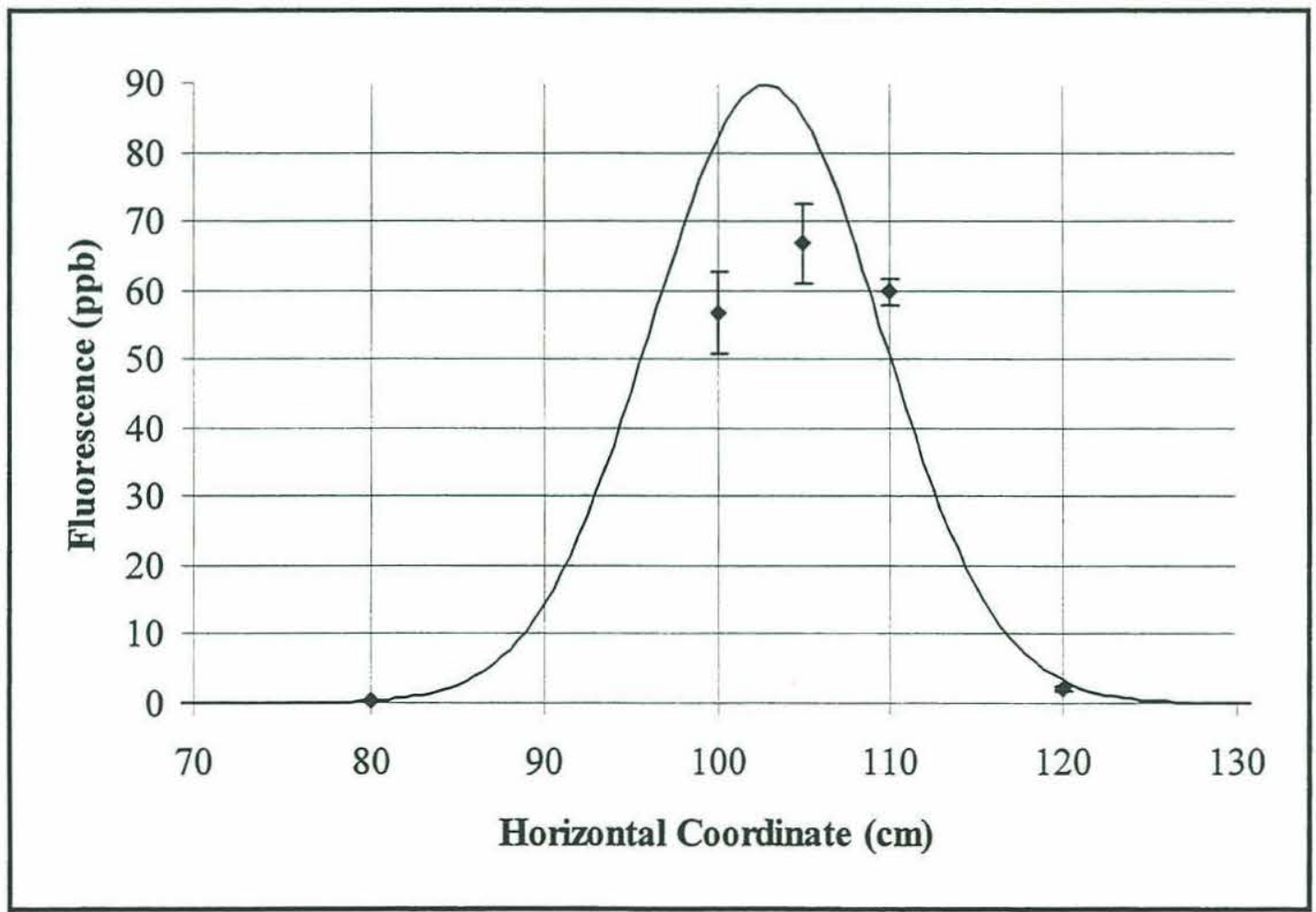

Figure A-28: Profile H-2H - July 31st, Set C, Points 1-5 


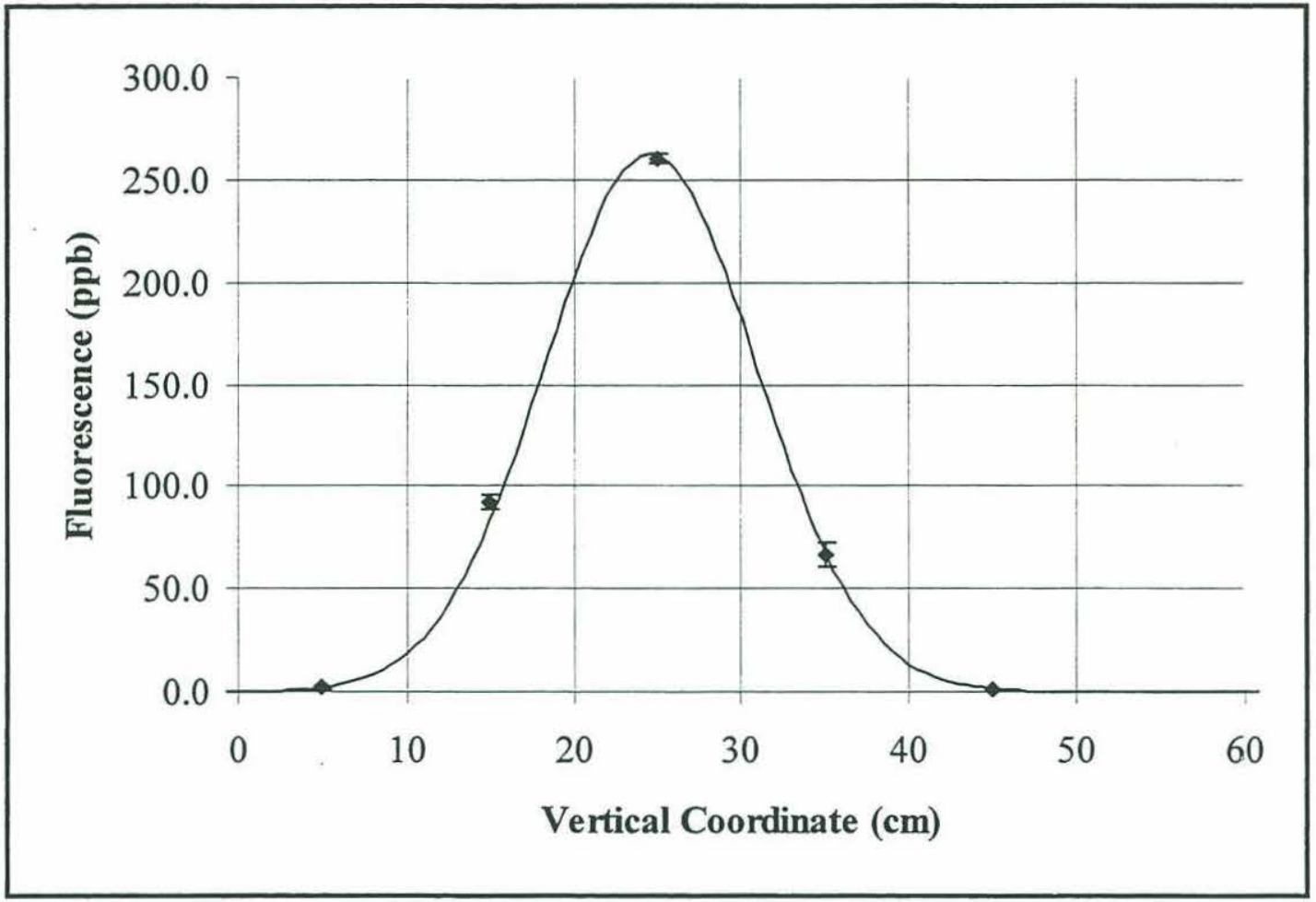

Figure A-29: Profile V-1H - July 31, Set C, Points 5-9

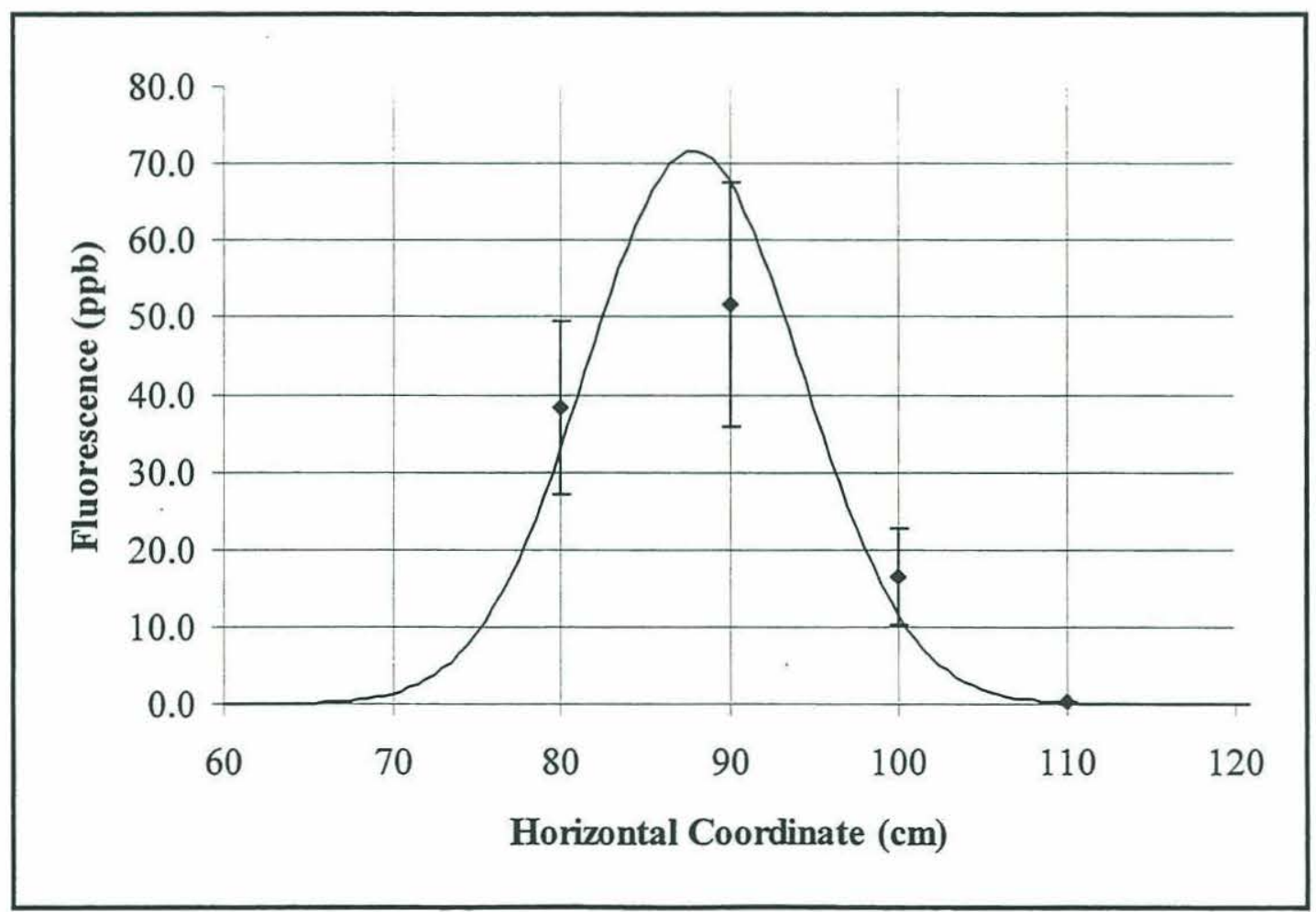

Figure A-30: Profile H-1Z - July 24th, Set C, Points 2-5 


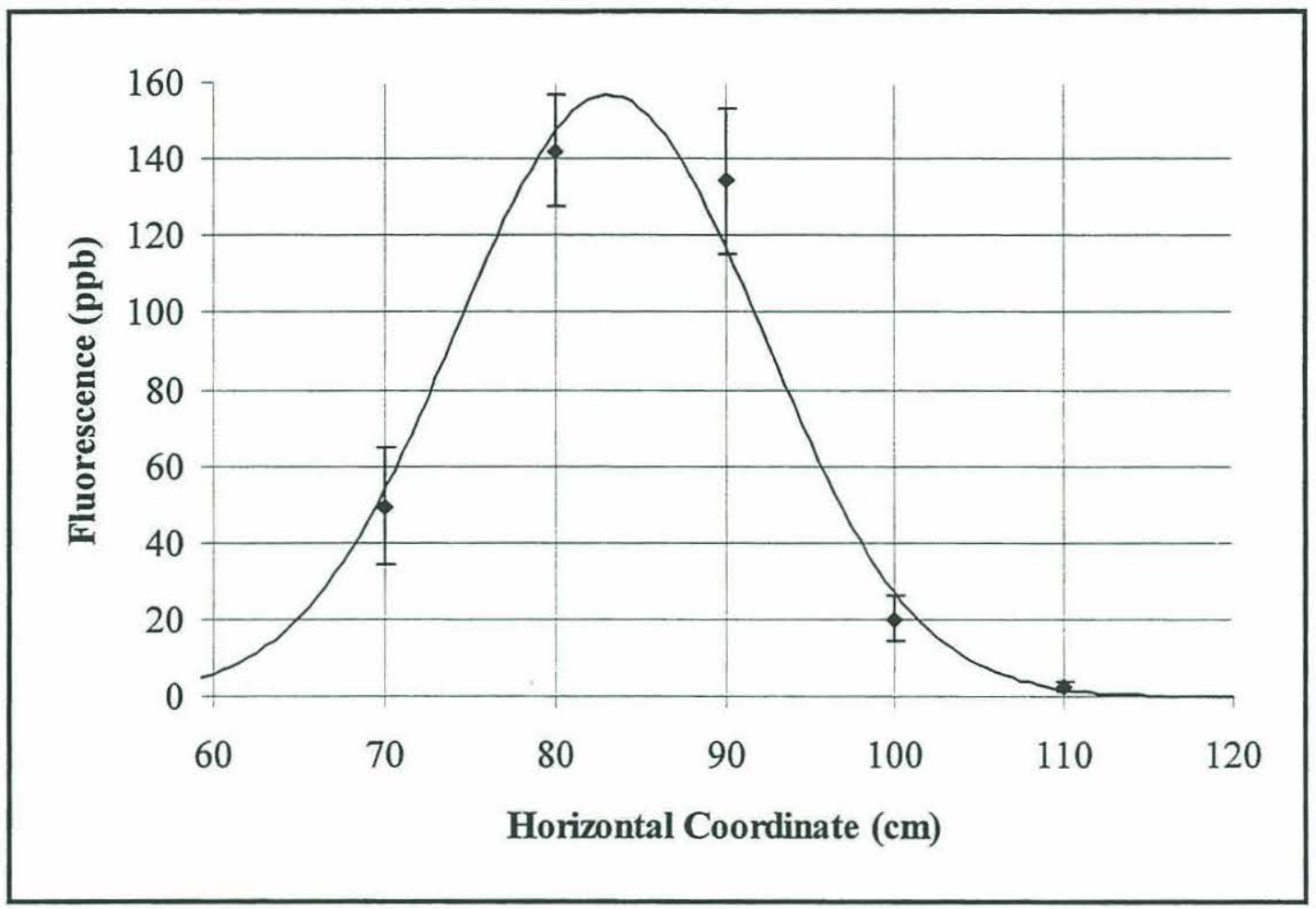

Figure A-31: Profile H-2Z - July 24th, Set C, Points 6-10

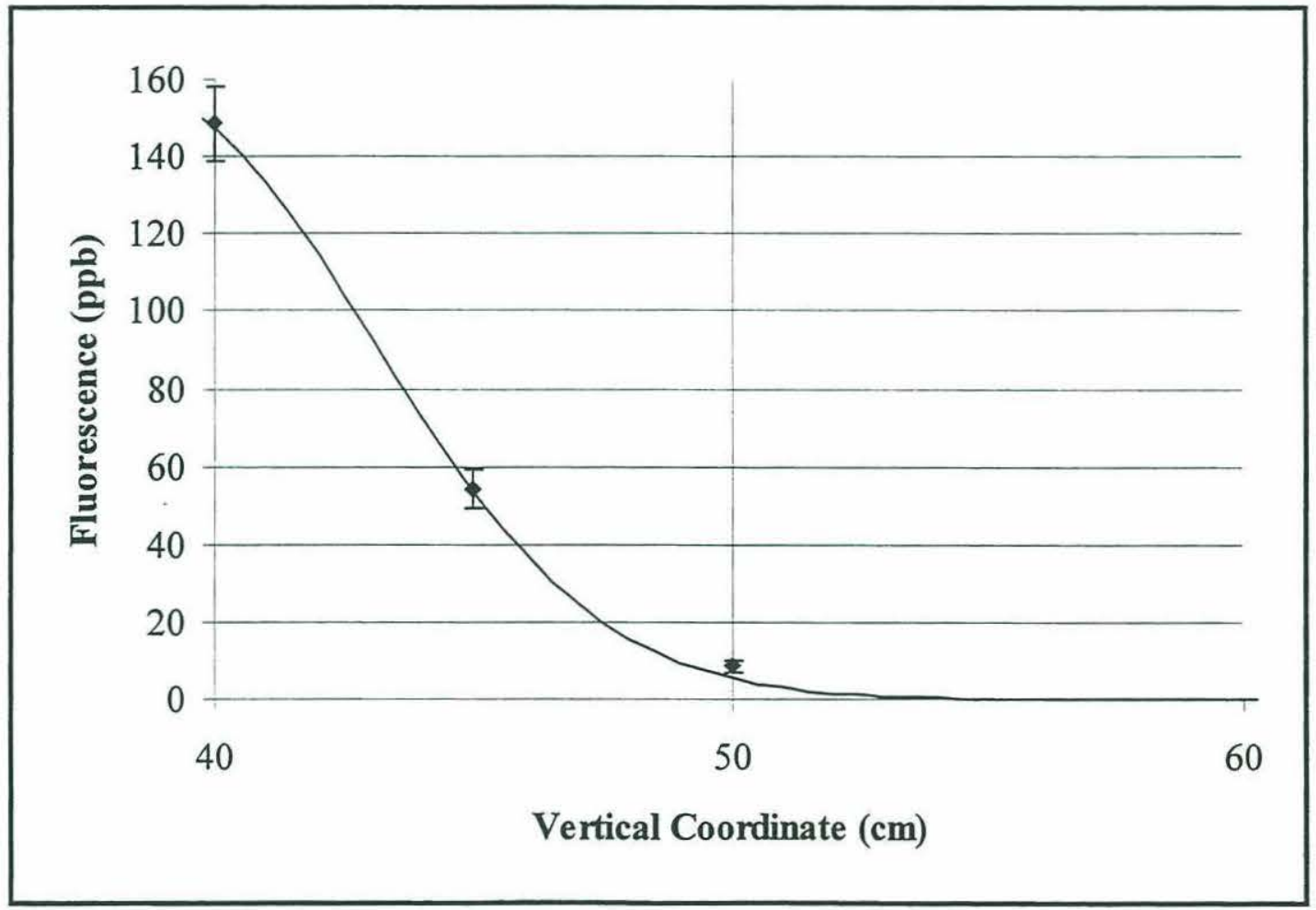

Figure A-32: Profile V-1Z - August 8th, Set A, Points 10-12 


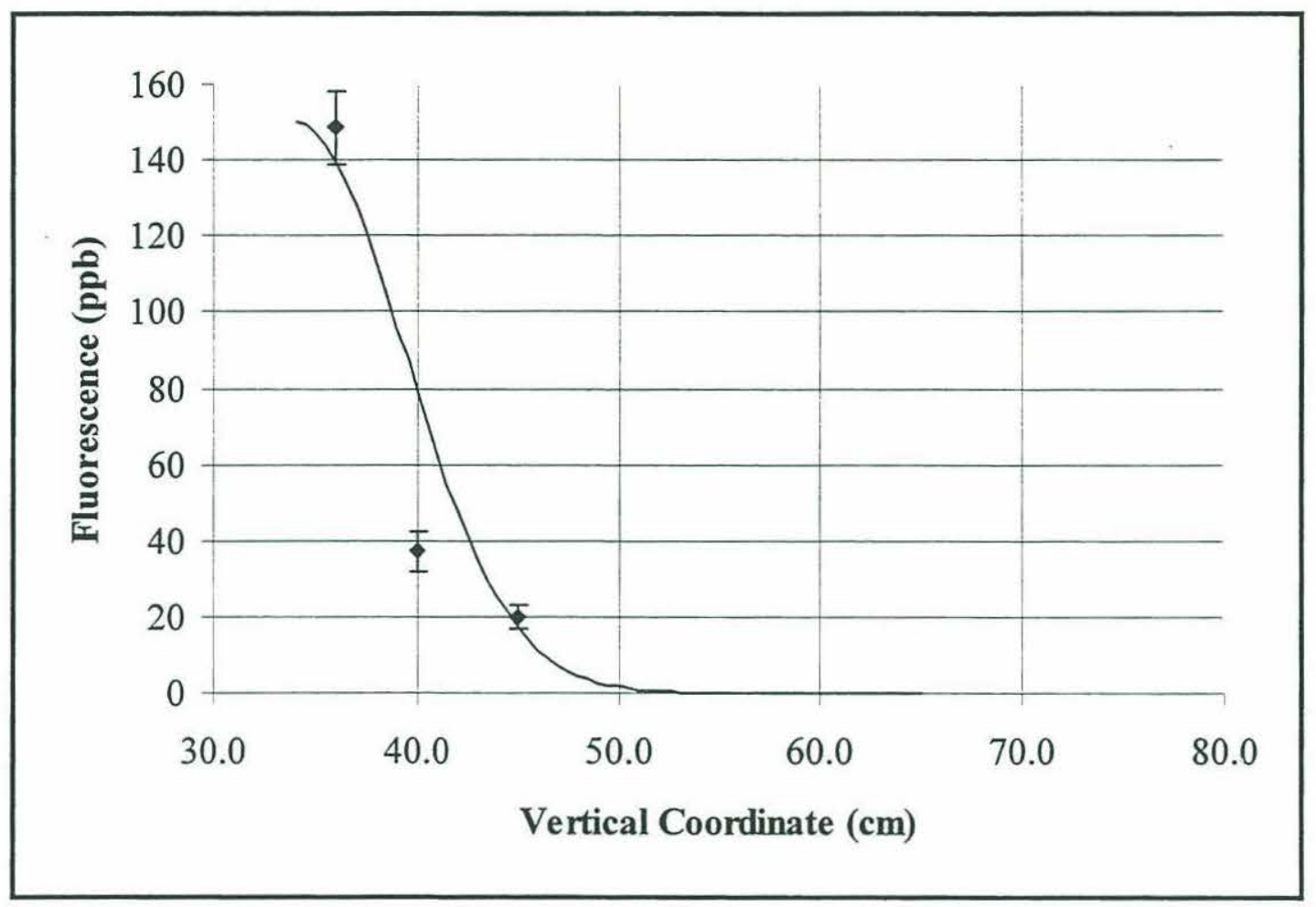

Figure A-33: Profile V-2Z - August 8th, Set A, Points 12-14

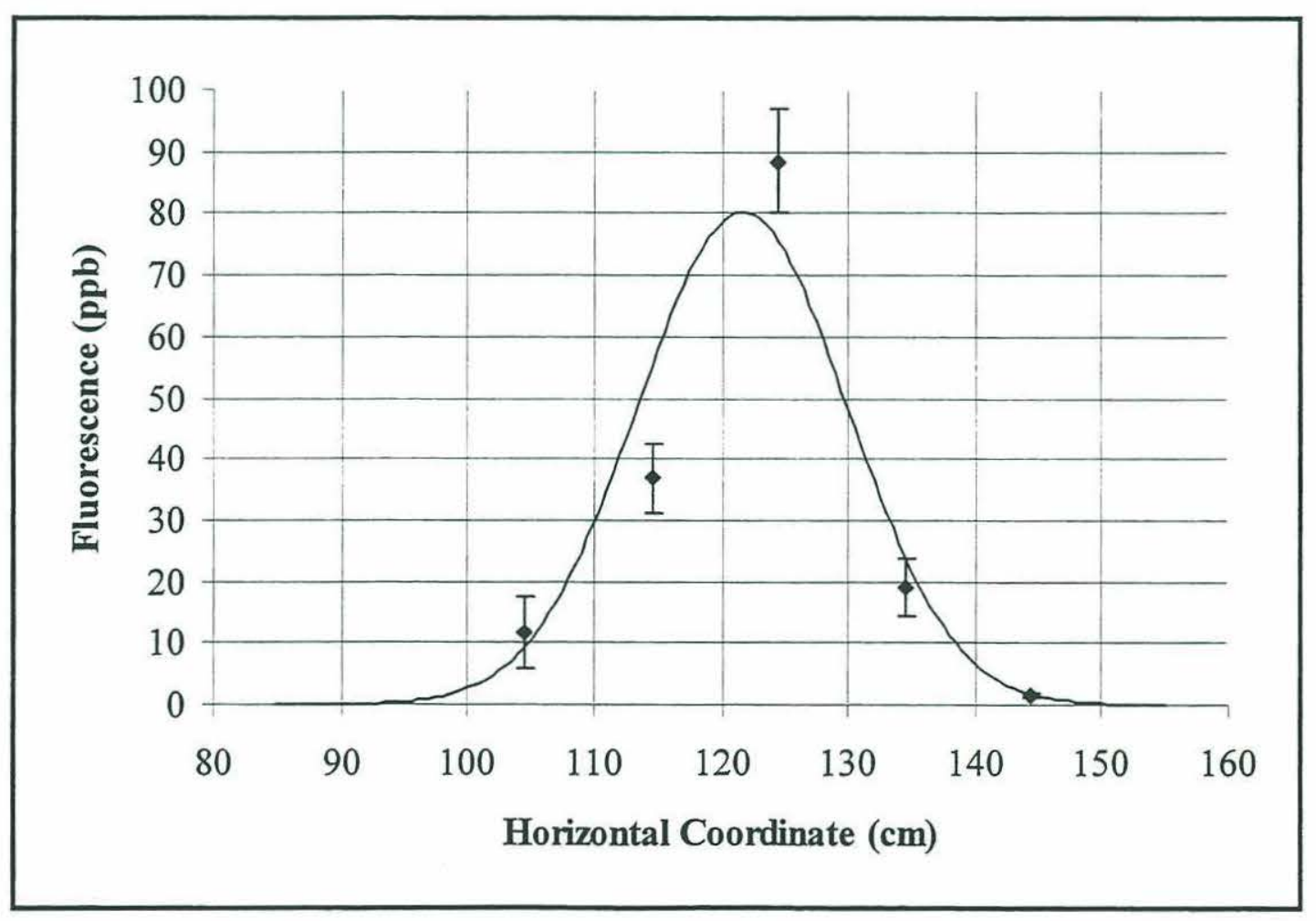

Figure A-34: Profile H-3Z - August 8th, Set A, Points 15-19 


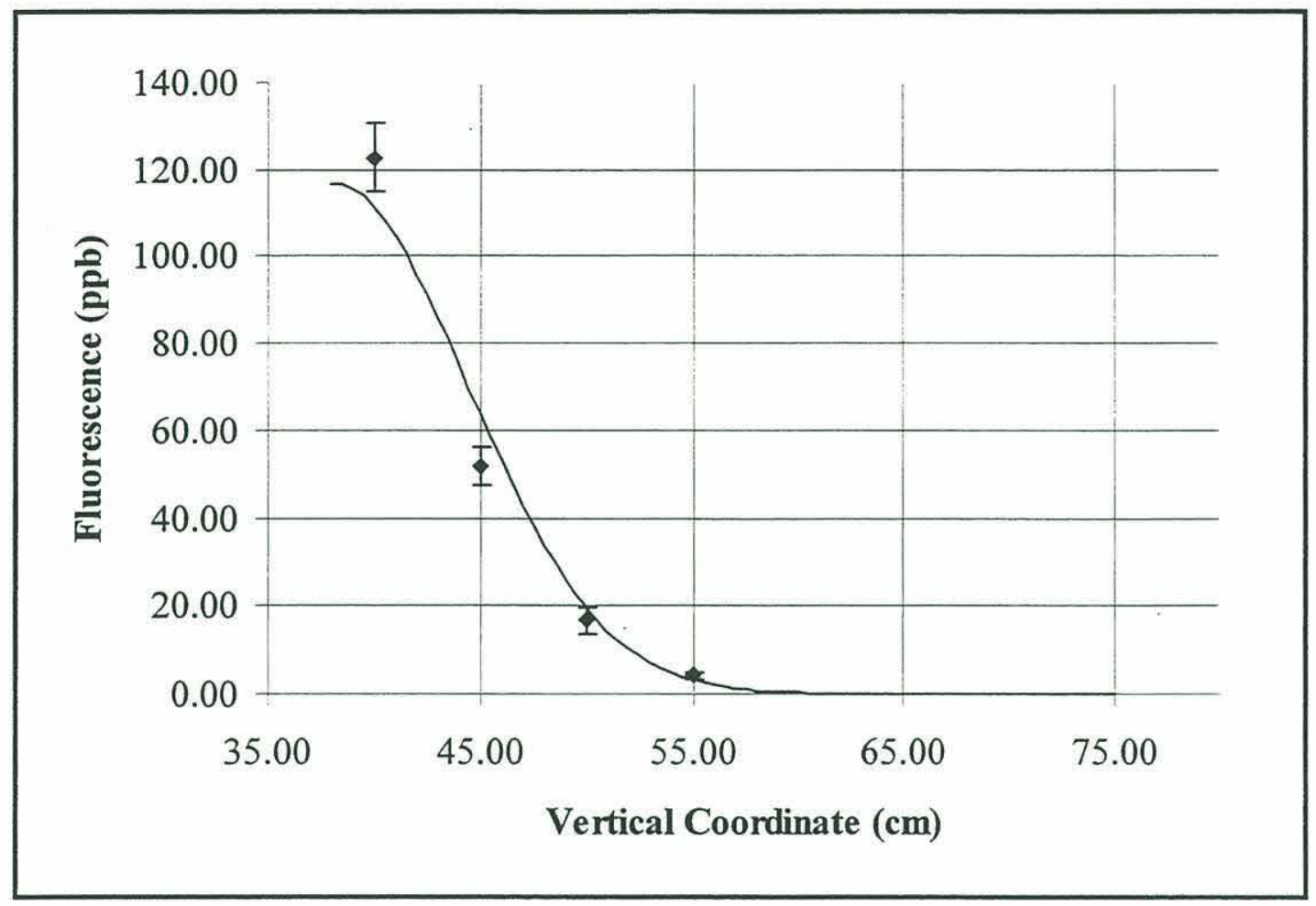

Figure A-35: Profile V-3Z - August 8th, Set A, Points 20-23 


\section{Appendix B - Daily Data Summaries}

Data is presented for each day of field study. Setups on each day are designated as Run A, Run B, and so on. Data is also included on current and water depth measurements. 


\section{July $24^{\text {th }}$ Data}

\section{Run C}

\begin{tabular}{rlrrrrrr} 
Point & Time & H. Coord. V. Coord. & F (ppb) & sigma F & \# of pts. & \multicolumn{1}{c}{ Error } \\
1 & $3: 57: 00$ & 100.00 & 55.00 & 20.60 & 49.40 & 661.00 & 3.77 \\
2 & $4: 04: 00$ & 80.00 & 55.00 & 38.40 & 62.20 & 118.00 & 11.20 \\
3 & $4: 06: 00$ & 90.00 & 55.00 & 51.70 & 76.80 & 91.00 & 15.80 \\
4 & $4: 08: 20$ & 100.00 & 55.00 & 16.40 & 30.20 & 91.00 & 6.20 \\
5 & $4: 10: 20$ & 110.00 & 55.00 & 0.16 & 0.13 & 86.00 & 0.03 \\
6 & $4: 12: 45$ & 110.00 & 45.00 & 2.49 & 6.20 & 76.00 & 1.39 \\
7 & $4: 14: 00$ & 100.00 & 45.00 & 20.10 & 29.50 & 91.00 & 6.07 \\
8 & $4: 16: 00$ & 90.00 & 45.00 & 134.00 & 93.90 & 91.00 & 19.30 \\
9 & $4: 18: 30$ & 80.00 & 45.00 & 142.00 & 71.70 & 91.00 & 14.70 \\
10 & $4: 20: 30$ & 70.00 & 45.00 & 49.50 & 73.50 & 91.00 & 15.10 \\
11 & $4: 22: 30$ & 80.00 & 35.00 & 18.60 & 33.00 & 91.00 & 6.79 \\
12 & $4: 24: 30$ & 90.00 & 35.00 & 10.10 & 18.90 & 91.00 & 3.88 \\
13 & $4: 26: 30$ & 100.00 & 35.00 & 16.70 & 17.50 & 91.00 & 3.59 \\
14 & $4: 28: 30$ & 110.00 & 35.00 & 19.50 & 26.10 & 241.00 & 3.30
\end{tabular}

\section{Currents}

\begin{tabular}{rrrrrrr} 
Point & Time & Current & \multicolumn{1}{c}{ Sigma } & Readings & Error & Depth \\
1 & $3: 45$ & 7.01 & 1.17 & 3 & 1.97 & $27 "$ \\
2 & $4: 00$ & 7.61 & 0.96 & 5 & 0.91 & \\
3 & $4: 30$ & 11.53 & 0.26 & 6 & 0.21 & $22 "$
\end{tabular}

\begin{tabular}{|c|c|c|c|c|c|c|c|c|}
\hline \multicolumn{3}{|c|}{ Sample Time $=3: 00$} & \multicolumn{3}{|c|}{ Sample Time $=4: 00$} & \multicolumn{3}{|c|}{ Sample Time $=4: 30$} \\
\hline t (seconds) & $d(\mathrm{~cm})$ & $\mathrm{u}(\mathrm{cm} / \mathrm{sec})$ & $t$ (seconds) & $\mathrm{d}(\mathrm{cm})$ & $\mathrm{u}(\mathrm{cm} / \mathrm{sec})$ & t (seconds) & $\mathrm{d}(\mathrm{cm})$ & $\mathrm{u}(\mathrm{cm} / \mathrm{sec})$ \\
\hline 16.71 & 100 & 5.98 & 10.92 & 100 & 9.16 & 8.7 & 100 & 11.49 \\
\hline 14.80 & 100 & 6.76 & 15.14 & 100 & 6.61 & 8.43 & 100 & 11.86 \\
\hline \multirow[t]{7}{*}{12.06} & 100 & 8.29 & 12.91 & 100 & 7.75 & 8.65 & 100 & 11.56 \\
\hline & & & 13.57 & 100 & 7.37 & 8.8 & 100 & 11.36 \\
\hline & & & 13.97 & 100 & 7.16 & 8.52 & 100 & 11.74 \\
\hline & & & & & & 8.97 & 100 & 11.15 \\
\hline & Average & 7.01 & & Average & 7.61 & & Average & 11.53 \\
\hline & Sigma & 1.17 & & Sigma & 0.96 & & Sigma & 0.26 \\
\hline & Points & 3 & & Points & 5 & & Points & 6 \\
\hline
\end{tabular}




\section{July $31^{\text {st }}$ Data}

\section{Run B}

$\begin{array}{rlrrrrrr}\text { Point } & \text { Time } & \text { H. Coord. V. Coord. } & \mathbf{F}(\mathbf{p p b}) & \text { sigma } \mathbf{F} & \text { \# of pts. } & \text { Error } \\ 1 & 9: 44: 00 & 110.00 & 30.00 & 164.98 & 49.68 & 30 & 17.78 \\ 2 & 9: 45: 00 & 100.00 & 30.00 & 133.53 & 16.29 & 30 & 5.83 \\ 3 & 9: 46: 00 & 90.00 & 30.00 & 219.86 & 5.04 & 30 & 1.80 \\ 4 & 9: 47: 00 & 70.00 & 30.00 & 186.29 & 8.37 & 30 & 3.00 \\ 5 & 9: 48: 00 & 50.00 & 30.00 & 40.70 & 15.35 & 30 & 5.49 \\ 6 & 9: 49: 00 & 40.00 & 30.00 & 0.65 & 0.17 & 30 & 0.06 \\ 7 & 9: 50: 00 & 50.00 & 30.00 & 0.35 & 0.08 & 30 & 0.03 \\ 8 & 9: 51: 00 & 80.00 & 30.00 & 0.57 & 0.38 & 30 & 0.14\end{array}$

\section{Run C}

$\begin{array}{ccccrrrc}\text { Point } & \text { Time } & \text { H. Coord. V. Coord. } & \text { F }(\mathbf{p p b}) & \text { sigma F } & \text { \# of pts. } & \text { Error } \\ 1 & 10: 02: 00 & 80.00 & 35.00 & 0.26 & 0.26 & 90 & 0.05 \\ 2 & 10: 04: 00 & 100.00 & 35.00 & 56.63 & 28.50 & 90 & 5.89 \\ 3 & 10: 06: 00 & 110.00 & 35.00 & 59.78 & 9.31 & 90 & 1.92 \\ 4 & 10: 08: 00 & 120.00 & 35.00 & 2.05 & 1.42 & 90 & 0.29 \\ 5 & 10: 10: 00 & 105.00 & 35.00 & 66.74 & 15.83 & 30 & 5.66 \\ 6 & 10: 11: 00 & 105.00 & 25.00 & 260.41 & 13.55 & 90 & 2.80 \\ 7 & 10: 13: 00 & 105.00 & 15.00 & 92.24 & 18.36 & 90 & 3.79 \\ 8 & 10: 15: 00 & 105.00 & 5.00 & 1.89 & 0.91 & 90 & 0.19 \\ 9 & 10: 17: 00 & 105.00 & 45.00 & 1.37 & 1.48 & 260 & 0.18 \\ 10 & 10: 22: 00 & 105.00 & 30.00 & 57.56 & 52.37 & 270 & 6.25 \\ 11 & 10: 27: 00 & 125.00 & 30.00 & 45.92 & 25.13 & 270 & 3.00 \\ 12 & 10: 32: 00 & 145.00 & 30.00 & 3.12 & 12.71 & 315 & 1.40 \\ 13 & 10: 37: 45 & 110.00 & 20.00 & 74.45 & 17.43 & 360 & 1.80 \\ 14 & 10: 44: 15 & 110.00 & 40.00 & 7.07 & 5.29 & 467 & 0.48\end{array}$

\section{Currents}

\begin{tabular}{rrrrrrr} 
Point & Time & Current & \multicolumn{1}{c}{ Sigma } & Readings & Error & Depth \\
1 & $9: 25$ & 2.32 & 0.16 & 7 & 0.12 & \\
2 & $9: 53$ & 3.18 & 0.22 & 6 & 0.18 & $33^{\prime \prime}$ \\
3 & $10: 20$ & 4.09 & 0.34 & 5 & 0.32 & $30 "$ \\
4 & $10: 45$ & 6.37 & 0.89 & 7 & 0.65 & $27^{\prime \prime}$
\end{tabular}




\section{July $31^{\text {st }}$ Data (cont.)}

Sample Time $=9: 25$

$\begin{array}{rrr}\text { t (sec) } & d \text { (inches) } & u(\mathrm{~cm} / \mathrm{sec}) \\ 19.00 & 16.00 & 2.14 \\ 16.40 & 16.00 & 2.48 \\ 6.02 & 6.00 & 2.53 \\ 6.27 & 6.00 & 2.43 \\ 7.08 & 6.00 & 2.15 \\ 6.65 & 6.00 & 2.29 \\ 6.85 & 6.00 & 2.22\end{array}$

Average

2.32

Sigma

Points

0.16

7
Sample Time $=9: 53$

$\begin{array}{rrr}t \text { (sec) } & \text { d (inches) } & u(\mathrm{~cm} / \mathrm{sec}) \\ 4.56 & 6.00 & 3.34 \\ 5.50 & 6.00 & 2.77 \\ 4.58 & 6.00 & 3.33 \\ 4.57 & 6.00 & 3.33 \\ 4.91 & 6.00 & 3.10 \\ 4.75 & 6.00 & 3.21\end{array}$

Sample Time $=10: 45$

$\begin{array}{rrr}t(\mathrm{sec}) & d \text { (inches) } & u(\mathrm{~cm} / \mathrm{sec}) \\ 5.47 & 12.00 & 5.57 \\ 5.07 & 12.00 & 6.01 \\ 6.03 & 12.00 & 5.05 \\ 4.57 & 12.00 & 6.67 \\ 4.58 & 12.00 & 6.66 \\ 4.37 & 12.00 & 6.97 \\ 3.97 & 12.00 & 7.68\end{array}$

3.18

Sigma

0.22

Points

6

$\begin{array}{lr}\text { Average } & 4.09 \\ \text { Sigma } & 0.34 \\ \text { Points } & 5\end{array}$

Average

6.37

Sigma

Sample Time $=10: 20$

$\begin{array}{rrr}\mathrm{t}(\mathrm{sec}) & \mathrm{d} \text { (inches) } & \mathrm{u}(\mathrm{cm} / \mathrm{sec}) \\ 6.51 & 12.00 & 4.68 \\ 7.80 & 12.00 & 3.91 \\ 7.81 & 12.00 & 3.90 \\ 7.91 & 12.00 & 3.85 \\ 7.40 & 12.00 & 4.12\end{array}$

Points

0.89 


\section{August $2^{\text {nd }}$ Data}

\section{Run A}

$\begin{array}{rcrrrrrr}\text { Point } & \text { Time } & \text { H. Coord. V. Coord. } & \text { F (ppb) } & \text { sigma F } & \text { \# of pts. } & \text { Error } \\ 1 & 11: 35: 00 & 68.00 & 40.00 & 140.25 & 32.89 & 90.00 & 6.80 \\ 2 & 11: 37: 00 & 55.00 & 40.00 & 122.52 & 46.33 & 90.00 & 9.57 \\ 3 & 11: 39: 00 & 45.00 & 40.00 & 9.42 & 9.70 & 90.00 & 2.00 \\ 4 & 11: 41: 00 & 35.00 & 40.00 & 8.29 & 4.98 & 30.00 & 1.78 \\ 5 & 11: 42: 00 & 35.00 & 40.00 & 56.82 & 6.92 & 30.00 & 2.47 \\ 6 & 11: 43: 00 & 25.00 & 40.00 & 4.59 & 0.90 & 30.00 & 0.32 \\ 7 & 11: 44: 00 & 45.00 & 40.00 & 157.77 & 25.72 & 30.00 & 9.20 \\ 8 & 11: 45: 00 & 55.00 & 40.00 & 195.60 & 15.58 & 30.00 & 5.57 \\ 9 & 11: 46: 00 & 65.00 & 40.00 & 4.96 & 1.50 & 30.00 & 0.54 \\ 10 & 11: 47: 00 & 50.00 & 40.00 & 200.57 & 3.20 & 30.00 & 1.15 \\ 11 & 11: 48: 00 & 50.00 & 30.00 & 93.47 & 5.68 & 30.00 & 2.03 \\ 12 & 11: 49: 00 & 50.00 & 20.00 & 6.93 & 1.55 & 30.00 & 0.55 \\ 13 & 11: 50: 00 & 50.00 & 50.00 & 75.25 & 1.88 & 30.00 & 0.67 \\ 14 & 11: 51: 00 & 50.00 & 60.00 & 2.25 & 0.23 & 30.00 & 0.08 \\ 15 & 11: 52: 00 & 50.00 & 40.00 & 95.15 & 35.27 & 30.00 & 12.62\end{array}$

Run B

$\begin{array}{rcrrrrrr}\text { Point } & \text { Time } & \text { H. Coord. V. Coord. } & \text { F }(\mathbf{p p b}) & \text { sigma F } & \text { \# of pts. } & \text { Error } \\ 1 & 12: 01: 00 & 85.00 & 40.00 & 2.30 & 8.32 & 210.00 & 1.12 \\ 2 & 12: 05: 00 & 70.00 & 40.00 & 5.66 & 6.02 & 150.00 & 0.96 \\ 3 & 12: 08: 00 & 60.00 & 40.00 & 91.92 & 23.80 & 150.00 & 3.81 \\ 4 & 12: 11: 00 & 50.00 & 40.00 & 33.36 & 12.87 & 150.00 & 2.06 \\ 5 & 12: 14: 00 & 40.00 & 40.00 & 15.55 & 21.09 & 210.00 & 2.85 \\ 6 & 12: 18: 00 & 70.00 & 40.00 & 12.32 & 14.91 & 210.00 & 2.02 \\ 7 & 12: 22: 00 & 50.00 & 40.00 & 44.36 & 19.57 & 90.00 & 4.04 \\ 8 & 12: 24: 00 & 50.00 & 30.00 & 30.12 & 35.47 & 30.00 & 12.69 \\ 9 & 12: 25: 00 & 70.00 & 30.00 & 67.73 & 7.98 & 90.00 & 1.65 \\ 10 & 12: 27: 00 & 70.00 & 20.00 & 2.94 & 1.38 & 90.00 & 0.28 \\ 11 & 12: 29: 00 & 70.00 & 40.00 & 31.62 & 18.49 & 90.00 & 3.82 \\ 12 & 12: 31: 00 & 70.00 & 50.00 & 1.70 & 3.45 & 390.00 & 0.34 \\ 13 & 12: 38: 00 & 70.00 & 35.00 & 46.06 & 18.84 & 210.00 & 2.55 \\ 14 & 12: 42: 30 & 70.00 & 30.00 & 13.23 & 8.86 & 200.00 & 1.23\end{array}$

\section{Currents}

$\begin{array}{rrrrrrr}\text { Point } & \text { Time } & \text { Current } & \text { Sigma } & \text { Readings } & \text { Error } & \text { Depth } \\ 1 & 11: 20 & 1.34 & 0.18 & 8 & 0.12 & 27^{\prime \prime} \\ 2 & 11: 55 & 3.61 & 0.41 & 15 & 0.19 & \\ 3 & 12: 15 & 5.04 & 0.42 & 8 & 0.28 & 25.5^{\prime \prime} \\ 4 & 12: 35 & 3.35 & 0.21 & 10 & 0.12 & 24 "\end{array}$




\section{August $2^{\text {nd }}$ Data (cont.)}

\begin{tabular}{crr} 
Sample Time $=11: 20$ & \\
\cline { 1 - 2 } $\mathrm{t}$ (seconds) & $\mathrm{d}$ (inches) & $\mathrm{u}(\mathrm{cm} / \mathrm{sec})$ \\
13.7 & 6 & 1.11 \\
13.5 & 6 & 1.13 \\
12.5 & 6 & 1.22 \\
11.5 & 6 & 1.33 \\
10.5 & 6 & 1.45 \\
10.65 & 6 & 1.43 \\
10.45 & 6 & 1.46 \\
9.5 & 6 & 1.60
\end{tabular}

Sample Time $=12: 15$

$\begin{array}{rrr}t \text { (seconds) } d \text { (inches) } & \mathrm{u}(\mathrm{cm} / \mathrm{sec}) \\ 4.7 & 9 & 4.86 \\ 4.8 & 9 & 4.76 \\ 4.9 & 9 & 4.67 \\ 5.1 & 9 & 4.48 \\ 4 & 9 & 5.72 \\ 4.2 & 9 & 5.44 \\ 4.5 & 9 & 5.08 \\ 4.3 & 9 & 5.32\end{array}$

Sample Time $=11: 55$

\begin{tabular}{rrr}
$t$ (seconds) d (inches) $u(\mathrm{~cm} / \mathrm{sec})$ \\
4.27 & 6 & 3.57 \\
4.29 & 6 & 3.55 \\
5.25 & 6 & 2.90 \\
4.23 & 6 & 3.60 \\
4.28 & 6 & 3.56 \\
4.76 & 6 & 3.20 \\
3.67 & 6 & 4.15 \\
5 & 9 & 4.57 \\
6.64 & 9 & 3.44 \\
7.23 & 9 & 3.16 \\
4.26 & 6 & 3.58 \\
4.26 & 6 & 3.58 \\
3.72 & 6 & 4.10 \\
4.09 & 6 & 3.73 \\
4.34 & 6 & 3.51 \\
\multicolumn{4}{c}{ Average } \\
Sigma & 3.61 \\
Points & 0.41 \\
& & 15
\end{tabular}

\section{Sample Time $=12: 35$}

$\begin{array}{rrr}t \text { (seconds) } d \text { (inches) } & u(\mathrm{~cm} / \mathrm{sec}) \\ 11.3 & 15 & 3.37 \\ 11.3 & 15 & 3.37 \\ 12.1 & 15 & 3.15 \\ 12.2 & 15 & 3.12 \\ 11.8 & 15 & 3.23 \\ 11.2 & 15 & 3.40 \\ 11.4 & 15 & 3.34 \\ 11.1 & 15 & 3.43 \\ 9.9 & 15 & 3.85 \\ 11.8 & 15 & 3.23\end{array}$

$\begin{array}{lrlr}\text { Average } & 5.04 & \text { Average } & 3.35 \\ \text { Sigma } & 0.42 & \text { Sigma } & 0.21 \\ \text { Points } & 8 & \text { Points } & 10\end{array}$




\section{August $5^{\text {th }}$ Data}

\section{Run A}

$\begin{array}{rlrrrrrr}\text { Point } & \text { Time } & \text { H. Coord. V. Coord. } & \text { F (ppb) } & \text { sigma F } & \text { \# of pts. } & \text { Error } \\ 1 & 2: 25: 00 & 100.00 & 40.00 & 37.55 & 13.70 & 30.00 & 4.90 \\ 2 & 2: 26: 00 & 110.00 & 40.00 & 296.83 & 7.15 & 30.00 & 2.56 \\ 3 & 2: 27: 00 & 120.00 & 40.00 & 55.20 & 6.81 & 30.00 & 2.44 \\ 4 & 2: 28: 00 & 130.00 & 40.00 & 0.60 & 0.52 & 30.00 & 0.19 \\ 5 & 2: 29: 00 & 110.00 & 40.00 & 306.76 & 12.08 & 30.00 & 4.32 \\ 6 & 2: 30: 30 & 110.00 & 30.00 & 155.28 & 33.47 & 30.00 & 11.98 \\ 7 & 2: 31: 30 & 110.00 & 20.00 & 0.10 & 0.03 & 30.00 & 0.01 \\ 8 & 2: 32: 30 & 110.00 & 50.00 & 8.98 & 4.85 & 30.00 & 1.74\end{array}$

\section{Run B}

$\begin{array}{rlrrrrrr}\text { Point } & & \text { Time } & \text { H. Coord. V. Coord. } & \text { F (ppb) } & \text { sigma F } & \text { \# of pts. } & \text { Error } \\ 1 & 2: 40: 00 & 110.00 & 50.00 & 22.40 & 22.60 & 90.00 & 4.68 \\ 2 & 2: 42: 00 & 120.00 & 50.00 & 57.70 & 14.60 & 90.00 & 3.01 \\ 3 & 2: 44: 00 & 130.00 & 50.00 & 122.00 & 24.50 & 90.00 & 5.07 \\ 4 & 2: 46: 00 & 140.00 & 50.00 & 10.50 & 3.91 & 90.00 & 0.81 \\ 5 & 2: 48: 00 & 133.00 & 50.00 & 77.00 & 31.70 & 90.00 & 6.56 \\ 6 & 2: 50: 00 & 133.00 & 40.00 & 72.10 & 9.26 & 90.00 & 1.91 \\ 7 & 2: 52: 00 & 133.00 & 30.00 & 4.18 & 1.74 & 90.00 & 0.36 \\ 8 & 2: 54: 00 & 133.00 & 45.00 & 127.00 & 27.60 & 90.00 & 5.71 \\ 9 & 2: 56: 00 & 133.00 & 60.00 & 5.88 & 2.51 & 270.00 & 0.30\end{array}$

\section{Run C}

$\begin{array}{rlrrrrrr}\text { Point } & \text { Time } & \text { H. Coord. V. Coord. } & \text { F }(\mathrm{ppb}) & \text { sigma F } & \text { \# of pts. } & \text { Error } \\ 1 & 3: 02: 00 & 130.00 & 45.00 & 67.40 & 28.00 & 210.00 & 3.79 \\ 2 & 3: 06: 00 & 140.00 & 45.00 & 29.90 & 14.80 & 210.00 & 2.00 \\ 3 & 3: 10: 00 & 120.00 & 45.00 & 0.98 & 1.20 & 210.00 & 0.16 \\ 4 & 3: 14: 00 & 130.00 & 45.00 & 61.60 & 30.10 & 210.00 & 4.07 \\ 5 & 3: 19: 00 & 130.00 & 55.00 & 21.30 & 3.32 & 210.00 & 0.45 \\ 6 & 3: 23: 00 & 130.00 & 65.00 & 0.99 & 0.18 & 90.00 & 0.04 \\ 7 & 3: 25: 00 & 130.00 & 60.00 & 4.53 & 1.20 & 90.00 & 0.25 \\ 8 & 3: 27: 00 & 130.00 & 50.00 & 73.00 & 8.17 & 90.00 & 1.69 \\ 9 & 3: 29: 00 & 130.00 & 40.00 & 55.70 & 32.70 & 90.00 & 6.77\end{array}$

\section{Currents}

\begin{tabular}{rrrrrrr} 
Point & \multicolumn{1}{c}{ Time } & Current & \multicolumn{1}{c}{ Sigma } & Readings & Error & Depth \\
1 & $2: 11$ & 1.12 & 0.02 & 2 & 0.09 & $20 "$ \\
2 & $2: 35$ & 2.55 & 0.27 & 6 & 0.22 & $19^{\prime \prime}$ \\
3 & $3: 00$ & 4.23 & 0.14 & 7 & 0.1 & $18 "$ \\
4 & $3: 15$ & 4.36 & 0.49 & 5 & 0.47 & \\
5 & $3: 30$ & 4.34 & 0.22 & 7 & 0.16 & $14 "$
\end{tabular}




\section{August $5^{\text {th }}$ Data (cont.)}

$\underline{\text { Sample Time }=2: 11}$

$\begin{array}{rrr}t \text { (seconds) } & d \text { (inches) } & u(\mathrm{~cm} / \mathrm{sec}) \\ 26.8 & 12 & 1.14 \\ 27.4 & 12 & 1.11\end{array}$

Sample Time $=3: 00$

$t$ (seconds) $d$ (inches) $u(\mathrm{~cm} / \mathrm{sec})$$$
7
$$

Average

1.12

Sigma

Points

0.02

2
Sample Time $=2: 35$

$\mathrm{t}$ (seconds) $d$ (inches) $u(\mathrm{~cm} / \mathrm{sec})$

$\begin{array}{lll}12.9 & 12 & 2.36\end{array}$

$\begin{array}{lll}12.1 & 12 & 2.52\end{array}$

$\begin{array}{lll}12.5 & 12 & 2.44\end{array}$

$\begin{array}{lll}12.9 & 12 & 2.36\end{array}$

$\begin{array}{lll}11.9 & 12 & 2.56\end{array}$

$\begin{array}{lll}9.9 & 12 & 3.08\end{array}$

Average $\quad 2.55$

Sigma $\quad 0.27$

Points 6

Sample Time $=3: 15$

$\mathrm{t}$ (seconds) $d$ (inches) $u(\mathrm{~cm} / \mathrm{sec})$

$\begin{array}{lll}6.83 & 12 & 4.46\end{array}$

$\begin{array}{lll}7.3 & 12 & 4.18\end{array}$

$\begin{array}{lll}7.73 & 12 & 3.94\end{array}$

$\begin{array}{lll}7.55 & 12 & 4.04\end{array}$

$\begin{array}{lll}5.9 & 12 & 5.17\end{array}$

Average $\quad 4.36$

Sigma $\quad 0.49$

Points 5

Sample Time $=3: 30$

\begin{tabular}{rrr}
$t$ (seconds) & $d$ (inches) & $u(\mathrm{~cm} / \mathrm{sec})$ \\
7.38 & 12 & 4.13 \\
7.43 & 12 & 4.10 \\
7.24 & 12 & 4.21 \\
7.17 & 12 & 4.25 \\
6.88 & 12 & 4.43 \\
6.51 & 12 & 4.68 \\
6.68 & 12 & 4.56 \\
\multicolumn{3}{c}{ Average } \\
Sigma & 4.34 \\
Coints & 0.22 \\
& & 7
\end{tabular}




\section{August $6^{\text {th }}$ Data}

\section{Run A}

Point

$\begin{array}{ll}1 & 2: 27: 00 \\ 2 & 2: 35: 30 \\ 3 & 2: 36: 30 \\ 4 & 2: 37: 30 \\ 5 & 2: 39: 00\end{array}$

H. Coord. V. Coord.

$$
120.00
$$

170.00

180.00

190.00

190.00
45.00

45.00

45.00

45.00

35.00
$\mathrm{F}(\mathrm{ppb})$

71.77

92.43

83.44

80.14

42.72 sigma $\mathrm{F}$ \# of pts. Error

$\begin{array}{rrr}91.60 & 480.00 & 8.20 \\ 26.69 & 30.00 & 9.55 \\ 35.62 & 30.00 & 12.74 \\ 42.57 & 30.00 & 15.23 \\ 70.24 & 390.00 & 6.97\end{array}$

\section{Run B}

Point

$\begin{array}{ll}1 & 3: 29: 00 \\ 2 & 3: 30: 00 \\ 3 & 3: 31: 00 \\ 4 & 3: 32: 00 \\ 5 & 3: 33: 00 \\ 6 & 3: 34: 00 \\ 7 & 3: 35: 00 \\ 8 & 3: 36: 00 \\ 9 & 3: 37: 00\end{array}$

H. Coord. V. Coord.

$$
150.00
$$

140.00

130.00

120.00

110.00

125.00

130.00

130.00

130.00
50.00

50.00

50.00

50.00

50.00

50.00

50.00

40.00

60.00
$\mathrm{F}(\mathrm{ppb})$

0.05

0.05

3.12

91.35

3.29

25.00

51.99

19.05

3.58 sigma

$F \quad \#$ of pts.

$0.00 \quad 30.00$

$\begin{array}{lll}0.01 & 30.00 & 0.00\end{array}$

$\begin{array}{lll}1.15 & 30.00 & 0.41\end{array}$

$\begin{array}{lll}8.48 & 30.00 \quad 3.03\end{array}$

$\begin{array}{lll}2.52 & 30.00 \quad 0.90\end{array}$

$\begin{array}{lll}18.06 & 30.00 \quad 6.46\end{array}$

$\begin{array}{lll}18.27 & 30.00 & 6.54\end{array}$

$\begin{array}{lll}11.00 & 30.00 \quad 3.93\end{array}$

$\begin{array}{lll}2.23 & 30.00 \quad 0.80\end{array}$

\section{Run C}

Point

$\begin{array}{rl}1 & 3: 45: 00 \\ 2 & 3: 46: 00 \\ 3 & 3: 47: 00 \\ 4 & 3: 48: 00 \\ 5 & 3: 49: 00 \\ 6 & 3: 50: 00 \\ 7 & 3: 51: 00 \\ 8 & 3: 52: 00 \\ 9 & 3: 53: 00 \\ 10 & 3: 54: 00 \\ 11 & 3: 55: 00\end{array}$

H. Coord. V. Coord.

$$
135.00
$$

135.00

135.00

135.00

135.00

130.00

120.00

140.00

145.00

150.00

135.00
60.00

50.00

40.00

30.00

50.00

50.00

50.00

50.00

50.00

50.00

50.00
$F(p p b)$

$$
48.61
$$

125.10

54.83

0.86

201.57

77.94

3.59

85.23

32.64

3.69

116.92 sigma

\# of pts.

Error

$27.15 \quad 30.00-3.23$

$\begin{array}{lll}6.42 & 30.00 & 2.30\end{array}$

$\begin{array}{lll}0.24 & 30.00 & 0.09\end{array}$

$\begin{array}{lll}9.16 & 30.00 \quad 3.28\end{array}$

$\begin{array}{lll}22.23 & 30.00 \quad 7.95\end{array}$

$\begin{array}{lll}2.95 & 30.00 \quad 1.06\end{array}$

$\begin{array}{lll}30.51 & 30.00 \quad 10.92\end{array}$

$\begin{array}{lll}16.80 & 30.00 & 6.01\end{array}$

\begin{tabular}{|c|c|c|c|c|c|c|c|}
\hline Point & Time & Current & Sigma & Readings & Error & Depth & \\
\hline 1 & $2: 30$ & 1.35 & 0.13 & 5 & 0.12 & 20.5" & (@ 2:40) \\
\hline 2 & $3: 20$ & 2.02 & 0.27 & 5 & 0.26 & & \\
\hline 3 & $3: 40$ & 6.20 & 0.70 & 7 & 0.51 & $17.5^{\prime \prime}$ & \\
\hline 4 & $4: 00$ & 8.04 & 0.62 & 10 & 0.36 & $16.25^{\prime \prime}$ & \\
\hline
\end{tabular}

$\begin{array}{lll}1.42 & 30.00 & 0.51\end{array}$

$\begin{array}{lll}61.09 & 30.00 \quad 21.86\end{array}$

\section{Currents}




\section{August $6^{\text {th }}$ Data (cont.)}

Sample Time $=2: 30$

$\begin{array}{rrr}t \text { (seconds) } & d \text { (inches) } & u(\mathrm{~cm} / \mathrm{sec}) \\ 23.3 & 12 & 1.31 \\ 25.8 & 12 & 1.18 \\ 21.8 & 12 & 1.40 \\ 19.8 & 12 & 1.54 \\ 22.8 & 12 & 1.34\end{array}$

Average

1.35

Sigma

Points

0.13

5
Sample Time $=3: 20$

$\mathrm{t}$ (seconds) $\mathrm{d}$ (inches) $\mathrm{u}(\mathrm{cm} / \mathrm{sec})$

$\begin{array}{lll}12.4 & 12 & 2.46\end{array}$

$\begin{array}{lll}17.1 & 12 & 1.78\end{array}$

$\begin{array}{lll}16.8 & 12 & 1.81\end{array}$

$\begin{array}{lll}15 & 12 & 2.03\end{array}$

$\begin{array}{lll}15.2 & 12 & 2.01\end{array}$
Sample Time $=3: 40$

$t$ (seconds) $d$ (inches) $u(\mathrm{~cm} / \mathrm{sec})$

$\begin{array}{lll}5.6 & 12 & 5.44\end{array}$

$\begin{array}{lll}5.8 & 12 & 5.26\end{array}$

$\begin{array}{lll}4.9 & 12 & 6.22\end{array}$

$\begin{array}{lll}5.1 & 12 & 5.98\end{array}$

$\begin{array}{lll}4.7 & 12 & 6.49\end{array}$

$\begin{array}{lll}4.4 & 12 & 6.93\end{array}$

$\begin{array}{lll}4.3 & 12 & 7.09\end{array}$
Sample Time $=4: 00$

$\begin{array}{crr}t \text { (seconds) } d \text { (inches) } & \mathrm{u}(\mathrm{cm} / \mathrm{sec}) \\ 4.15 & 12 & 7.34 \\ 3.75 & 12 & 8.13 \\ 4.08 & 12 & 7.47 \\ 3.92 & 12 & 7.78 \\ 4.22 & 12 & 7.22 \\ 3.44 & 12 & 8.86 \\ 3.65 & 12 & 8.35 \\ 3.85 & 12 & 7.92 \\ 3.37 & 12 & 9.04 \\ 3.66 & 12 & 8.33\end{array}$

Average

6.20

Sigma

0.70

Points

$\begin{array}{lr}\text { Average } & 2.02 \\ \text { Sigma } & 0.27 \\ \text { Points } & 5\end{array}$

5 


\section{August $7^{\text {th }}$ Data}

\section{Run A}

Point

$\begin{array}{rl}1 & \text { Time } \\ 2 & 4: 25: 00 \\ 3 & 4: 27: 00 \\ 4 & 4: 28: 00 \\ 5 & 4: 29: 00 \\ 6 & 4: 30: 00 \\ 7 & 4: 31: 00 \\ 8 & 4: 32: 00 \\ 9 & 4: 33: 00 \\ 10 & 4: 34: 00 \\ 11 & 4: 35: 00 \\ 12 & 4: 36: 00 \\ 13 & 4: 37: 00 \\ 14 & 4: 38: 00 \\ 15 & 4: 39: 00\end{array}$

H. Coord. V. Coord

$$
140.00
$$

30.00

(ppb)

sigma $\mathrm{F}$

130.00

30.00

23.73

13.67

24.20

120.00

30.00

18.00

10.76

110.00

30.00

0.27

0.20

120.00

0.16

50.00

0.05

125.00

42.14

50.00

7.60

130.00

118.77

23.14

37.97

140.00

50.00

191.97

13.32

150.00

50.00

60.77

2.90

125.00

50.00

177.92

0.68

125.00

60.00

74.82

20.05

9.86

125.00

40.00

73.42

26.06

1.26

125.00

50.00

28.79

39.67

\# of pts. Error

$30.00 \quad 4.89$

$30.00 \quad 8.66$

$30.00 \quad 3.85$

$30.00 \quad 0.07$

$30.00 \quad 0.02$

$30.00 \quad 2.72$

$30.00 \quad 8.28$

$30.00 \quad 13.59$

$30.00 \quad 4.77$

$30.00 \quad 0.24$

$60.00 \quad 5.07$

$30.00 \quad 3.53$

$60.00 \quad 6.59$

$30.00 \quad 0.45$

$30.00 \quad 14.20$

Run B

\begin{tabular}{rlrrrrrr} 
Point & Time & H. Coord. V. Coord. & F (ppb) & sigma F & \# of pts. & \multicolumn{1}{c}{ Error } \\
1 & $4: 44: 00$ & 125.00 & 50.00 & 1.90 & 6.28 & 90.00 & 1.30 \\
2 & $4: 46: 00$ & 135.00 & 50.00 & 61.33 & 38.36 & 90.00 & 7.93 \\
3 & $4: 48: 00$ & 140.00 & 50.00 & 143.29 & 35.79 & 90.00 & 7.40 \\
4 & $4: 50: 00$ & 145.00 & 50.00 & 168.03 & 44.06 & 90.00 & 9.10 \\
5 & $4: 52: 00$ & 155.00 & 50.00 & 36.82 & 44.76 & 90.00 & 9.25 \\
6 & $4: 54: 00$ & 140.00 & 50.00 & 146.59 & 40.56 & 90.00 & 8.38 \\
7 & $4: 56: 00$ & 140.00 & 40.00 & 32.36 & 8.79 & 90.00 & 1.82 \\
8 & $4: 58: 00$ & 140.00 & 60.00 & 125.13 & 39.96 & 90.00 & 8.26 \\
9 & $5: 00: 00$ & 140.00 & 65.00 & 23.23 & 11.74 & 90.00 & 2.42 \\
10 & $5: 02: 00$ & 140.00 & 55.00 & 71.57 & 62.15 & 90.00 & 12.84 \\
11 & $5: 12: 00$ & 150.00 & 55.00 & 50.76 & 22.68 & 210.00 & 3.07 \\
12 & $5: 16: 00$ & 130.00 & 55.00 & 1.33 & 2.57 & 210.00 & 0.35 \\
13 & $5: 20: 00$ & 120.00 & 55.00 & 0.30 & 0.88 & 210.00 & 0.12 \\
14 & $5: 24: 00$ & 140.00 & 55.00 & 151.78 & 28.88 & 210.00 & 3.91
\end{tabular}

\section{Currents}

$\begin{array}{rrrrrrr}\text { Point } & \begin{array}{r}\text { Time } \\ 4: 04\end{array} & \text { Current } & \text { Sigma } & \text { Readings } & \text { Error } & \begin{array}{r}\text { Depth } \\ 18.5 "\end{array} \\ 1 & 4: 15 & 2.55 & 0.31 & 12 & 0.16 & \\ 2 & 4: 42 & 7.21 & 0.66 & 7 & 0.48 & 17 " \\ 3 & 5: 02 & 7.66 & 0.73 & 10 & 0.42 & 14.5^{\prime \prime} \\ 4 & 5: 17 & 7.06 & 0.62 & 8 & 0.42 & 13 "\end{array}$




\section{August $7^{\text {th }}$ Data (cont.)}

\section{$\underline{\text { Sample Time }=4: 15}$}

$\mathrm{t}$ (seconds) $d$ (inches) $u(\mathrm{~cm} / \mathrm{sec})$ 13.44

9.8

10.23

10.11

12.8

12.04

12.04

12.74

13.38

12.84

12.89

12.99
$12 \quad 2.27$

$12 \quad 3.11$

$12 \quad 2.98$

$12 \quad 3.01$

$12 \quad 2.38$

$12 \quad 2.53$

$12 \quad 2.53$

$12 \quad 2.39$

$12 \quad 2.28$

$12 \quad 2.37$

$12 \quad 2.36$

$12 \quad 2.35$
Sample Time $=4: 42$

$\mathrm{t}$ (seconds) $d$ (inches) $u(\mathrm{~cm} / \mathrm{sec})$

$\begin{array}{rll}4.8 & 12 & 6.35 \\ 4.6 & 12 & 6.63 \\ 4.37 & 12 & 6.97 \\ 3.8 & 12 & 8.02 \\ 3.94 & 12 & 7.74 \\ 4.43 & 12 & 6.88 \\ 3.86 & 12 & 7.90\end{array}$

$\begin{array}{lr}\text { Average } & 7.21 \\ \text { Sigma } & 0.66 \\ \text { Points } & 7\end{array}$

Sample Time $=5: 17$

$\mathrm{t}$ (seconds) $\mathrm{d}$ (inches) $\mathrm{u}(\mathrm{cm} / \mathrm{sec})$ $\begin{array}{lll}4.08 & 12 & 7.47\end{array}$

$\begin{array}{lll}3.79 & 12 & 8.04\end{array}$

$\begin{array}{lll}4.55 & 12 & 6.70\end{array}$

$\begin{array}{lll}4.31 & 12 & 7.07\end{array}$

$\begin{array}{lll}3.97 & 12 & 7.68\end{array}$

$\begin{array}{lll}4.55 & 12 & 6.70\end{array}$

$\begin{array}{lll}4.75 & 12 & 6.42\end{array}$

$\begin{array}{lll}4.79 & 12 & 6.36\end{array}$
Average

Sigma

Points
7.66

0.73

10
Average

Sigma

Points
7.06

0.62 


\section{August $8^{\text {th }}$ Data}

\section{Run A}

$\begin{array}{rlrrrrrr}\text { Point } & \text { Time } & \text { H. Coord. V. Coord. } & \text { F (ppb) } & \text { sigma F } & \text { \# of pts. } & \text { Error } \\ 1 & 5: 06: 00 & 85.00 & 45.00 & 11.04 & 15.66 & 630.00 & 1.22 \\ 2 & 5: 17: 00 & 95.00 & 45.00 & 6.69 & 11.04 & 330.00 & 1.19 \\ 3 & 5: 23: 00 & 85.00 & 45.00 & 5.30 & 6.20 & 90.00 & 1.28 \\ 4 & 5: 25: 00 & 95.00 & 45.00 & 6.98 & 9.45 & 90.00 & 1.95 \\ 5 & 5: 27: 00 & 105.00 & 45.00 & 8.28 & 7.87 & 90.00 & 1.63 \\ 6 & 5: 29: 00 & 115.00 & 45.00 & 3.65 & 4.73 & 270.00 & 0.56 \\ 7 & 5: 34: 00 & 125.00 & 45.00 & 4.91 & 7.64 & 150.00 & 1.22 \\ 8 & 5: 37: 00 & 135.00 & 45.00 & 1.20 & 1.75 & 90.00 & 0.36 \\ 9 & 5: 39: 00 & 145.00 & 45.00 & 0.11 & 0.23 & 90.00 & 0.05 \\ 10 & 5: 41: 00 & 125.00 & 45.00 & 8.43 & 7.51 & 90.00 & 1.55 \\ 11 & 5: 43: 00 & 125.00 & 40.00 & 54.35 & 24.42 & 90.00 & 5.05 \\ 12 & 5: 45: 00 & 125.00 & 36.00 & 148.61 & 47.27 & 90.00 & 9.77 \\ 13 & 5: 47: 00 & 125.00 & 45.00 & 19.78 & 15.15 & 90.00 & 3.13 \\ 14 & 5: 49: 00 & 125.00 & 40.00 & 37.05 & 34.57 & 150.00 & 5.53 \\ 15 & 5: 52: 00 & 115.00 & 40.00 & 36.80 & 26.58 & 90.00 & 5.49 \\ 16 & 5: 54: 00 & 105.00 & 40.00 & 11.69 & 28.73 & 90.00 & 5.94 \\ 17 & 5: 56: 00 & 125.00 & 40.00 & 88.42 & 40.13 & 90.00 & 8.29 \\ 18 & 5: 58: 00 & 135.00 & 40.00 & 19.16 & 22.61 & 90.00 & 4.67 \\ 19 & 6: 00: 00 & 145.00 & 40.00 & 1.58 & 1.69 & 90.00 & 0.35 \\ 20 & 6: 02: 00 & 125.00 & 40.00 & 122.83 & 38.45 & 90.00 & 7.94 \\ 21 & 6: 04: 00 & 125.00 & 45.00 & 51.69 & 22.07 & 90.00 & 4.56 \\ 22 & 6: 06: 00 & 125.00 & 50.00 & 16.67 & 14.29 & 90.00 & 2.95 \\ 23 & 6: 08: 00 & 125.00 & 55.00 & 4.09 & 4.00 & 90.00 & 0.83\end{array}$

\section{Currents}

$\begin{array}{ccccccr}\text { Point } & \text { Time } & \text { Current } & \text { Sigma } & \text { Readings } & \text { Error } & \text { Depth } \\ 1 & 5: 00 & 3.16 & 0.33 & 9 & 0.20 & 16 " \\ 2 & 5: 20 & 6.14 & 0.47 & 11 & 0.26 & 15.5^{\prime \prime} \\ 3 & 5: 35 & 8.06 & 1.33 & 9 & 0.82 & 14 " \\ 4 & 6: 07 & 13.26 & 0.86 & 7 & 0.63 & 11.25 "\end{array}$




\section{August $8^{\text {th }}$ Data (cont.)}

Sample Time $=5: 00$

$\begin{array}{rrr}t \text { (seconds) } d \text { (inches) } u(\mathrm{~cm} / \mathrm{sec}) \\ 11.7 & 12 & 2.61 \\ 10.76 & 12 & 2.83 \\ 10.11 & 12 & 3.01 \\ 9.93 & 12 & 3.07 \\ 9.83 & 12 & 3.10 \\ 9.3 & 12 & 3.28 \\ 8.65 & 12 & 3.52 \\ 8.87 & 12 & 3.44 \\ 8.42 & 12 & 3.62\end{array}$

Sample Time $=5: 20$

$t$ (seconds) $d$ (inches) $u(\mathrm{~cm} / \mathrm{sec})$

$\begin{array}{rll}5.55 & 12 & 5.49 \\ 4.84 & 12 & 6.30 \\ 5.39 & 12 & 5.65 \\ 5.17 & 12 & 5.90 \\ 5.4 & 12 & 5.64 \\ 4.91 & 12 & 6.21 \\ 4.99 & 12 & 6.11 \\ 4.92 & 12 & 6.20 \\ 4.88 & 12 & 6.25 \\ 4.46 & 12 & 6.83 \\ 4.36 & 12 & 6.99\end{array}$

$\begin{array}{lr}\text { Average } & 3.16 \\ \text { Sigma } & 0.33 \\ \text { Points } & 9\end{array}$

Average

6.14

Sigma

Points

0.47

11

\section{$\underline{\text { Sample Time }=5: 35}$}

$\begin{array}{rrr}t \text { (seconds) } d \text { (inches) } & u(\mathrm{~cm} / \mathrm{sec}) \\ 4.37 & 12 & 6.97 \\ 4.83 & 12 & 6.31 \\ 4.64 & 12 & 6.57 \\ 3.09 & 12 & 9.86 \\ 3.63 & 12 & 8.40 \\ 3.81 & 12 & 8.00 \\ 3.55 & 12 & 8.59 \\ 3.92 & 12 & 7.78 \\ 3.04 & 12 & 10.03\end{array}$

Sample Time $=6: 07$

$\begin{array}{crr}t \text { (seconds) } & d \text { (inches) } & \mathrm{u}(\mathrm{cm} / \mathrm{sec}) \\ 2.39 & 12 & 12.75 \\ 2.11 & 12 & 14.45 \\ 2.51 & 12 & 12.14 \\ 2.35 & 12 & 12.97 \\ 2.16 & 12 & 14.11 \\ 2.42 & 12 & 12.60 \\ 2.21 & 12 & 13.79\end{array}$

$\begin{array}{lrlr}\text { Average } & 8.06 & \text { Average } & 13.26 \\ \text { Sigma } & 1.33 & \text { Sigma } & 0.86 \\ \text { Points } & 9 & \text { Points } & 7\end{array}$

